\title{
Patterns of Sea-Ice Retreat in the Transition to a Seasonally Ice-Free Arctic
}

\author{
Patricia DeRepentigny \\ Master of Science \\ Department of Atmospheric and Oceanic Sciences
}

McGill University

Montreal,Quebec

December 10, 2015

A thesis submitted to the Faculty of Graduate Studies and Research in partial fulfillment of the requirements for the degree of Master of Science

(C) Patricia DeRepentigny, 2015 


\section{ACKNOWLEDGEMENTS}

This work was funded by the Office of Naval Research (N000141110977). Patricia DeRepentigny is grateful to the Natural Sciences and Engineering Council of Canada (NSERC) and to Fonds de recherche du Québec - Nature et technologies (FRQNT) for their financial support through research scholarships, as well as ArcticNet, Québec-Océan and ArcTrain Canada. Bruno Tremblay is grateful for the financial support of ArcticNet, the NSERC Discovery Program, Environment Canada Grants and Contribution program, and the Canadian Sea Ice and Snow Evolution (CanSISE) Network funded by NSERC Climate Change and Atmospheric Research program. 


\begin{abstract}
We investigate the future patterns of sea-ice retreat in the Arctic Ocean using two coupled Global Climate Models (GCMs) that have profound differences in their large-scale mean winter atmospheric circulation and sea-ice drift patterns. The Community Earth System Model Version 1 Large Ensemble (CESM-LE) has a mean sea-level pressure pattern that is in general agreement with observations for the late $20^{\text {th }}$ century. The Community Climate System Model Version 4 (CCSM4) exhibits a bias low in its mean sea-level pressure with deeper Icelandic and Aleutian Lows. We present a dynamical mechanism through which the large-scale mean winter atmospheric circulation has significant effect on the following September minimum sea-ice extent anomaly by influencing ice-area divergence in coastal seas. We use a Lagrangian model to backtrack the $80^{\circ} \mathrm{N}$ line from the time of the melt onset to its prior position throughout the previous winter and quantify the area of divergence from the Pacific (Beaufort and Chukchi seas) and the Eurasian (East Siberian, Laptev and Kara seas) sectors. We find that CCSM4 simulates larger areas of sea-ice divergence in the Beaufort and Chukchi seas and smaller areas of divergence in the Eurasian sector when compared to CESM-LE, leading to a Pacific-centric sea-ice retreat. On the other hand, CESM-LE shows a more symmetrical retreat between the Pacific, Eurasian and Atlantic sectors of the Arctic. Given that a positive trend in the AO index is a robust feature of GCMs participating in the fifth Coupled Model Intercomparison Project (CMIP5), our results suggest that during the ongoing transition to a seasonally ice-free Arctic, the sea-ice retreat will continue to be Pacific-centric.
\end{abstract}




\begin{abstract}
ABRÉGÉ
Nous étudions le patron futur de retrait de la glace de mer dans l'océan Arctique en utilisant deux modèles de circulation générale qui présentent d'importantes différences au niveau de leur circulation atmosphérique globale durant l'hiver. Le Community Earth System Model Version 1 (CESM-LE) présente une moyenne de la pression au niveau de la mer qui est semblable aux observations de la fin du $21^{\text {ième }}$ siècle. Le Community Climate System Model Version 4 (CCSM4) possède un bias négatif sur la pression au niveau de la mer avec les dépressions d'Islande et des Aléoutiennes plus intenses. Pour se faire, nous présentons un mécanisme dynamique à travers lequel la circulation atmosphérique globale durant l'hiver a un impact significatif sur l'anomalie d'étendue de glace en septembre en influençant l'aire de divergence de glace dans les mers périphériques. Nous utilisons un modèle de trajectoires Lagrangiennes pour retracer la position de la ligne à $80^{\circ} \mathrm{N}$ durant l'hiver précédant le début de la saison de fonte afin de quantifier l'aire de divergence dans le secteur Pacifique (mers de Beaufort et Chukchi) et Eurasien (mers de Sibérie orientale, Laptev et Kara). Les résultats montrent que CCSM4 simule une aire de divergence de glace de mer plus grande que CESM-LE pour les mers de Beaufort et Chukchi, mais plus petite pour le secteur Eurasien, menant à un retrait des glaces plus prononcé dans le secteur Pacifique. D'autre part, CESM-LE simule un retrait plus symétrique entre les secteurs Pacifique, Eurasien et Atlantique de l'océan Arctique. Puisque les modèles de circulation générale participant au cinquième Coupled Model Intercomparison Project (CMIP5) prévoient une tendance positive de l'indice de l'Oscillation Arctique dans le futur, nos résultats suggèrent que le retrait des glaces va continuer de s'opérer
\end{abstract}


de manière préférentielle dans le secteur Pacifique lors de la transition vers une couverture de glace saisonnière en Arctique. 


\section{TABLE OF CONTENTS}

ACKNOWLEDGEMENTS .................. . . ii

ABSTRACT ............................ ii

ABRÉGÉ ............................ iv

LIST OF FIGURES .................... . . vii

1 Introduction . . . . . . . . . . . . . . . . 1

2 Data .......................... 7

2.1 Observations . . . . . . . . . . . . . . . 7

2.2 Global Climate Models . . . . . . . . . . . . 8

3 Methodology ...................... . . 10

4 Error Analysis . . . . . . . . . . . . . . . . . . . . 12

5 Results and Discussion . . . . . . . . . . . . . . . 15

6 Conclusion . . . . . . . . . . . . . . . . . . . . . . 31

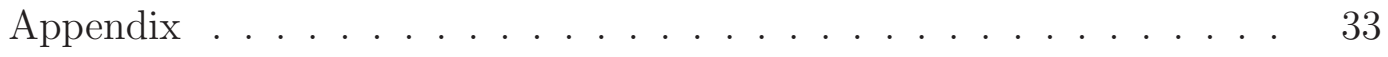


4-1 (a) Median (solid) and interquartile range (shaded) of the error in drift distance of the Lagrangian ice trajectory model using Polar Pathfinder sea-ice motion vectors with two different time resolutions by comparing with IABP buoy data. (b) Number of trajectories of each maximum time length used to calculate the error in drift distance. . . . . . . . . . . .

5-1 Observations: (a) Winter (NDJFMAM) mean sea-ice velocity field (arrows) and sea-level pressure contours (red line) from 1990 to 1999. (b) Mean September sea-ice concentration from 1990 to 1999. Sea-ice velocity vectors are capped at 5 $\mathrm{cm} / \mathrm{s}$ for clarity. . . . . . . . . . . . . .

5-2 Winter (NDJFMAM) mean sea-level pressure averaged over the region above $70^{\circ} \mathrm{N}$ from 1900 to 2100 for $\mathrm{NCEP} / \mathrm{NCAR}$ reanalysis (red), ERA-Interim reanalysis (orange), CCSM4 (black) and the 30-ensemble members of CESM-LE (from blue to green). . . . . . . . . . . . . . . .

5-3 September sea-ice extent from 1980 to 2100 for observations (red), CCSM4 (black) and the 30-ensemble members of CESM-LE (from blue to green). . . . . . . . . . . .

5-4 [left] Winter (NDJFMAM) mean sea-ice velocity field (arrows) and sea-level pressure contours (red line) from 1990 to 1999. [right] Mean September sea-ice concentration from 1990 to 1999. (a-b) CCSM4, (c-d) CESM-LE 30-ensemble average. Sea-ice velocity vectors are capped at $5 \mathrm{~cm} / \mathrm{s}$ for clarity. .

5-5 Winter (NDJFMAM) mean sea-ice velocity field (arrows) and sea-level pressure contours (red line) for years of sealevel pressure anomaly greater [left] or lesser [right] than 1 standard deviation from the mean during the 1990-1999 period. (a-b) Observations, (c-d) CCSM4, (e-f) CESM-LE 30-ensemble average. Sea-ice velocity vectors are capped at $5 \mathrm{~cm} / \mathrm{s}$ for clarity. . . . . . . . . . . . . . . . . 24 
5-6 Lagrangian trajectories of the year 1997 using member \#002 of CESM-LE. The $80^{\circ} \mathrm{N}$ line has been backtracked from June $1^{\text {st }}, 1997$ to March $1^{\text {st }}, 1997$ in order to quantify the divergence from the Pacific (red) and the Eurasian sectors (blue). The difference between Area B (outflow) and Area A (inflow) is the divergence from the Pacific sector. The difference between Areas $\mathrm{C}$ and $\mathrm{D}$ (outflow) and Area E (inflow) is the divergence from the Eurasian sector. . . . . .

5-7 Timeseries of the net area of divergence (defined in figure 5-6) from November to June using our Lagrangian backtrajectory model for the Pacific and Eurasian sectors. For CCSM4, the 30-year running mean (solid line) and standard deviation (shaded), and for CESM-LE, the 30-ensemble average (solid line) and standard deviation (shaded). . . . . . . . . 26

5-8 CESM-LE 30-ensemble mean September sea-ice concentration. (a) 2000 to 2009, (b) 2010 to 2019, (c) 2020 to 2029, (d) 2030 to 2039 , (e) 2040 to 2049 , (f) 2050 to 2059 . . . . . . . . .

5-9 CCSM4 mean September sea-ice concentration. (a) 2000 to 2009, (b) 2010 to 2019, (c) 2020 to 2029, (d) 2030 to 2039, (e) 2040 to 2049 , (f) 2050 to 2059, (g) 2060 to 2069, (h) 2070 to $2079 \ldots \ldots \ldots \ldots \ldots \ldots$

5-10 Observations: (a) Winter (NDJFMAM) mean sea-ice velocity field (arrows) and sea-level pressure contours (red line) from 2000 to 2009. (b) Mean September sea-ice concentration from 2000 to 2009. Sea-ice velocity vectors are capped at 5 $\mathrm{cm} / \mathrm{s}$ for clarity. . . . . . . . . . . . . . .

5-11 Late winter (from the first week of March to the first week of June) observed net area of divergence using our Lagrangian backtrajectory model for the Beaufort (red), Chukchi (blue), East Siberian (green), Laptev (magenta) and Kara (cyan) seas. For each sea, the dash-dot line shows the linear trend.

6-1 Observations: Backward trajectories of ice parcels between 1980 and 1990 for a maximum duration of 5 years in the Beaufort (a), Chukchi (b), East Siberian (c), Laptev (d), Kara (e) and Barents (f) seas. The colors indicate the duration of the tracking from the initial position (black crosses). . . . . . . 
6-2 CCSM4: Backward trajectories of ice parcels between 1980 and 1990 for a maximum duration of 5 years in the Beaufort (a), Chukchi (b), East Siberian (c), Laptev (d), Kara (e) and Barents (f) seas. The colors indicate the duration of the tracking from the initial position (black crosses). . . . . . .

6-3 CESM-LE: Backward trajectories of ice parcels between 1980 and 1990 for a maximum duration of 5 years in the Beaufort (a), Chukchi (b), East Siberian (c), Laptev (d), Kara (e) and Barents (f) seas. The colors indicate the duration of the tracking from the initial position (black crosses). . . . . .

6-4 Observations: Backward trajectories of ice parcels between 1990 and 2000 for a maximum duration of 5 years in the Beaufort (a), Chukchi (b), East Siberian (c), Laptev (d), Kara (e) and Barents (f) seas. The colors indicate the duration of the tracking from the initial position (black crosses). . . . . .

6-5 CCSM4: Backward trajectories of ice parcels between 1990 and 2000 for a maximum duration of 5 years in the Beaufort (a), Chukchi (b), East Siberian (c), Laptev (d), Kara (e) and Barents (f) seas. The colors indicate the duration of the tracking from the initial position (black crosses). . . . . . .

6-6 CESM-LE: Backward trajectories of ice parcels between 1990 and 2000 for a maximum duration of 5 years in the Beaufort (a), Chukchi (b), East Siberian (c), Laptev (d), Kara (e) and Barents (f) seas. The colors indicate the duration of the tracking from the initial position (black crosses). . . . . .

6-7 Observations: Backward trajectories of ice parcels between 2000 and 2010 for a maximum duration of 5 years in the Beaufort (a), Chukchi (b), East Siberian (c), Laptev (d), Kara (e) and Barents (f) seas. The colors indicate the duration of the tracking from the initial position (black crosses). . . . . . .

6-8 CCSM4: Backward trajectories of ice parcels between 2000 and 2010 for a maximum duration of 5 years in the Beaufort (a), Chukchi (b), East Siberian (c), Laptev (d), Kara (e) and Barents (f) seas. The colors indicate the duration of the tracking from the initial position (black crosses). . . . . . .

6-9 CESM-LE: Backward trajectories of ice parcels between 2000 and 2010 for a maximum duration of 5 years in the Beaufort (a), Chukchi (b), East Siberian (c), Laptev (d), Kara (e) and Barents (f) seas. The colors indicate the duration of the tracking from the initial position (black crosses). . . . . . . 
6-10 CCSM4: Backward trajectories of ice parcels between 2000 and 2020 for a maximum duration of 5 years in the Beaufort (a), Chukchi (b), East Siberian (c), Laptev (d), Kara (e) and Barents (f) seas. The colors indicate the duration of the tracking from the initial position (black crosses). . . . . .

6-11 CESM-LE: Backward trajectories of ice parcels between 2000 and 2020 for a maximum duration of 5 years in the Beaufort (a), Chukchi (b), East Siberian (c), Laptev (d), Kara (e) and Barents (f) seas. The colors indicate the duration of the tracking from the initial position (black crosses). . . . . .

6-12 CCSM4: Backward trajectories of ice parcels between 2040 and 2060 for a maximum duration of 5 years in the Beaufort (a), Chukchi (b), East Siberian (c), Laptev (d), Kara (e) and Barents (f) seas. The colors indicate the duration of the tracking from the initial position (black crosses). . . . . . . 46

6-13 CESM-LE: Backward trajectories of ice parcels between 2040 and 2060 for a maximum duration of 5 years in the Beaufort (a), Chukchi (b), East Siberian (c), Laptev (d), Kara (e) and Barents (f) seas. The colors indicate the duration of the tracking from the initial position (black crosses). . . . . .

6-14 CCSM4: Backward trajectories of ice parcels between 2080 and 2100 for a maximum duration of 5 years in the Beaufort (a), Chukchi (b), East Siberian (c), Laptev (d), Kara (e) and Barents (f) seas. The colors indicate the duration of the tracking from the initial position (black crosses). . . . . .

6-15 CCSM4: Backward trajectories of ice parcels between 2080 and 2100 for a maximum duration of 5 years in the Beaufort (a), Chukchi (b), East Siberian (c), Laptev (d), Kara (e) and Barents (f) seas. The colors indicate the duration of the tracking from the initial position (black crosses). . . . . . 


\section{CHAPTER 1 Introduction}

Significant changes in the Arctic sea-ice coverage have been observed in recent years, particularly at the end of the summer. The decline in minimum sea-ice extent has accelerated from approximately $-2.2 \%$ per decade in $1979-1996$ to $-10.1 \%$ per decade in 1996-2007 [Comiso et al., 2008]. The decline in sea-ice cover is also accompanied by thinning that could potentially lead to extensive sea-ice loss due to increased open water formation efficiency and the ice-albedo feedback [Holland et al., 2006]. A thin ice cover is also more vulnerable to strong summer retreat under anomalous atmospheric forcing [Maslanik et al., 1996, Stroeve et al., 2012b]. In addition to the loss of perennial ice cover [Tucker et al., 2001], there has been a significant decrease in the oldest and thickest ice within the multi-year ice pack [Pfirman et al., 2004, Maslanik et al., 2007].

The spatial variability of the sea-ice retreat also has impacts on global weather patterns. Arctic highs, cold and dry air masses forming under persistent surface inversions, can be advected into the mid-latitudes and create cold outbreaks [Walsh et al., 2001]. Several studies have identified the role of the Arctic sea-ice loss in the increased storm surge activity and cold winter extremes in northern continents [Maslanik et al., 1996, Francis and Vavrus, 2012, Inoue et al., 2012, Tang et al., 2013, Vermaire et al., 2013, Vihma, 2014, Francis and Vavrus, 2015]. Gervais et al. [2015] find a significant increase in the frequency of patterns with large positive and negative anomalies of equivalent potential temperature at $850 \mathrm{hPa}$ over North America in the future, leading to amplified planetary wave and high impact cold weather events. They suggest 
that this increase in frequency is related to climatological sea-ice loss in the Chukchi Sea. Also, reduced sea-ice in the Barents and Kara seas can lead to extreme cold winter events in Europe and northern Asia [Petoukhov and Semenov, 2010]. Moreover, Hakkinen et al. [2008] identified an increasing trend in the magnitude of surface wind stresses, making the reciprocal link between storm activity and sea-ice movement.

As the summer Arctic sea ice retreats, industrial and commercial interests are evolving. Travel distance between the North Atlantic and Asia can be reduced by $50 \%$ when the Northern Sea Route and Northwest Passage are free of ice [Peters et al., 2011]. The navigation season of those alternative sea routes will considerably increase during this century, enabling expanded September navigability by mid-century [Smith and Stephenson, 2013]. Specifically, the time length of the navigation season of the Northern Sea Route and Northwest Passage is projected to increase by $173 \%$ and $156 \%$ respectively by the end of the twenty-first century [Khon et al., 2010]. In addition, oil and gas companies are expanding their activities in the Arctic [Gautier et al., 2009]. Although oil and gas extraction remains dominated by Russia, new leases in the Beaufort/Chukchi sector have recently been allocated at approximately twice the rate as those in the Siberian sector [Blanken et al., 2015]. The details of the rate and patterns of change will be an important input to planning for development, resource management, species preservation, national security, and international environmental monitoring programs [Campbell et al., 2007, Byers, 2010].

Several studies have investigated the different mechanisms that drive the observed sea-ice retreat, which reflects a combination of thermodynamic and dynamics processes [Serreze et al., 2007]. The closely-studied minimum ice event in 2007 is a good example. During the summer of 2007, prior to the 
record September sea-ice extent minimum, anomalously large ocean heat fluxes entered the Arctic Ocean through Bering Strait, reaching a total of approximately $5-6 \times 10^{20} \mathrm{~J} / \mathrm{yr}$, enough to melt one third of the 2007 estimated total summer sea-ice loss [Woodgate et al., 2010]. Bering Strait inflow influences sea-ice by providing a trigger for the onset of solar-driven melt [Perovich et al., 2007]. In the summer of 2007 , the ocean gained twice the amount of solar and oceanic heat compared to the average of the 7 previous years [Steele et al., 2010]. Zhang et al. [2008] argue that the large-scale summer atmospheric circulation strengthened the transpolar drift of sea ice in 2007, leaving behind an unusually large amount of thin ice and open water, allowing for more surface solar heating. The presence of the Arctic Dipole pattern persisting throughout the whole summer favored southerly winds, pushing ice from the Bering Strait toward the North Pole and across to Fram Strait and keeping the sky cloud-free, leading to important solar radiation input [Overland et al., 2012]. Nonetheless, despite the undeniable contributions from multiple factors, Lindsay et al. [2009] found that the 2007 ice mass loss followed the trend, as the area of thin ice at the beginning of the melt season and the total volume of ice in the summer have been steadily decreasing since 1987.

Sea-level pressure is directly related to surface wind stresses, the primary force driving the movement of sea ice in the Arctic Ocean, and can be characterized by the Arctic Oscillation (AO), the first EOF of Northern Hemisphere sea-level pressure, or the Northern Annular Mode (NAM), a closely related high-latitude pattern. Rigor et al. [2002] show that the AO explains $52 \%$ of the variance of sea-level pressure over the Arctic Ocean during winter. They also suggest that the summer sea-ice concentration is correlated with the AO index of the previous winter, reflecting the dynamical influence of the wintertime sea-level pressure on the thickness distribution. Likewise, Rigor and 
Wallace [2004] observe a reduction of the mean sea-ice thickness during the transition to extremely high AO conditions in 1989. They find that more than half of the variance in summer sea-ice extent can be explained by the age of the ice pack, a proxi for ice thickness. More recently, Williams et al. [2015] link the large-scale mean winter atmospheric circulation, characterized by the $\mathrm{AO}$, to the formation of first-year ice off the Eurasian and Alaskan coastlines and find that the amount of sea-ice divergence along the coasts is strongly correlated to the phase of the winter (DJFM) mean AO index $(r=0.76)$. These results reinforce the idea of a potential predictability of the September sea-ice extent based on the previous winter mean sea-ice circulation.

The overall thinning of the ice pack could lead to changes in seasonal sea-ice predictor relationships. Holland and Stroeve [2011], looking at climate model projections through the end of the $21^{\text {st }}$ century, found that the correlation between September sea-ice extent anomalies and winter-spring predictors, such as the area of the Arctic basin covered by thin ice, increases as the pack ice transitions from a perennial to a seasonal ice cover. On the other hand, the variance of modeled sea-ice extent explained by summer large-scale circulation over the Arctic Ocean decreases from the late $20^{\text {th }}$ century to the middle of the $21^{\text {st }}$ century. Moreover, Williams et al. [2015] find a good correlation $(r=$ -0.73) between the coastal sea-ice divergence in the late winter, which leads to anomalous formation of thin first-year ice, and the following September sea-ice extent minimum.

During winter, the observed NAM index had a pronounced positive trend up to 1995 followed by a strong negative phase in recent years [Overland and Wang, 2005]. In Global Climate Models (GCMs), a steady positive trend in the NAM is simulated [Fyfe et al., 1999, Rauthe and Paeth, 2004, Miller et al., 2006], suggesting either that the return to a strong negative phase is a 
manifestation of internal variability, or results from a mechanism not resolved by models [Gillett and Fyfe, 2013, Jin-Qing et al., 2013]. In particular, Gillett and Fyfe [2013] show that CMIP5 models on average simulate increases in the NAM in every season by 2100, with the largest increases in DJF and SON. A positive NAM index is characterized by deep penetration of storms into the Eastern Arctic [Sorteberg et al., 2005], reducing the size of the Beaufort Gyre, thus decreasing the drift of ice into the Eurasian Arctic and increasing coastal divergence in the East Siberian Sea by pushing ice toward Fram Strait [Dickson et al., 2000, Rigor et al., 2002]. Moreover, a projected increase in the AO index and therefore number of storms entering the Arctic through the Nordic seas can lead to an increase of the inflow of warm Atlantic waters, enhancing the winter sea-ice retreat north of Scandinavia [Bengtsson et al., 2004, Sorteberg et al., 2005, Sorteberg and Kvingedal, 2006].

GCMs that have a reasonable late $20^{\text {th }}$ century Arctic climate forecast ice-free summers in the Arctic before the end of this century [Holland et al., 2006, Stroeve et al., 2012a]. While these models agree on the decline of seaice extent and the likelihood of a seasonal Arctic sea-ice cover, the pattern of the predicted sea-ice loss varies widely [Bitz et al., 2005]. While there are also uncertainties regarding the predicted magnitude of ice volume loss, all models simulate a decrease in ice volume as a result of an increase in the annual net melt [Holland et al., 2010]. Moreover, only few individual model simulations from the (CMIP3) exhibit trends in sea-ice decline that are comparable to observations [Stroeve et al., 2007]. More recently, Stroeve et al. [2012a] show that simulated trends from the models contributing to CMIP5 are more consistent with observations, but they nevertheless exhibit declines that are slower than the observed value. Even though the mean thickness distributions from GCMs are in good agreement with observations, there are 
large biases in the spatial patterns of sea-ice thickness in CMIP3 and CMIP5 models [Bitz et al., 2002, Stroeve et al., 2014]. The poor representation of spatial thickness distributions is due to the difficulty of models to capture the details of the mean atmospheric circulation pattern that drive the movement of sea ice. This will have a direct impact on the patterns of sea-ice retreat since thick multi-year ice is less likely to melt during summer than first-year ice.

In this paper, we expand on the work of Williams et al. [2015] and link future decadal trends in the regional (Pacific, Eurasian and Atlantic sectors) summer sea-ice extent loss in the Arctic to trends in sea-ice drift patterns from the previous winter. To this end, we look at two GCMs that have profound differences in their late $20^{\text {th }}$ century large-scale mean winter atmospheric circulation: one that is similar to observations (CESM-LE) and one that exhibits an anomalous positive AO index (CCSM4). As a result, CCSM4 simulates larger areas of divergence in the sea-ice field in the Beaufort and Chukchi seas compared to CESM-LE, leading to a Pacific-centric sea-ice retreat. CESMLE on the other hand, with a large-scale mean winter atmospheric circulation similar to the observed late $20^{\text {th }}$ century that persists throughout the $21^{\text {st }}$ century, shows a more symmetrical retreat between the Pacific, Eurasian and Atlantic sectors of the Arctic. Given that a positive trend in the AO index is a robust feature of GCMs participating in CMIP5, our results suggest that sea-ice retreat in the Pacific sector could the amplified during the transition to a seasonally ice-free Arctic, in addition to other important mechanisms that already influence the sea-ice extent in this region. 


\section{CHAPTER 2}

Data

\section{$2.1 \quad$ Observations}

We use the National Snow and Ice Data Center (NSIDC) Polar Pathfinder Daily 25km EASE-Grid Sea Ice Motion Vectors, Version 2 [Fowler et al., 2013] for the period from January 1988 to December 2012. This dataset is constructed using an optimal interpolation of sea ice motion vectors from the Scanning Multichannel Microwave Radiometer (SMMR), Special Sensor Microwave/Imager (SSM/I), Advanced Microwave Scanning Radiometer-EOS (AMSR-E), Advanced Very High Resolution Radiometer (AVHRR), drifting buoys from the International Arctic Buoy Program (IABP) and free drift estimates derived from the 10-meter winds NCEP/NCAR Reanalysis data. In this analysis, we do not consider the satellite-derived velocities from SMMR (1979 to 1987) because of a reported low bias in sea-ice velocity before the change of satellite from SMMR to SSM/I in July 1987 [National Snow and Ice Data Center, cited 2015]. In this product, IABP data is considered as truth and is used with a weight of unity that decrease to zero with a radius of influence of approximately $200 \mathrm{~km}$. Sea-ice drift vectors have been derived using a maximum cross-correlation method [Emery et al., 1997, Meier et al., 2000, Fowler et al., 2004, Meier and Dai, 2006] that matches features in two coincident images separated by some time interval using the highest correlation in a grid cell of the first image with a grid cell in the second image. Satellite-derived

daily ice-motion vector fields were then interpolated on the $25 \mathrm{~km}$ Equal-Area Scalable Earth Grid (EASE-Grid) [Brodzik et al., 2012] and averaged over a 
one week time period so that the end product has low enough RMS errors that long-term Lagrangian tracking is possible [Meier and Maslanik, 2001].

We use sea-ice concentration data derived from passive microwave brightness temperatures from January 1988 to December 2012 from the National Oceanic and Atmospheric Administration/National Snow and Ice Data Center (NOAA/NSIDC) Climate Data Record (CDR) [Meier et al., 2013]. The sea-ice concentration is defined as the fraction of a grid cell area covered by sea ice. CDR concentrations are derived by combining concentration estimates from the NASA Team algorithm and the Bootstrap algorithm [Peng et al., 2013]. The sea-ice concentration data were interpolated to the same $25 \mathrm{~km}$ EASE-Grid.

Monthly mean sea-level pressure is obtained from the ERA-Interim reanalysis, a product of the European Centre for Medium-Range Weather (ECMWF) [Dee et al., 2011], for the period from January 1979 to December 2013, as well as from the National Centers for Environmental Prediction and the National Center for Atmospheric Research (NCEP/NCAR) from January 1948 to December 2014. Sea-level pressures were interpolated to the same $25 \mathrm{~km}$ EASE-Grid.

\subsection{Global Climate Models}

We use the monthly mean fields of the $\mathrm{u}$ - and v-components of sea-ice velocity, sea-ice concentration and sea-level pressure from 1900 to 2100 from the $20^{\text {th }}$ century and RCP8.5 simulations (ensemble member \#6, Mother Of All Runs) of the Community Climate System Model Version 4 (CCSM4) [Gent et al., 2011] of the National Center for Atmospheric Research (NCAR).

We also use the monthly mean $\mathrm{u}$ - and v- component of sea-ice velocity, sea-ice concentration and sea-level pressure from 1920 to 2100 from the 30ensemble members historical and RCP8.5 forcings of the Community Earth 
System Model Version 1 (CESM-LE) [Kay et al., 2014]. CESM-LE uses the latest version of the Community Atmosphere Model (CAM-5.2), which has undergone substantial improvements in the representation of physical processes in the atmosphere (e.g. parameterizations of diabatic processes, treatment of water substances and aerosols) [Hurrell et al., 2013]. CCSM4 and CESM-LE are two of the models that participated in CMIP5. 


\section{CHAPTER 3 Methodology}

Our goal is to assess the spatial patterns of future sea-ice retreat on decadal time scales given the projected robust changes in large-scale atmospheric circulation pattern over the Arctic Ocean. To this end, we quantify the divergence of sea ice in different regions of the Arctic using a Lagrangian model to backtrack a selected set of points (virtual ice floes) from the time of melt onset to their prior positions throughout the previous winter. A similar approach was used successfully to track ice age over several years [Fowler et al., 2004, Pfirman et al., 2004, Rigor and Wallace, 2004, Maslanik et al., 2007] and results compared well with ice thickness data, a proxi for ice age [Maslanik et al., 2007].

In this analysis, we use the simulated ice-drift vectors to backtrack an imaginary line at $80^{\circ} \mathrm{N}$ latitude and quantify divergence in two separate regions: the Beaufort and Chukchi seas (Pacific sector of the Arctic) and the East Siberian, Laptev and Kara seas (the Eurasian sector of the Arctic). All Lagrangian ice trajectories are initialized on June $1^{\text {st }}$, the approximate start of the melt onset. At the beginning of the integration, each selected grid cell is considered an independent Lagrangian particle and is advected using monthly sea-ice motion vectors. After each time step, the ice velocity is interpolated at the new particle location. This procedure is done repeatedly until November $1^{\text {st }}$ of the previous year, when the sea-ice extent is large enough to cover most parts of the Arctic basin [Williams et al., 2015]. We then calculate the net outflow of ice along the $80^{\circ} \mathrm{N}$ line in both regions. We do not include the Barents Sea in the Eurasian sector because the ice edge in this region is strongly 
affected by ocean heat flux [Bitz et al., 2005]. In chapter 4, we present an error analysis to quantify the biases in sea-ice drift associated with the use of the Polar Pathfinder data and the reduced temporal resolution of the observation data (weekly) and the model data (monthly). To this end, we use NSIDC IABP drifting buoy data product that includes 12-hour lat/lon position from 1979 to 2011 [Rigor, 2002].

The advection of individual ice parcels is done using a second order in time finite-difference approximation of the ice velocity :

$$
\frac{x(t+\Delta t)-x(t)}{\Delta t}=v\left(t+{ }^{1} /{ }_{2} \Delta t\right)=\left.\frac{\mathrm{d} x}{\mathrm{~d} t}\right|_{t+1 / 2 \Delta t}
$$

where $v\left(t+{ }^{1} /{ }_{2} \Delta t\right)$ is the monthly mean sea-ice velocity at time $t+{ }^{1} /{ }_{2} \Delta t, x(t)$ is location of the particle at time $t$ and $\Delta t=1$ month. 


\section{CHAPTER 4 \\ Error Analysis}

To quantify the error in the drift distances from the Lagrangian model, we compare simulated sea-ice drift distances forced with weekly and monthly mean sea-ice velocities from the Polar Pathfinder dataset with the actual buoy drift trajectories from the IABP buoy data [Meier and Maslanik, 2001]. To this end, we track each individual IABP buoy from its initial position to its last recorded position for a maximum of 1 year. For each simulated trajectory, the error in distance compared to the actual buoy position was calculated at each time step until the final position of the buoy. The procedure allows us to estimate model errors as well as to quantify the impact of temporal resolution on the estimated errors. Recall that the observed IABP drift velocities are used to construct the Polar Pathfinder sea-ice motion vectors, making an error estimate of the drift trajectories more difficult. Averaging daily sea-ice drift into longer time periods introduces an error in the initial velocity of the simulated trajectory. This error will grow in time as the distance between the simulated position and the actual buoy position increases.

Figure 4-1 shows the median, the interquartile range and the number of trajectories used to calculate the error in drift distance using weekly and monthly time resolutions for trajectories of up to 1 year. Note that, as expected, the error growth is faster for pairs of points separated by more than $200 \mathrm{~km}$, the radius-of-influence used for IABP data in the NSIDC's interpolation scheme. Reducing the temporal resolution by a factor of 4 leads to an increase of the error in drift distance from about 83 to $128 \mathrm{~km}$ after a year of tracking. Nev-

ertheless, given an observed mean sea-ice drift speed in the Arctic Ocean of 
about $3-5 \mathrm{~cm} / \mathrm{s}$, this gives a total mean drift of approximately $1200 \mathrm{~km}$. The median error in the trajectories using weekly and monthly time resolutions are therefore $7 \%$ and $11 \%$, and the upper quartile error is about $23 \%$ and $35 \%$, respectively. 
a)

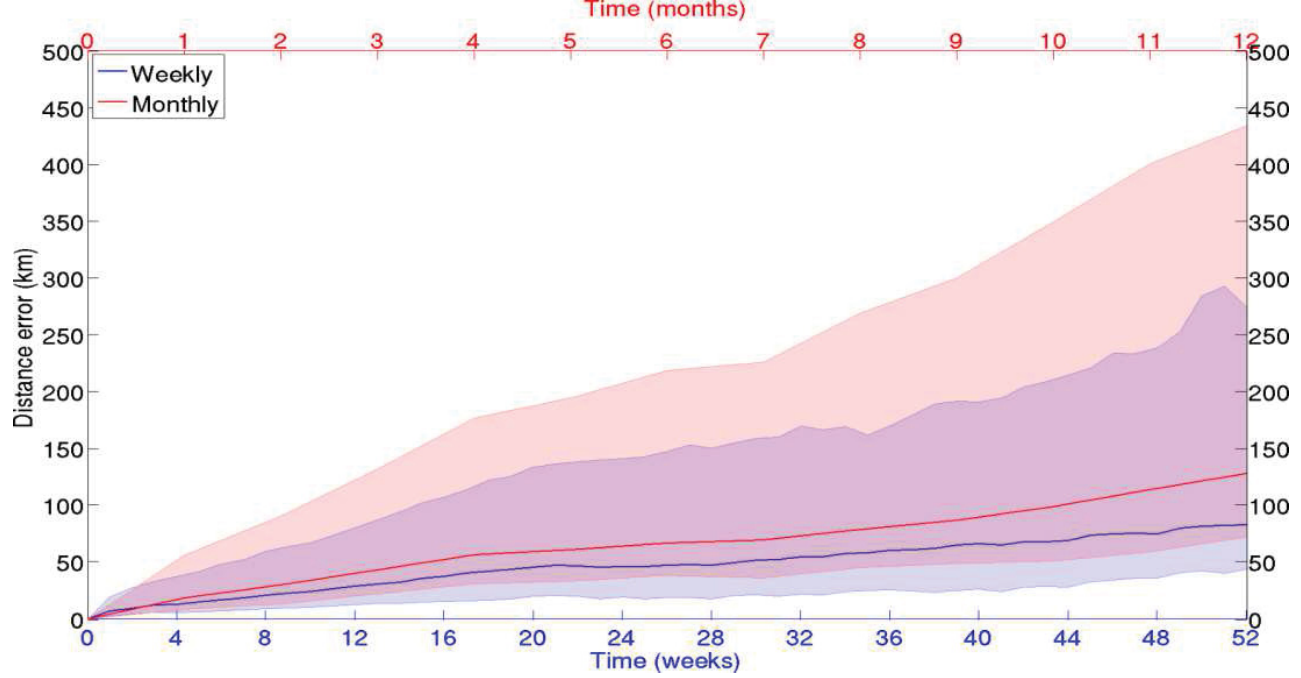

b)

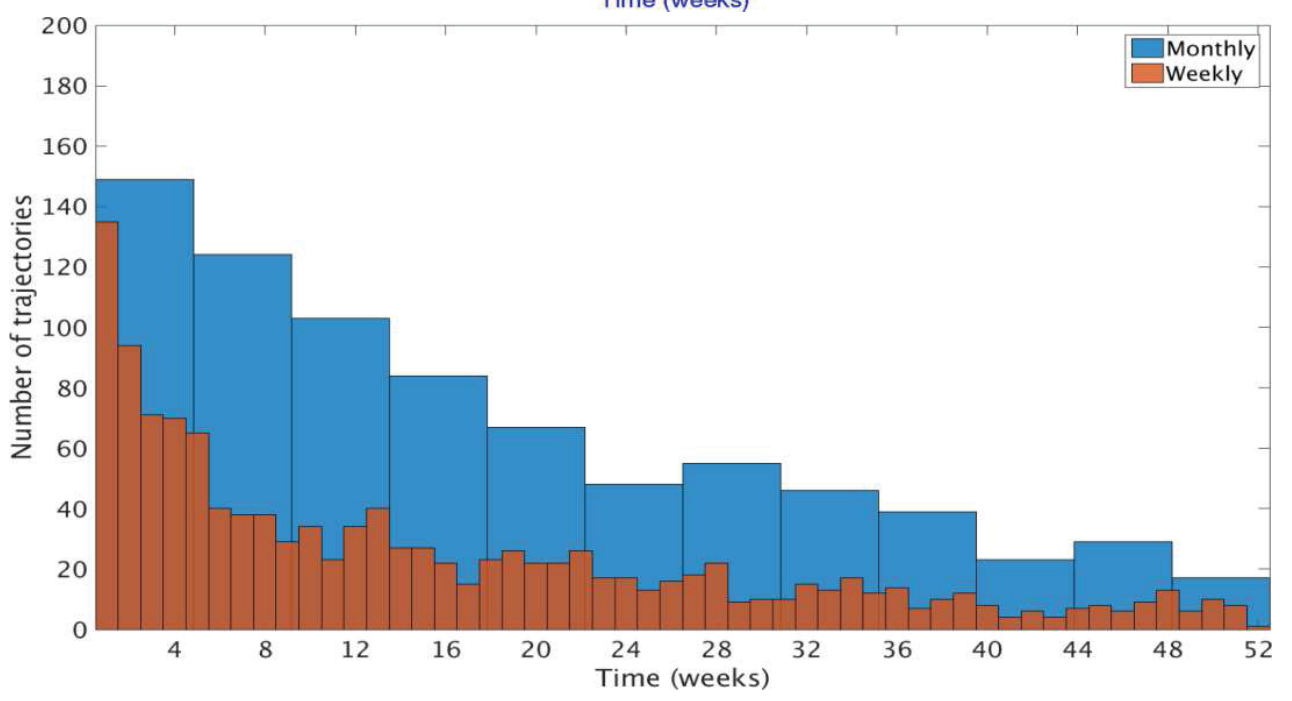

Figure 4-1: (a) Median (solid) and interquartile range (shaded) of the error in drift distance of the Lagrangian ice trajectory model using Polar Pathfinder sea-ice motion vectors with two different time resolutions by comparing with IABP buoy data. (b) Number of trajectories of each maximum time length used to calculate the error in drift distance. 


\section{CHAPTER 5 \\ Results and Discussion}

The winter mean Arctic atmospheric circulation is characterized by a semipermanent high pressure system (Arctic or Beaufort High), flanked by two semi-permanent climatological low pressure systems in the Atlantic (Icelandic Low) and Pacific sectors (Aleutian Low). The resulting observed winter mean sea-ice drift pattern is a Beaufort Gyre, an anticyclonic circulation that redistributes thick multi-year ice north of the Canadian Arctic Archipelago (CAA) and thinner Eurasian ice in the central Arctic, and a Transpolar Drift Stream that carries ice from the Eurasian coastline toward the North Pole and out through Fram Strait (figure 5-1a). The winter (November to May) mean Arctic sea-level pressure (above $70^{\circ} \mathrm{N}$ ) from $\mathrm{NCEP} / \mathrm{NCAR}$, ERA-Interim, CCSM4 and CESM-LE is shown in figure 5-2. CESM-LE mean and interannual variability in wintertime sea-level pressure are similar to observations. On the other hand, CCSM4 has a bias of around $-7 \mathrm{mb}$ over the Arctic region when compared to the observations [De Boer et al., 2012, Jahn et al., 2012], as well has larger internal variability than observed [Vavrus et al., 2012]. This is indicative of a mean state with a very positive $\mathrm{AO}$ index. Note that the years with highest mean sea-level pressure in CCSM4 are comparable to years with the lowest observed values. The decreasing trend in winter mean sea-level pressure in CESM-LE and CCSM4 starts in the first and second halves of the $21^{\text {st }}$ century respectively, in line with a late transition to a seasonal sea-ice cover in CCSM4 when compared to CESM-LE (figure 5-3).

The last decade of the $20^{\text {th }}$ century in CESM-LE is characterized by a broader Beaufort Gyre with faster sea-ice drift speed when compared with 
observations, and a smaller Transpolar Drift Stream that advects sea ice from the Kara Sea to Fram Strait (figure 5-4c). Also, there is a bias in the location of the center of the Beaufort Gyre toward the Eurasian coastline, redistributing thinner ice from the East Siberian Sea and part of the Laptev Sea in the central Arctic. The years with high sea-level pressure anomaly (figure 5-5e) are characterized by a further strengthening of the Beaufort Gyre circulation and a weakening of the Transpolar Drift Stream, along with a larger bias in the location of the center of the Beaufort Gyre toward the Eurasian sector. Conversely, the years with low sea-level pressure anomaly see a weakening of the Beaufort Gyre circulation and a strengthening of the Transpolar Drift Stream, in closer agreement with the observed mean sea-ice drift pattern (figure 5-5f).

There is no clear evidence of the presence of a Beaufort Gyre circulation in the winter mean sea-ice velocities averaged over 1990 to 1999 in CCSM4 (figure 5-4a). In this model, the Icelandic Low is deeper than observed and it penetrates farther into the eastern Arctic Ocean, weakening the Arctic High and carrying thick ice from the central Arctic and regions north of the Queen Elizabeth Islands toward Fram Strait and out of the Arctic Ocean [De Boer et al., 2012]. This atmospheric pattern is a typical manifestation of an extremely positive AO index (e.g. 1968, in figure 3a of Tremblay et al. [1997]). The large internal variability of the sea-level pressure in CCSM4 [Vavrus et al., 2012] accounts for important interannual variability in the large-scale mean winter atmospheric circulation. In fact, the sea-ice circulation shown in figure 5-4a with the absence of a clear Beaufort Gyre is the result of the average of two very different regimes. In years with high sea-level pressure anomaly (figure 5-5c), the winter sea-ice velocities are very similar to those from years with observed low sea-level pressure anomaly (figure 5-5b), with the presence of a weak Beaufort Gyre circulation and a broad Transpolar Drift Stream. 
This circulation is characteristic of a typical positive AO index in the observational record. In years with low sea-level pressure anomaly (figure 5-5d), the winter sea-ice velocities follow a cyclonic circulation over the whole Arctic basin, driven by a deep Icelandic Low, and a Transpolar Drift Stream that carries ice from the Beaufort Sea directly into the Fram Strait via the Lincoln Sea [Rigor et al., 2002].

Future projections of sea-ice extent from CESM-LE are characterized by a sea-ice retreat that is more symmetric around Lincoln Sea (north of Ellesmere Island) and thick ice north of the CAA is maintained by the presence of the Beaufort Gyre throughout the $21^{\text {st }}$ century (figure 5-8). In CCSM4, the simulated patterns of sea-ice retreat are drastically different. The positive AO state that characterizes the large-scale mean winter atmospheric circulation in CCSM4 results in a sea-ice retreat preferentially in the Beaufort Sea (figure 5-9). The region north of the CAA becomes ice-free in September before the central Arctic (North Pole), with sea ice remaining in the region north of Greenland and in the narrow channels of the CAA [Jahn and Holland, 2013].

We quantify the sea-ice divergence from the Pacific and Eurasian sectors of the Arctic Ocean from November to June using the Lagrangian model (figure 5-6). Figure 5-7 shows the net area of divergence from the Pacific and Eurasian sectors for CCSM4 and CESM-LE from the early $20^{\text {th }}$ century to 2100. Note that the results are similar when integrating from June $1^{\text {st }}$ to March $1^{\text {st }}$, the period with the highest correlation between the September seaice extent anomaly and coastal divergence reported by Williams et al. [2015]. In CESM-LE, the presence of a strong Beaufort Gyre circulation leads to a net convergence of ice in the Pacific sector. On the other hand, the extremely positive AO index in CCSM4 prevents the redistribution of thick ice north of the CAA into the Beaufort and Chukchi seas, so that the net divergence of sea-ice 
area is approximately zero. Conversely, divergence of sea ice is more important in CESM-LE than in CCSM4 in the Eurasian sector since the strong anticyclonic circulation of the Beaufort Gyre in CESM-LE carries ice away from the Eurasian coastlines toward the North Pole. This highlights the importance of the different large-scale atmospheric circulation patterns on projected Arctic sea-ice conditions [Liu et al., 2013, Meehl et al., 2013].

In the observations, the first decade of the $21^{\text {st }}$ century has seen successive record low sea-ice extent minima [Stroeve et al., 2012b], most dramatically visible in the sea-ice retreat in the Chukchi, East Siberian and Laptev seas. The general thinning of the ice-pack has led to increasing sea-ice velocities across the whole Arctic Ocean and a more mobile ice pack, except for the area immediately north of the CAA (figure 5-10a). The observed increase in ice drift speed along the Alaskan coastline strengthened the anticyclonic circulation in the Pacific sector (figure 5-10b). We again use our Lagrangian model to evaluate the trend in the net divergence area from the different peripheral seas of the Arctic (i.e. Beaufort, Chukchi, East Siberian, Laptev and Kara seas). Following Williams et al. [2015], we calculate the late winter sea-ice divergence along the coastlines between the first week of March and the beginning of the melt season, which they show is the period with the highest correlation between the September sea-ice extent anomaly and coastal divergence.

During the last two decades, we observe a positive trend in the net area of divergence in the East Siberian, Laptev and Kara seas, but no significant trend in the Beaufort and Chukchi seas (figure 5-11), where the retreat has been greatest. Clearly, ice advection is not the only factor driving the sea-ice retreat in this sector. This result puts in question the idea of a potential predictability of the sea-ice retreat on the regional scale. For instance, Rigor and Wallace 
[2004] found that the AO index can explain as much as $64 \%$ of the variance in summer sea-ice extent in the Eurasian sector, while it explains less than $20 \%$ of the variance in the region north of Alaska. The Pacific region is greatly influence by the oceanic heat inflow through the Bering Strait [Bitz et al., 2005, Steele et al., 2010, Woodgate et al., 2010]. The effect of summertime wind circulation can also lead to enhanced surface ocean warming under anomalous southerly winds associated with the Arctic Dipole [Wang et al., 2009, Overland et al., 2012]. The increase in sea-ice velocity along the Alaskan coast also favors the upwelling of warm summer Bering Sea waters due to the Ekman pumping divergence [Zhang et al., 1998, Yang, 2006]. These factors can also be amplified by positive feedbacks including the ice-albedo feedback [Holland et al., 2006, Maslanik et al., 2007] and the increased presence of melt ponds at the surface of first-year ice [Perovich et al., 2007]. Finally, changes in multi-year ice concentration explain over $50 \%$ of the variance in sea-ice extent in the Beaufort/Chukchi region [Rigor and Wallace, 2004]. Multi-year ice, compared to thin first-year ice, is preferentially advected into the Pacific region when there is a strong Beaufort Gyre circulation. Since the intensity of the Beaufort High decreases with a rising AO index, it is possible that, even though the correlation with area of sea-ice divergence has recently been weak in this sector, the predictive value of the AO may nonetheless be significant, operating instead through a divergence of mass. 
a)

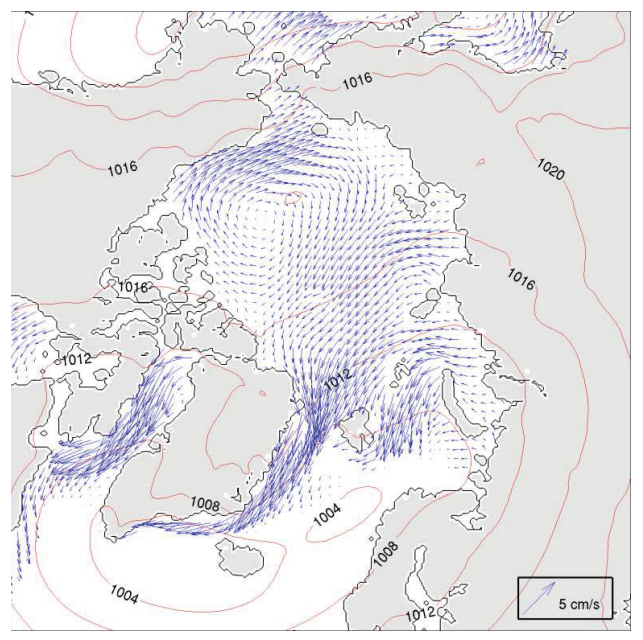

b)

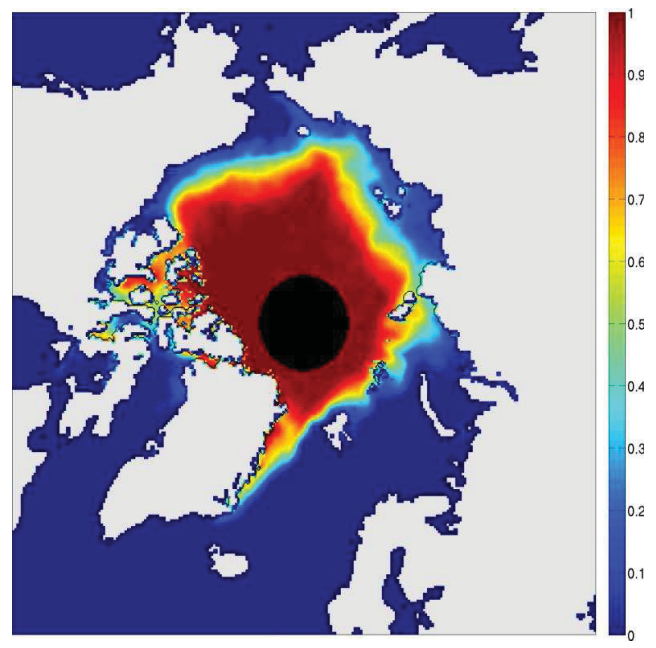

Figure 5-1: Observations: (a) Winter (NDJFMAM) mean sea-ice velocity field (arrows) and sea-level pressure contours (red line) from 1990 to 1999. (b) Mean September sea-ice concentration from 1990 to 1999. Sea-ice velocity vectors are capped at $5 \mathrm{~cm} / \mathrm{s}$ for clarity. 


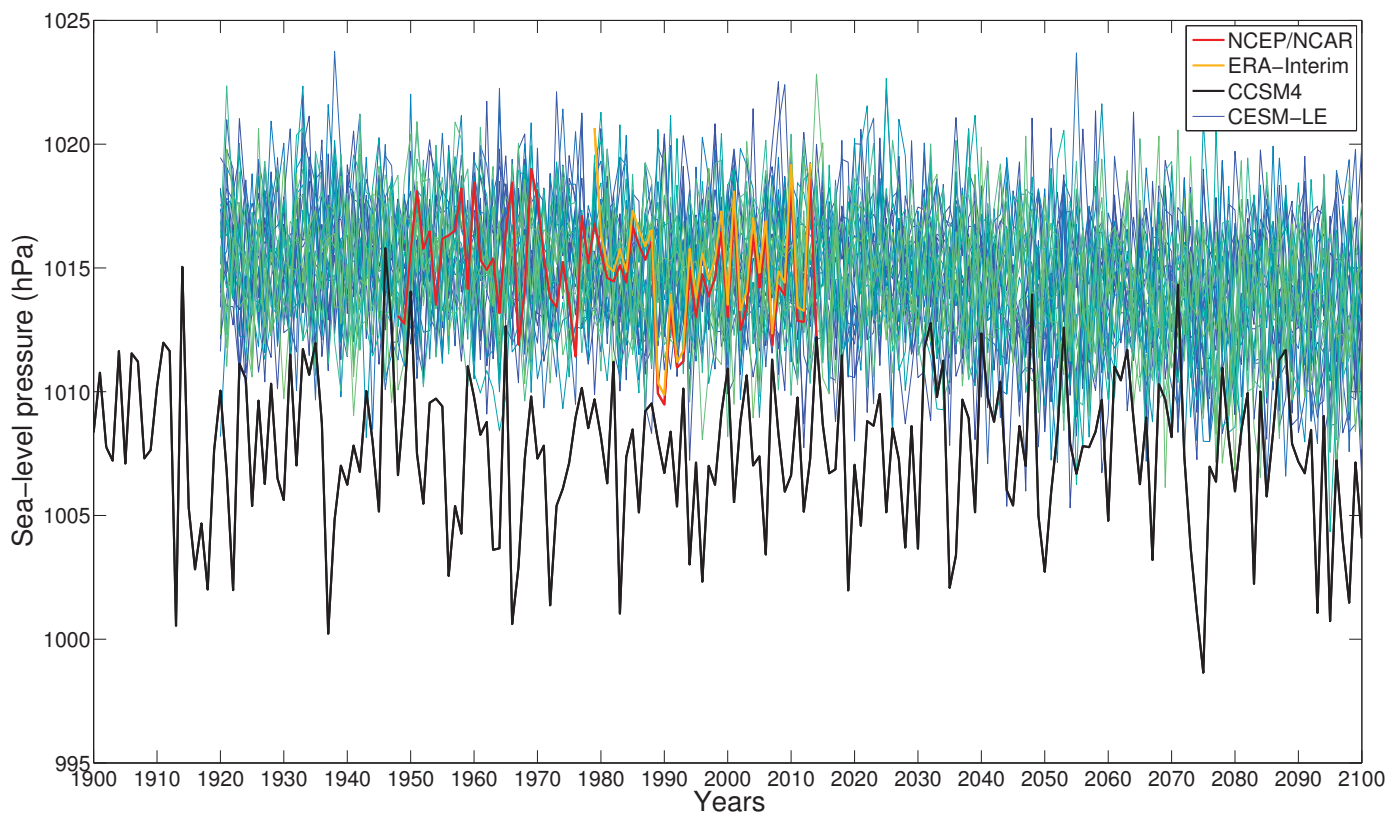

Figure 5-2: Winter (NDJFMAM) mean sea-level pressure averaged over the region above $70^{\circ} \mathrm{N}$ from 1900 to 2100 for NCEP/NCAR reanalysis (red), ERAInterim reanalysis (orange), CCSM4 (black) and the 30-ensemble members of CESM-LE (from blue to green). 


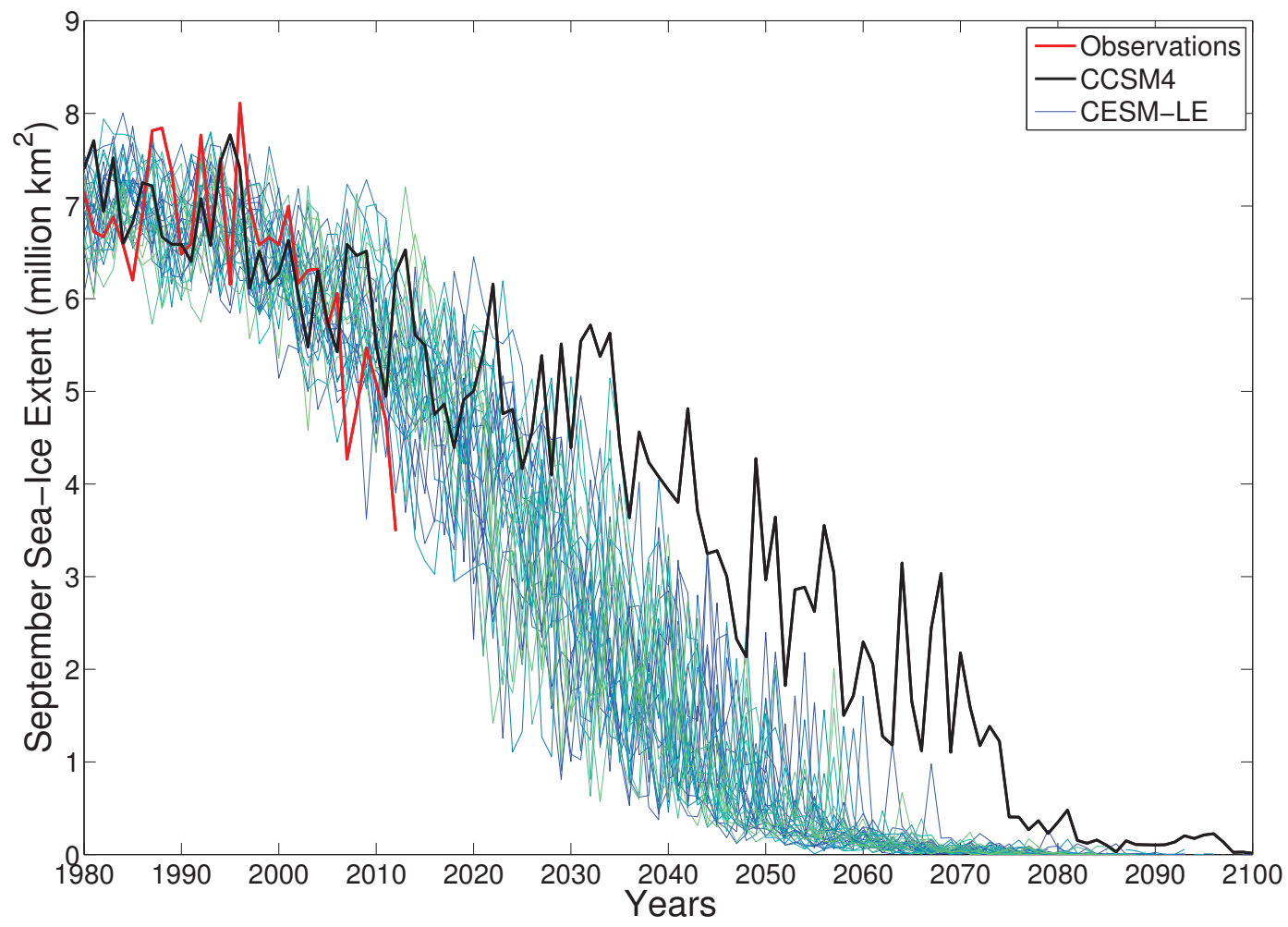

Figure 5-3: September sea-ice extent from 1980 to 2100 for observations (red), CCSM4 (black) and the 30-ensemble members of CESM-LE (from blue to green). 
a)

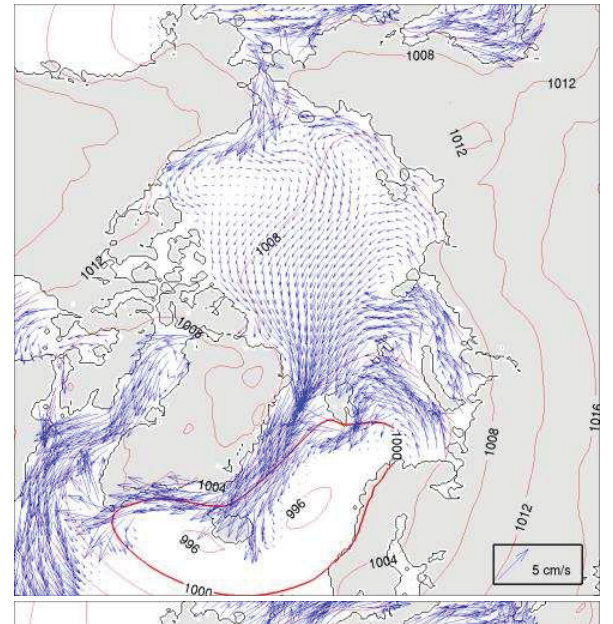

c)

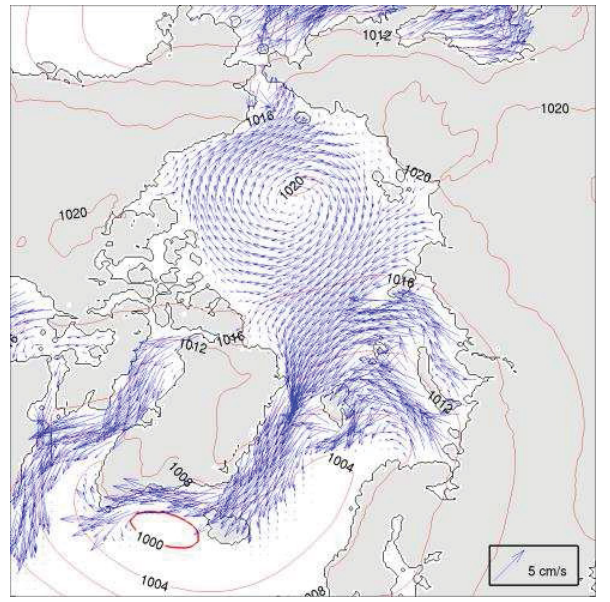

b)

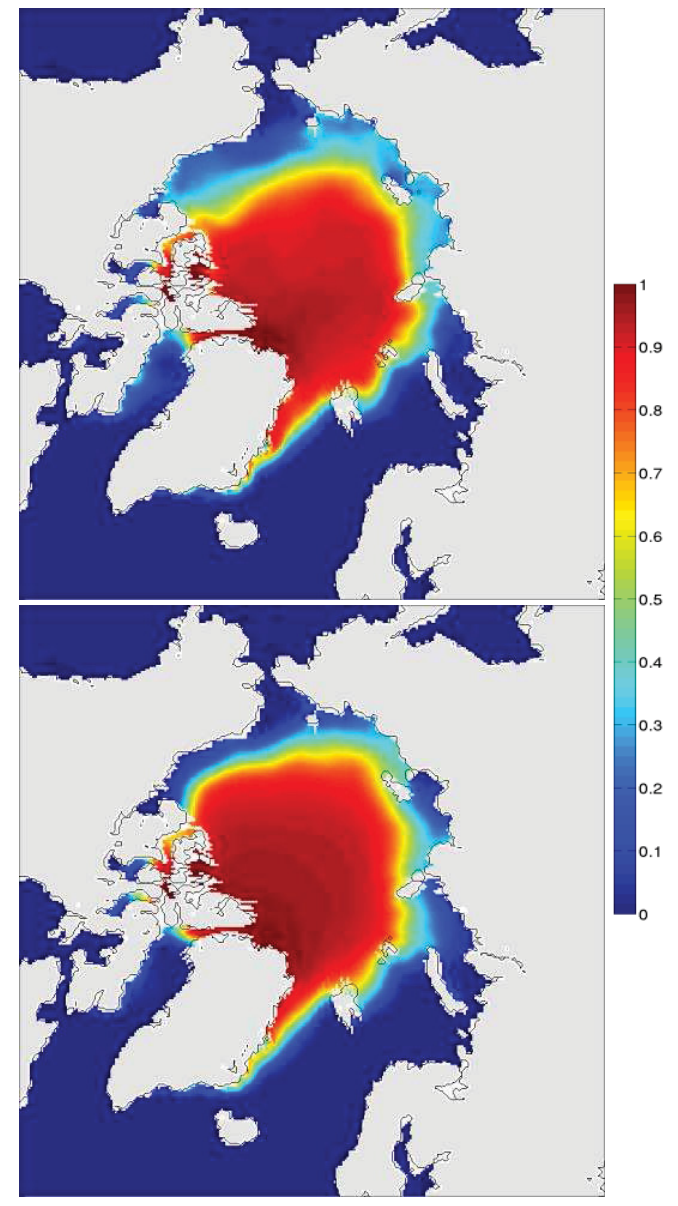

Figure 5-4: [left] Winter (NDJFMAM) mean sea-ice velocity field (arrows) and sea-level pressure contours (red line) from 1990 to 1999. [right] Mean September sea-ice concentration from 1990 to 1999. (a-b) CCSM4, (c-d) CESM-LE 30 -ensemble average. Sea-ice velocity vectors are capped at $5 \mathrm{~cm} / \mathrm{s}$ for clarity. 
a)

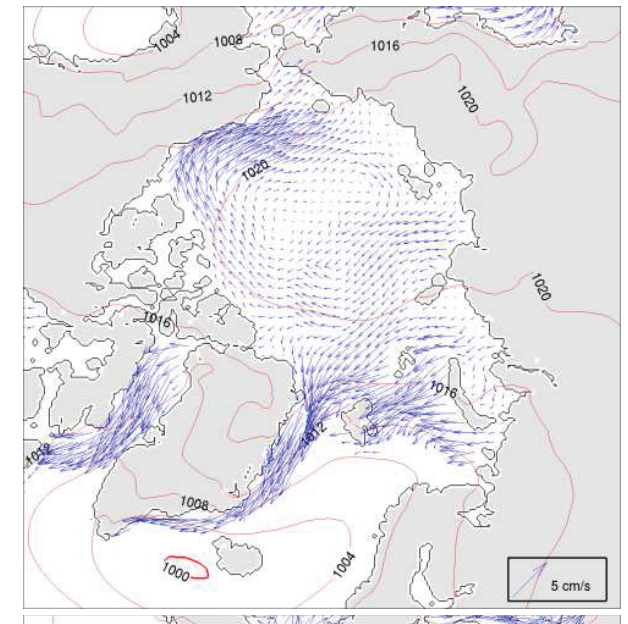

c)

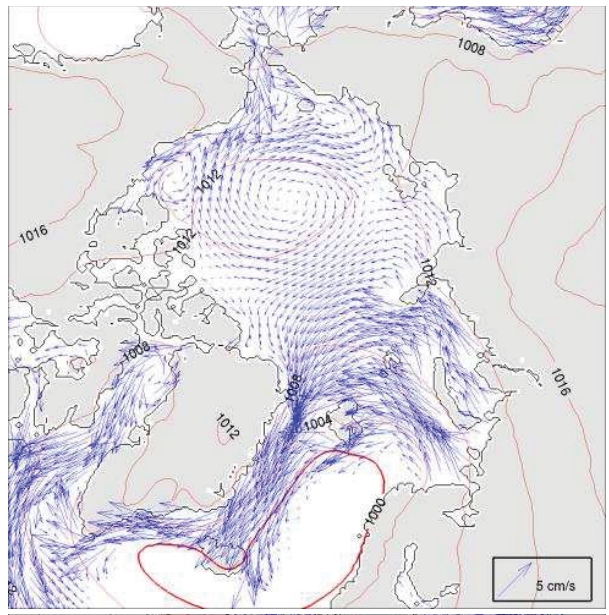

e)

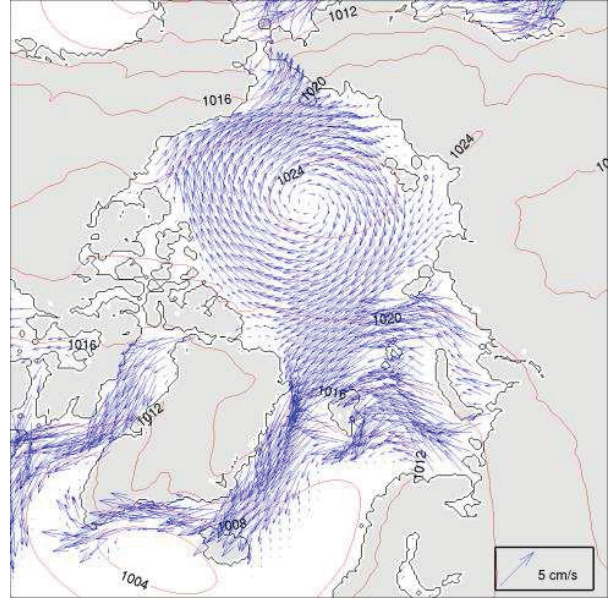

b)

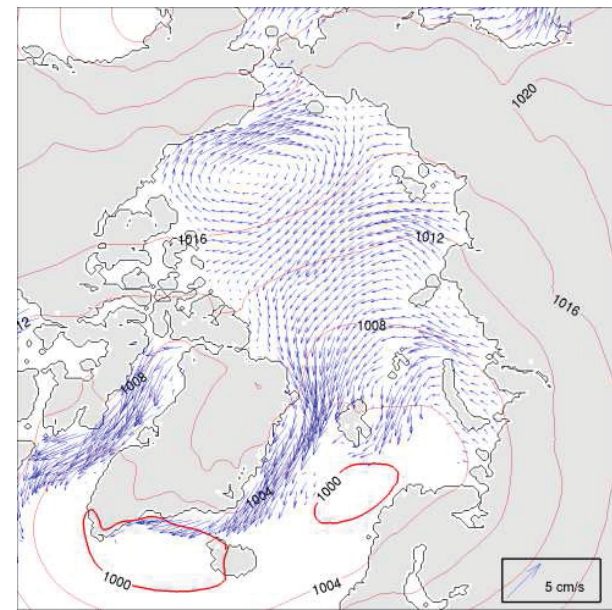

d)

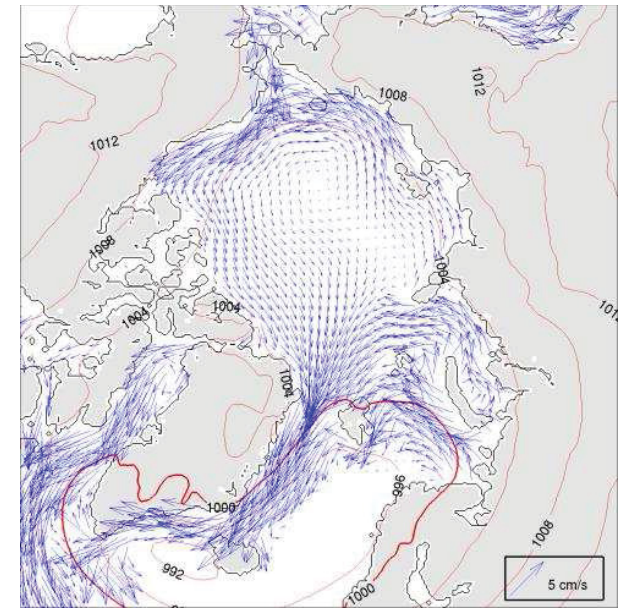

f)

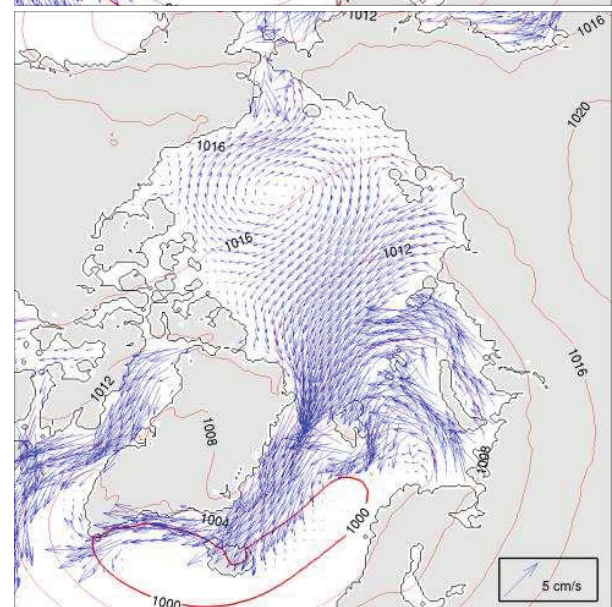

Figure 5-5: Winter (NDJFMAM) mean sea-ice velocity field (arrows) and sea-level pressure contours (red line) for years of sea-level pressure anomaly greater [left] or lesser [right] than 1 standard deviation from the mean during the 1990-1999 period. (a-b) Observations, (c-d) CCSM4, (e-f) CESM-LE 30ensemble average. Sea-ice velocity vectors are capped at $5 \mathrm{~cm} / \mathrm{s}$ for clarity. 


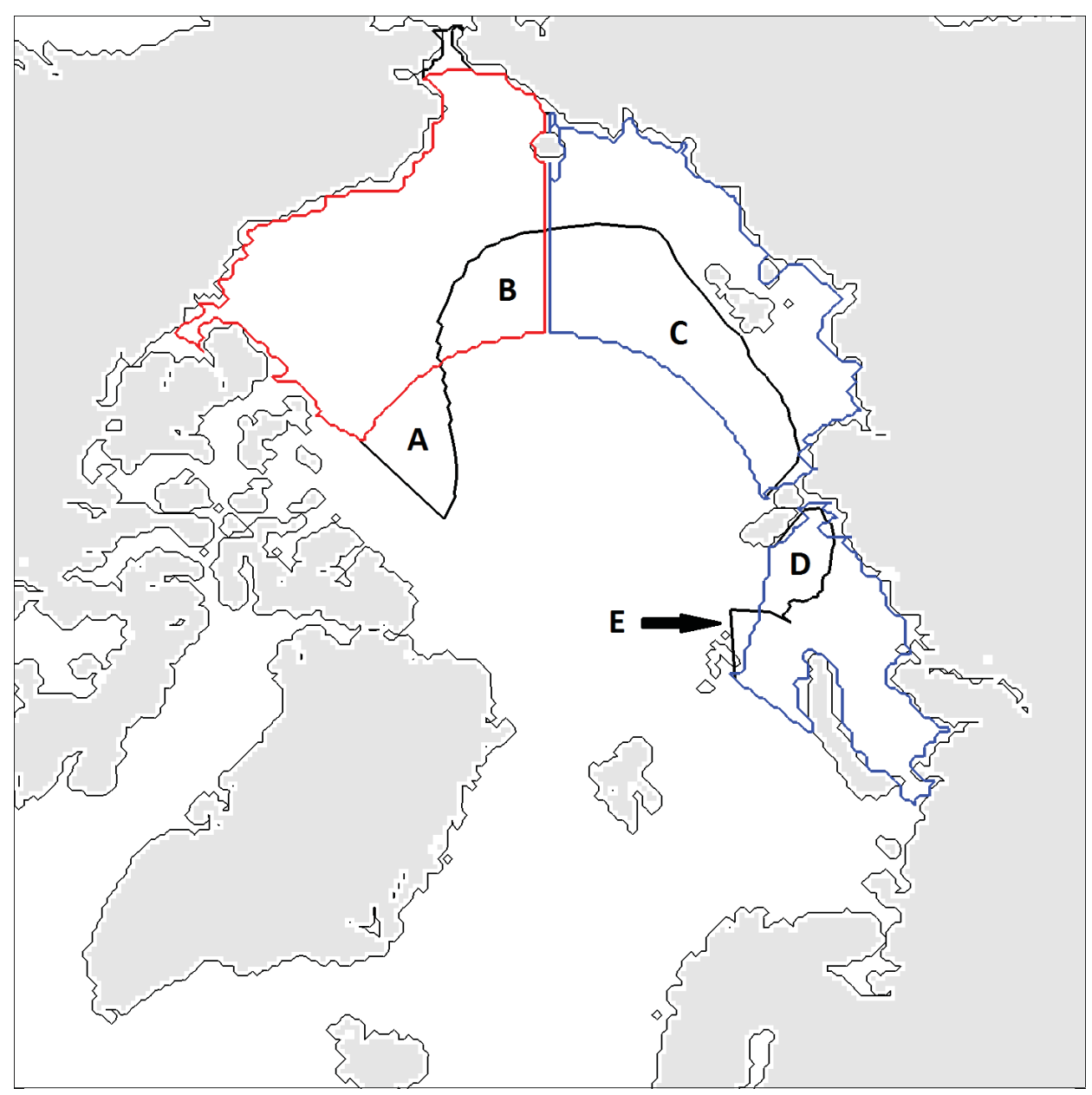

Figure 5-6: Lagrangian trajectories of the year 1997 using member \#002 of CESM-LE. The $80^{\circ} \mathrm{N}$ line has been backtracked from June $1^{\text {st }}, 1997$ to March $1^{\text {st }}, 1997$ in order to quantify the divergence from the Pacific (red) and the Eurasian sectors (blue). The difference between Area B (outflow) and Area A (inflow) is the divergence from the Pacific sector. The difference between Areas $\mathrm{C}$ and D (outflow) and Area E (inflow) is the divergence from the Eurasian sector. 


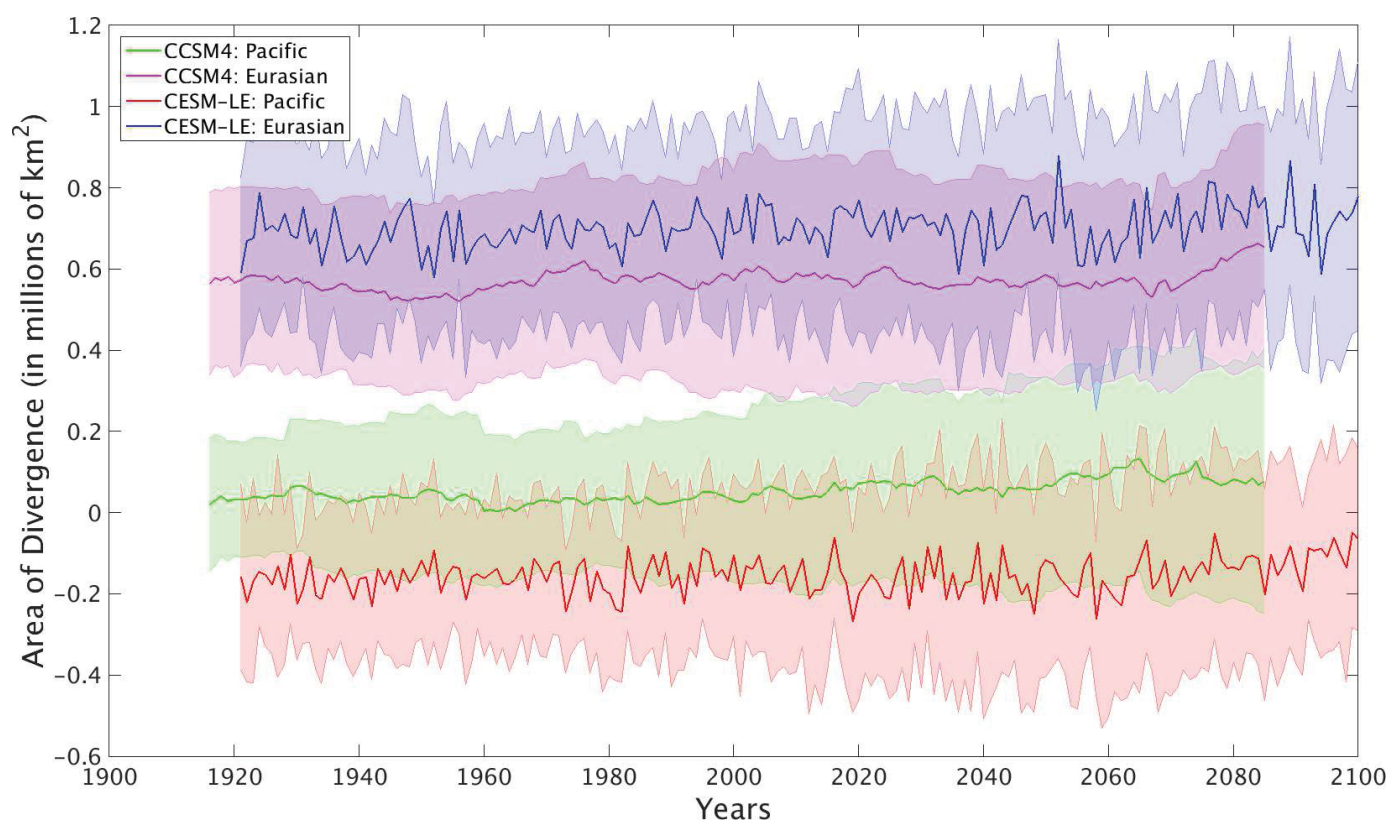

Figure 5-7: Timeseries of the net area of divergence (defined in figure 5-6) from November to June using our Lagrangian backtrajectory model for the Pacific and Eurasian sectors. For CCSM4, the 30-year running mean (solid line) and standard deviation (shaded), and for CESM-LE, the 30-ensemble average (solid line) and standard deviation (shaded). 
a)

b)

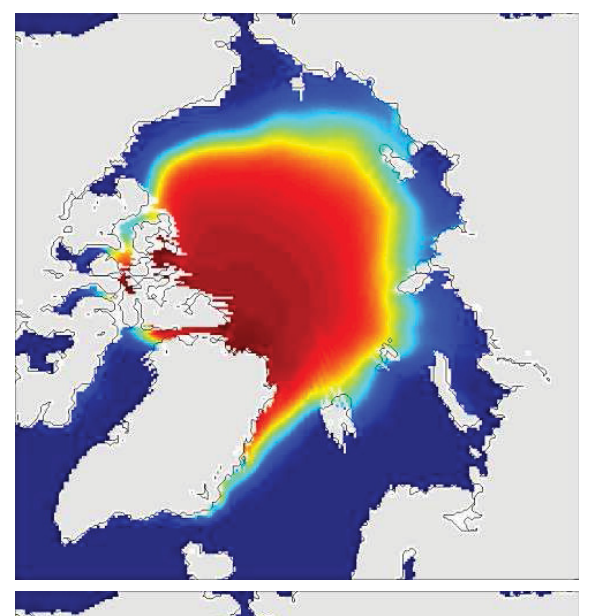

c)
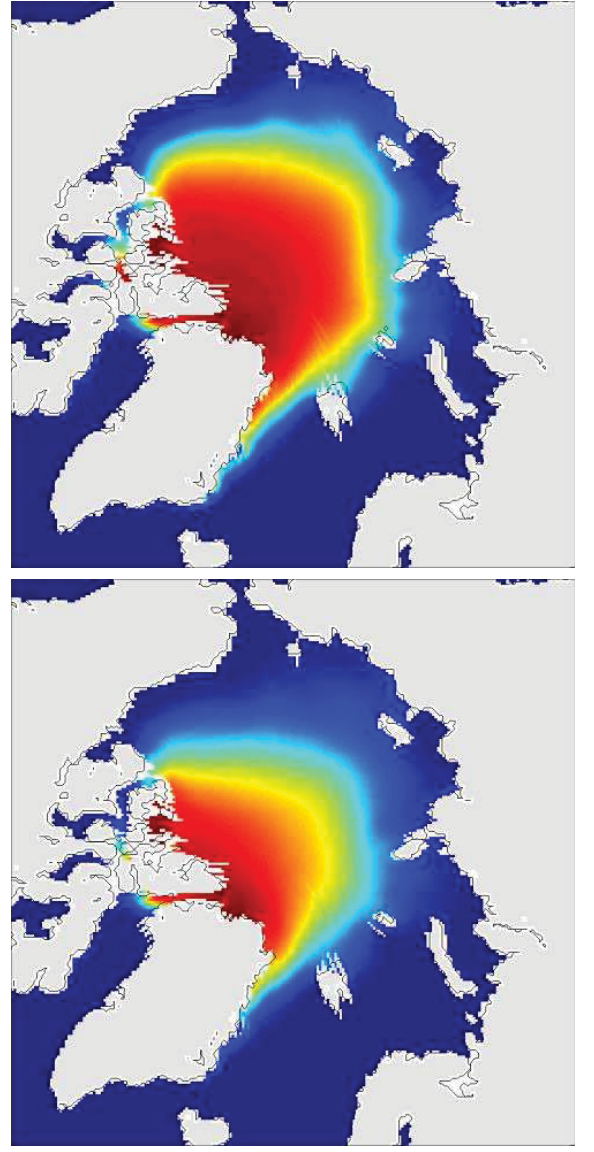

d)

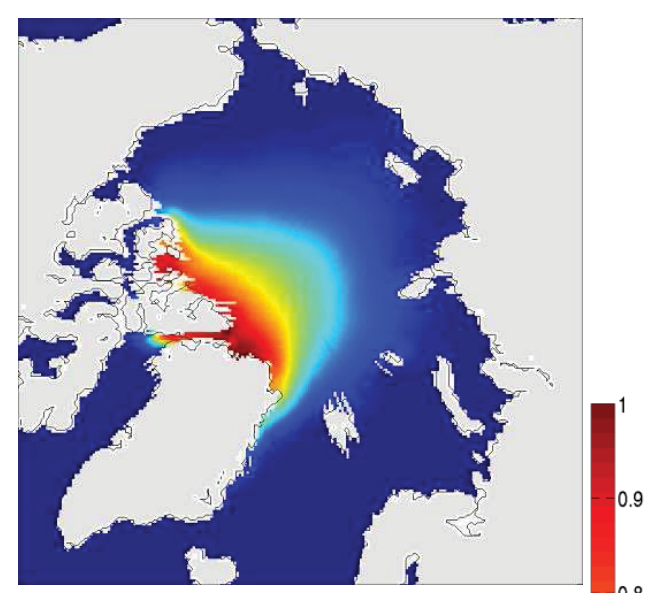

e)

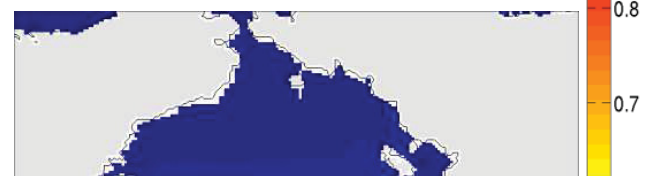

f)

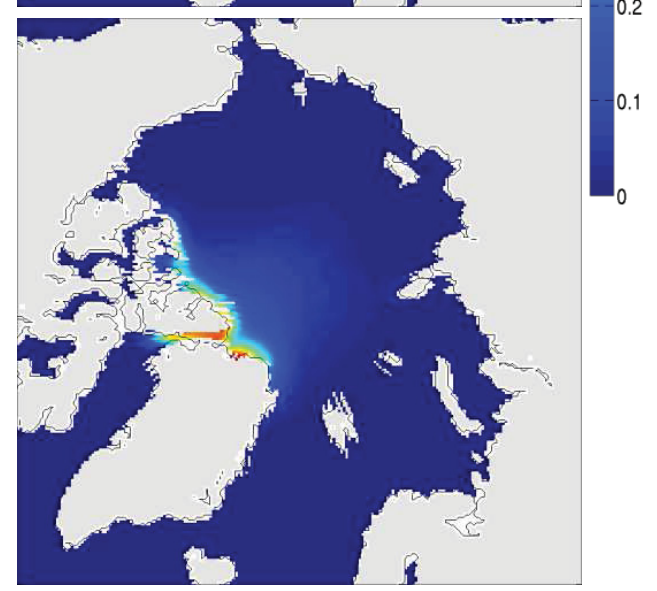

Figure 5-8: CESM-LE 30-ensemble mean September sea-ice concentration. (a) 2000 to 2009, (b) 2010 to 2019, (c) 2020 to 2029, (d) 2030 to 2039, (e) 2040 to 2049, (f) 2050 to 2059. 

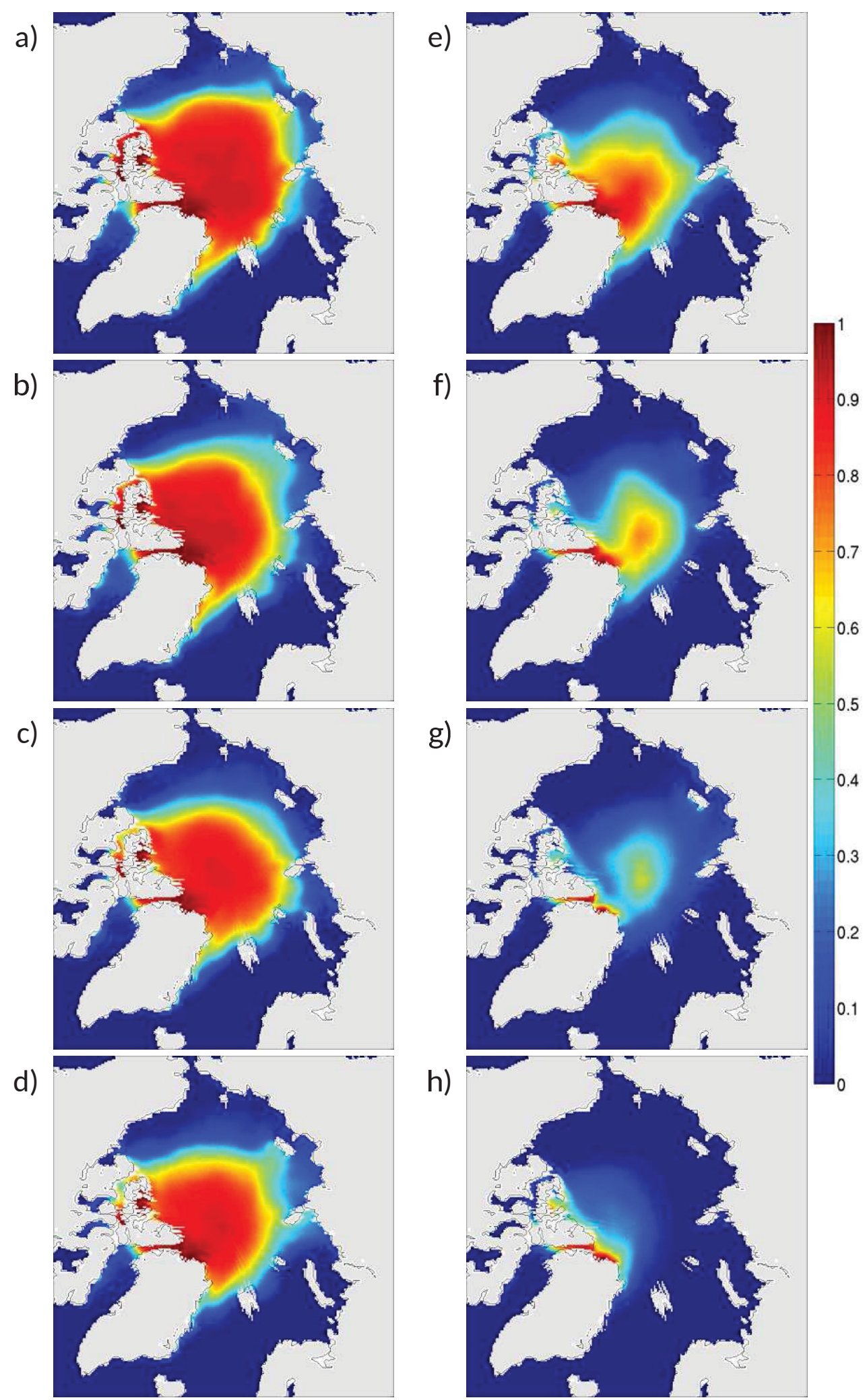

Figure 5-9: CCSM4 mean September sea-ice concentration. (a) 2000 to 2009, (b) 2010 to 2019, (c) 2020 to 2029, (d) 2030 to 2039, (e) 2040 to 2049, (f) 2050 to 2059 , (g) 2060 to 2069, (h) 2070 to 2079. 
a)

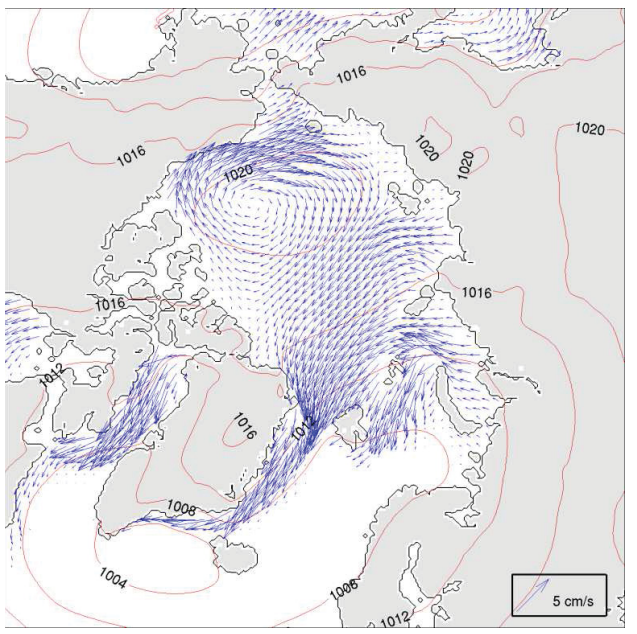

b)

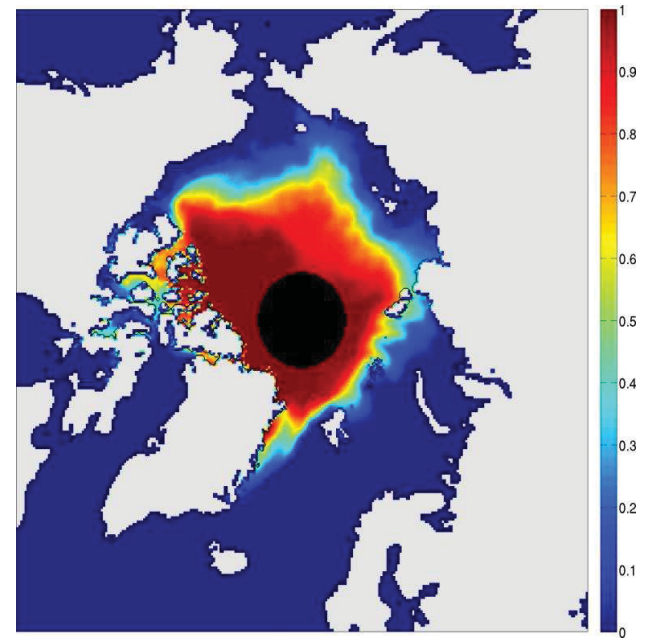

Figure 5-10: Observations: (a) Winter (NDJFMAM) mean sea-ice velocity field (arrows) and sea-level pressure contours (red line) from 2000 to 2009. (b) Mean September sea-ice concentration from 2000 to 2009. Sea-ice velocity vectors are capped at $5 \mathrm{~cm} / \mathrm{s}$ for clarity. 


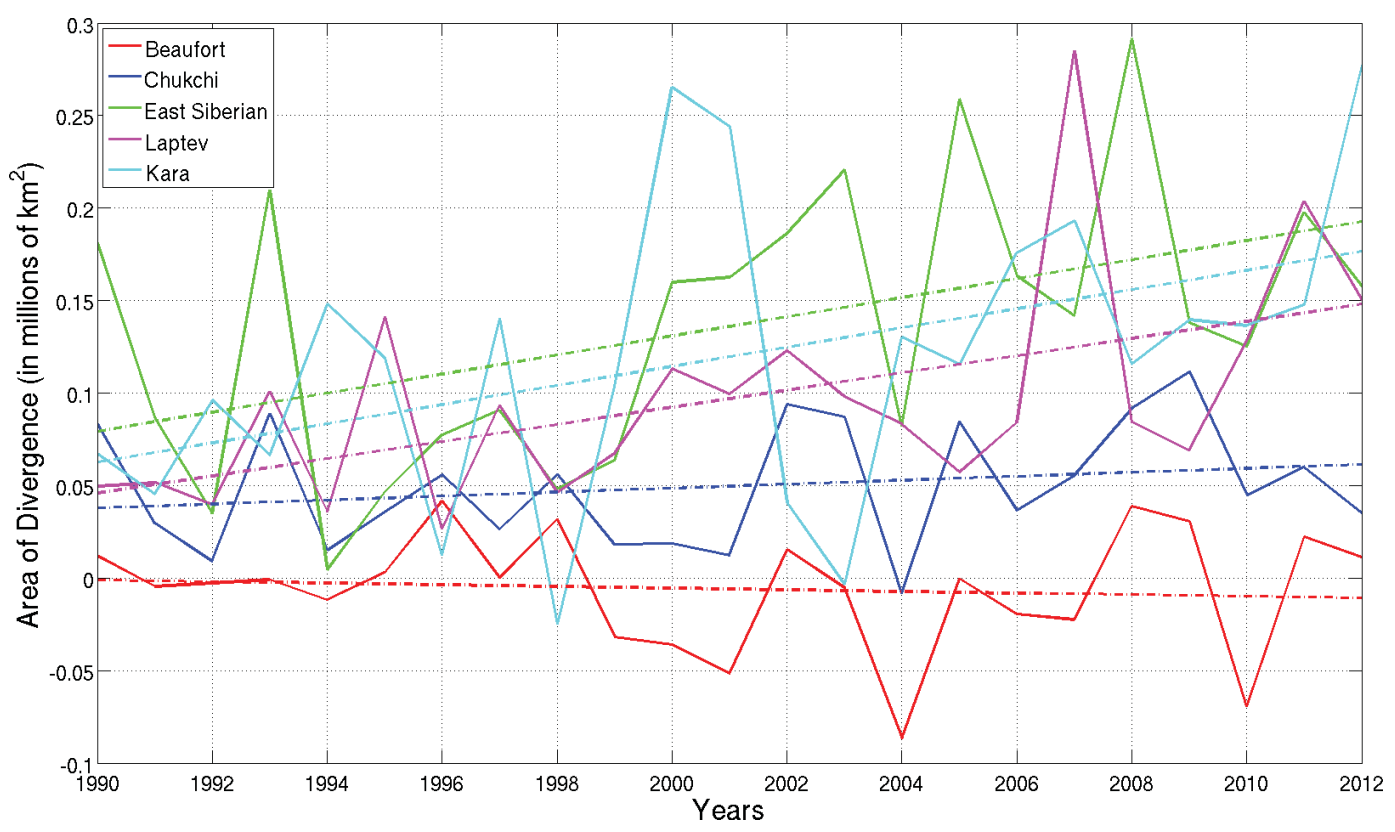

Figure 5-11: Late winter (from the first week of March to the first week of June) observed net area of divergence using our Lagrangian backtrajectory model for the Beaufort (red), Chukchi (blue), East Siberian (green), Laptev (magenta) and Kara (cyan) seas. For each sea, the dash-dot line shows the linear trend. 


\section{CHAPTER 6 \\ Conclusion}

In this study, we analysed the winter mean sea-ice motion in order to gain insight on the future patterns of sea-ice retreat in the Arctic Ocean. The wintertime sea-level pressure is directly linked to the large-scale mean atmospheric circulation, the main driver of sea-ice motion. Two different GCMs were used in this analysis: CCSM4 has an important low bias $(-7 \mathrm{mb})$ in the wintertime sea-level pressure over the Arctic, characteristic of an extremely positive AO index, and CESM-LE presents a strong Beaufort Gyre circulation, with the center of the Beaufort High shifted toward the Eurasian coast, a pattern typical of a low-to-neutral AO index.

To quantify the potential for sea-ice retreat, we looked at sea-ice divergence from the Pacific and the Eurasian sectors using our Lagrangian backtracking model. Sea-ice divergence is related to formation of first-year ice, which is more likely to melt in the summer [Rigor et al., 2002, Rigor and Wallace, 2004, Williams et al., 2015]. The absence of a Beaufort Gyre circulation in CCSM4 leads to a net divergence of approximately zero in the Pacific sector, compared to convergence there in CESM-LE. Coastal divergence in the Eurasian sector is more important in CESM-LE, along with a broad Beaufort High pushing ice toward the North Pole. The positive trend in the AO index predicted by CMIP5 models [Gillett and Fyfe, 2013] suggests that the Beaufort and Chukchi seas could continue to lead in future sea-ice retreat.

We do not claim that the mechanism applied here to two sets of climate output offers a full explanation of the dynamics underlying the future patterns of sea-ice retreat. The determinants of sea-ice extent are complex and factors 
other than the large-scale atmospheric circulation play an important role in determining its details, including ocean heat inflow from the sub-Arctic, smallscale atmospheric anomalies, vertical heat flux through Ekman pumping, and the interaction of ice growth/melt anomalies with the ice-albedo feedback. These mechanisms are likely to play a role, sometimes significantly, during the transition to a seasonally ice-free Arctic.

However, from related work [Williams et al., 2015], the mechanism applied here to climate model output is known to be correlated with approximately $50 \%$ of the interannual variance in sea-ice extent. Moreover, it rests on a straightforward and well-studied physical mechanism [Rigor et al., 2002], which is strong argument for causation. We leave as a next level of investigation the role of mechanisms that operate more locally, within particular sub-areas of the Arctic system. Nevertheless, this work, which links sea-ice retreat patterns to robust large-scale atmospheric patterns, constitutes an important advancement toward better predictability of the future Arctic climate. 


\section{Appendix}

This appendix is an extension of the work presented in the thesis and accepted with revision in the Journal of Climate. The concept behind the following results will be used in a more economical view of the Arctic as part of a scientific paper soon to be submitted.

In recent years, especially at the end of the summer, important changes in ice extent have been observed in the Arctic Ocean. In particular, the minimum sea ice extent is decreasing by $10 \%$ per decade [Stroeve et al., 2007, Comiso et al., 2008]. Climate models that have a reasonable late 20th century Arctic climate are forecasting ice-free summers in the Arctic before the end of this century [Holland et al., 2006].

Arctic sea-ice conditions are determined by the combined action of thermodynamics (ice formation and melting) and the dynamics of drift and deformation. Each fall, new sea ice floes are formed in the peripheral seas and are advected under the action of surface wind and water stresses. Some of these floes will drift over short distances and melt the next summer close to the place they were formed, while some will survive the following summer and become multi-year ice. Multi-year ice usually drifts longer distances and tends to increase in thickness along its trajectory through basal accretion and ridging.

Analysis of ice trajectories is a powerful tool for validation of model simulations. Currently, modellers compare simulated sea ice distributions to static snapshots, seasonal averages, or climatologies of satellite-derived sea ice extent. Since different source regions contain sea ice of different thickness, assessing whether climate models can reproduce the correct origin for sea ice melting in the MIZ will increase confidence in climate forecast. 
The goals of this project are to quantify the source regions for sea ice melting in one peripheral sea using back trajectories calculated from satellitederived sea ice drift (based on Maslank et al. [1995], Emery et al. [1997], Meier et al. [2000], Tschudi et al. [2010]) and to assess whether GCMs and regional sea ice models are able to reproduce the source region for sea ice melting in different peripheral seas the following summer. If thick ice is advected in one peripheral sea, it is less likely to melt the following summer than if the ice floe was thinner. Therefore, determining the source region, which is a proxy for ice thickness (for instance, ice north of Canada is thicker than ice from the Chukchi or Kara seas), becomes really important.

This project will allow us to identify limitations in the ability of GCMs to simulate source regions for sea ice being advected in more coastal areas and thus provide guidance for developing more reliable forecasts of the future sea-ice edge evolution.

In the following, we present figures of backward trajectories from 6 different peripheral seas for different time periods using various dataset. The trajectories have been computed using our Lagrangian model and have a duration of 5 years unless they reach a region of open water before. It allows to see how the source regions of sea ice change with time as sea ice gets more mobile and average drift speed increases. 
a)

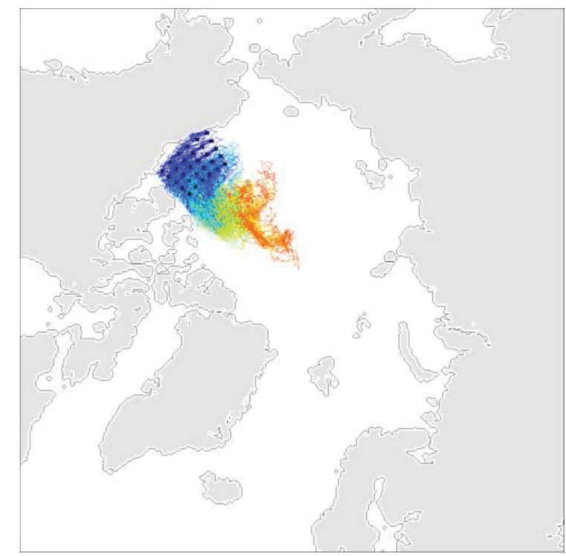

b)

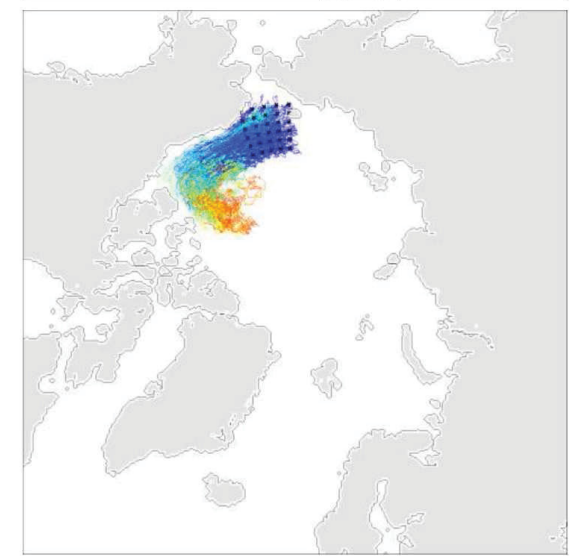

c)

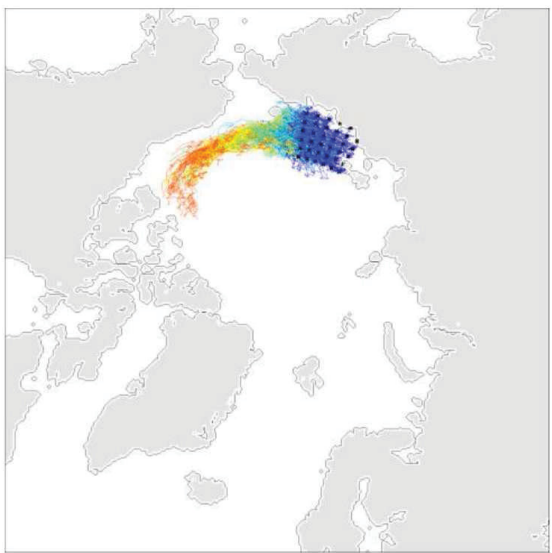

d)

e)
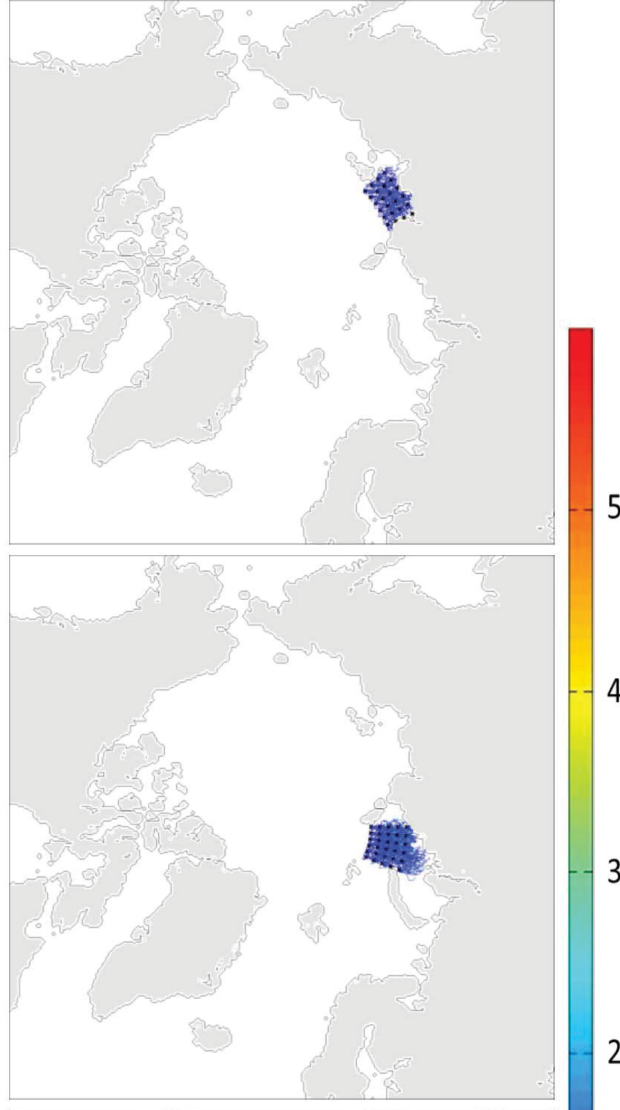

f)

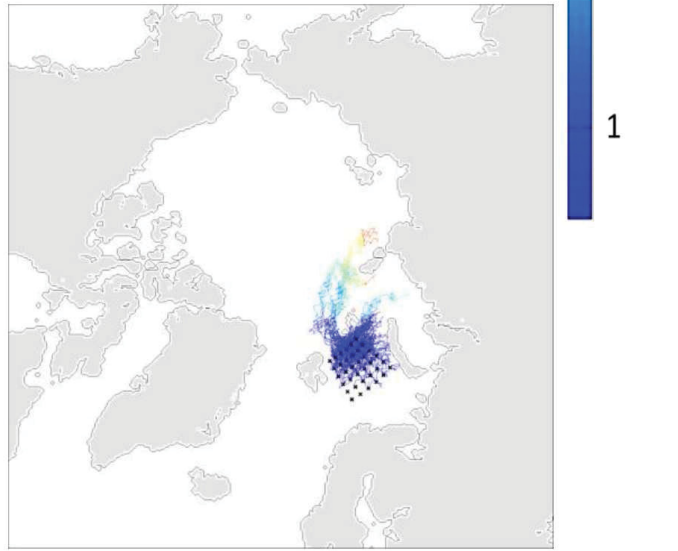

Figure 6-1: Observations: Backward trajectories of ice parcels between 1980 and 1990 for a maximum duration of 5 years in the Beaufort (a), Chukchi (b), East Siberian (c), Laptev (d), Kara (e) and Barents (f) seas. The colors indicate the duration of the tracking from the initial position (black crosses). 
a)

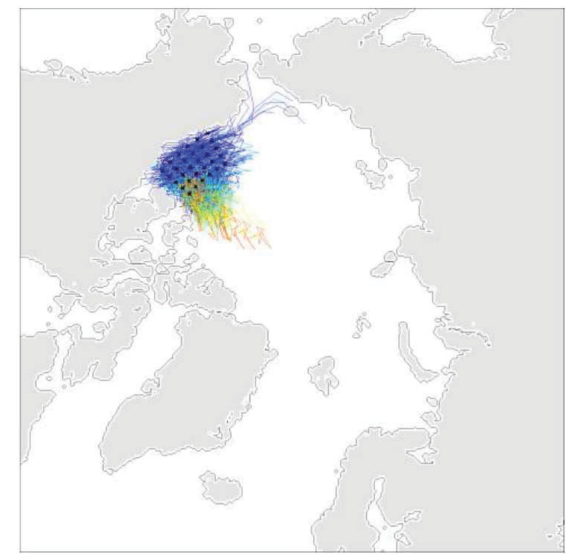

b)

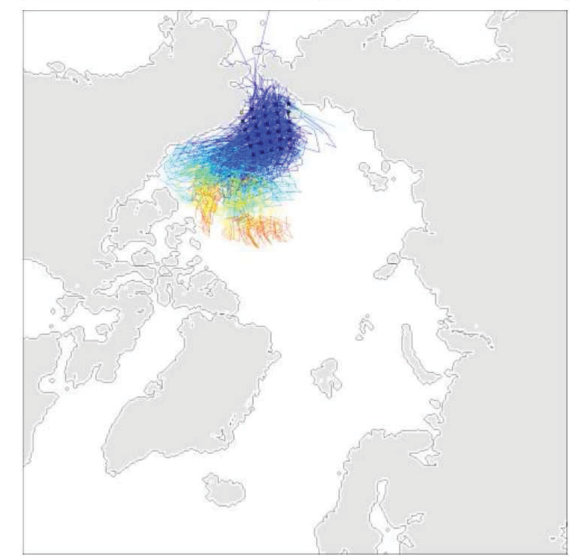

c)

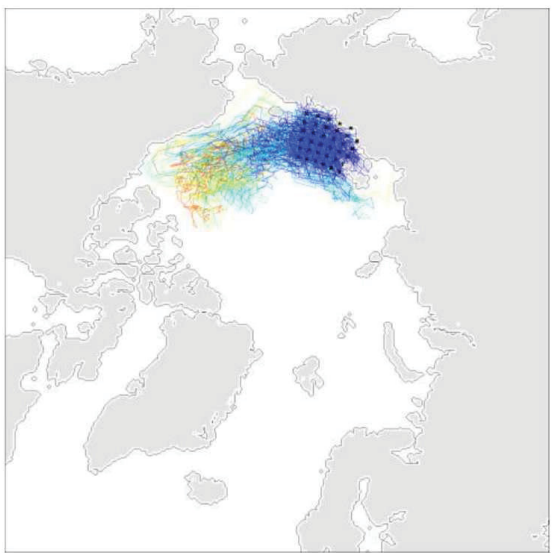

d)

e)
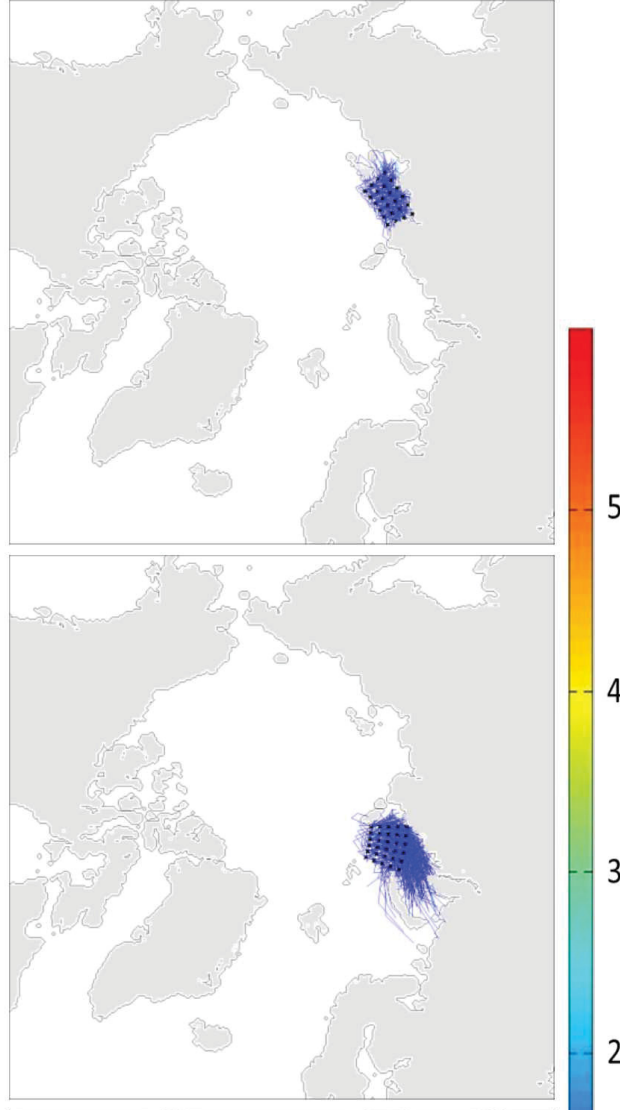

f)

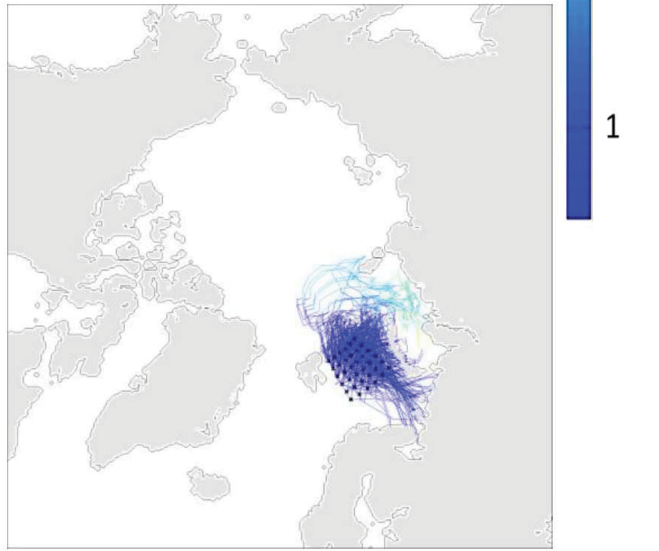

Figure 6-2: CCSM4: Backward trajectories of ice parcels between 1980 and 1990 for a maximum duration of 5 years in the Beaufort (a), Chukchi (b), East Siberian (c), Laptev (d), Kara (e) and Barents (f) seas. The colors indicate the duration of the tracking from the initial position (black crosses). 
a)

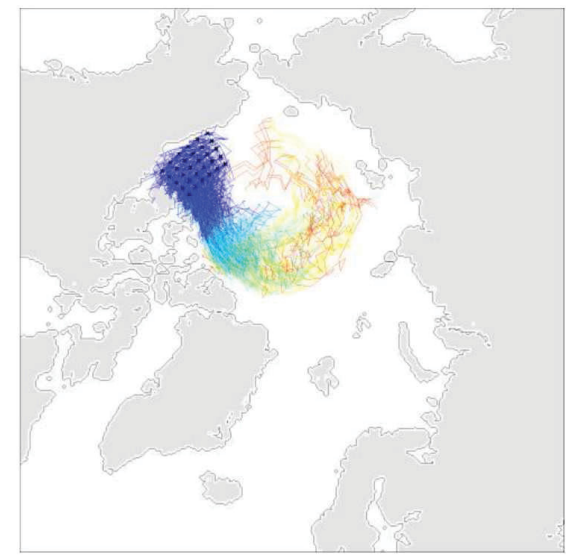

b)

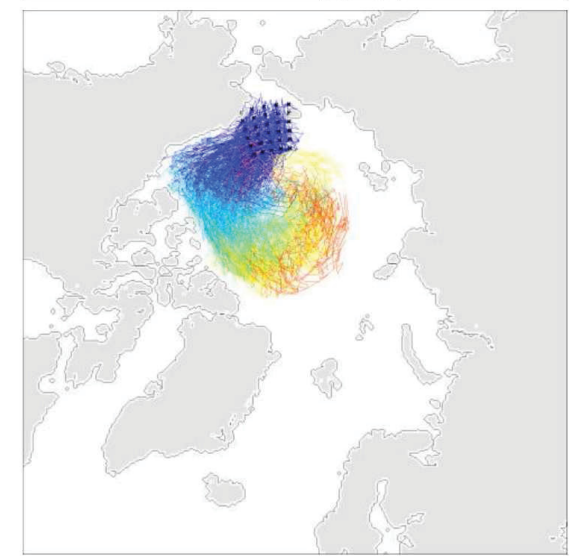

c)

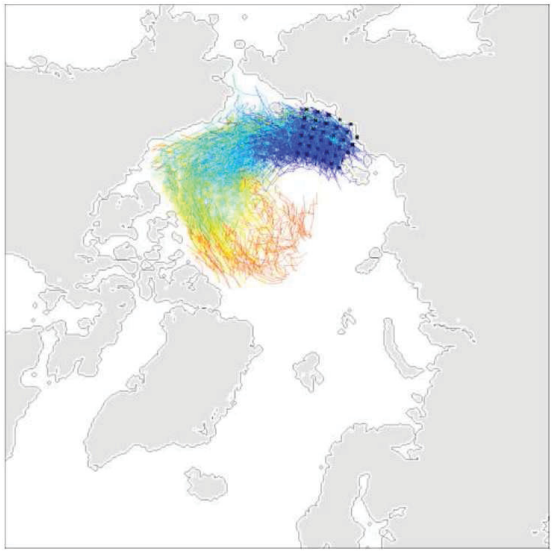

d)

e)
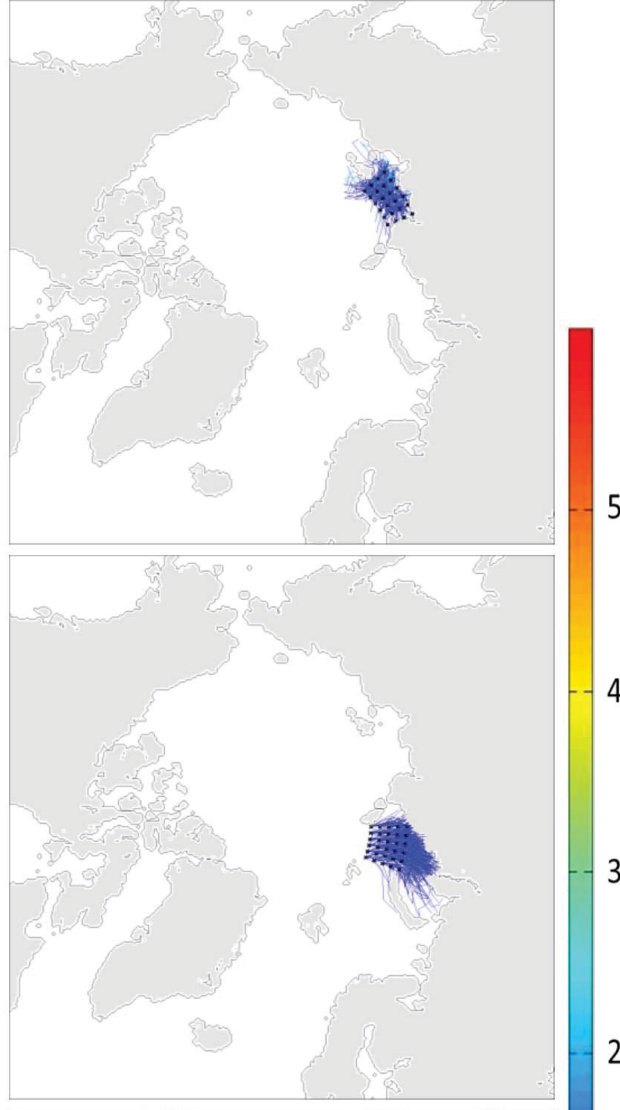

f)

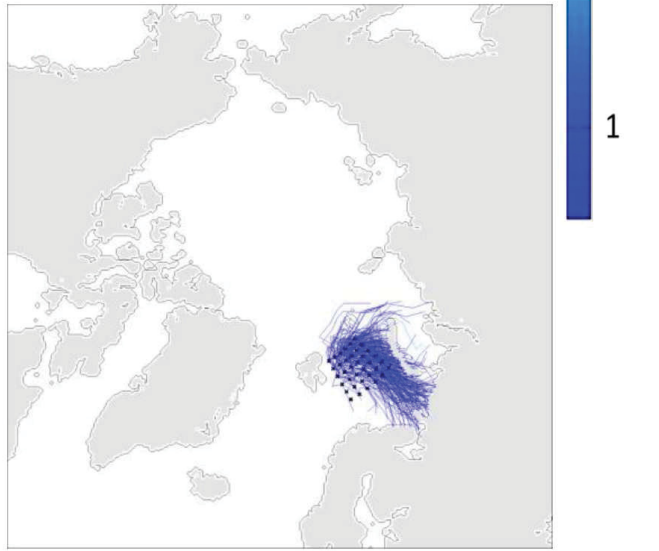

Figure 6-3: CESM-LE: Backward trajectories of ice parcels between 1980 and 1990 for a maximum duration of 5 years in the Beaufort (a), Chukchi (b), East Siberian (c), Laptev (d), Kara (e) and Barents (f) seas. The colors indicate the duration of the tracking from the initial position (black crosses). 
a)

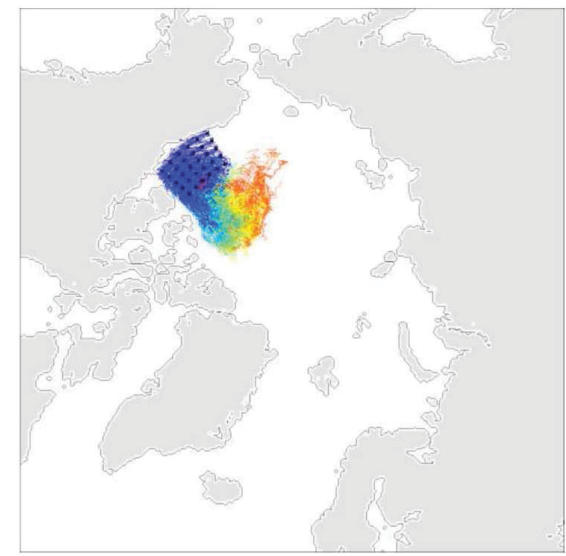

b)

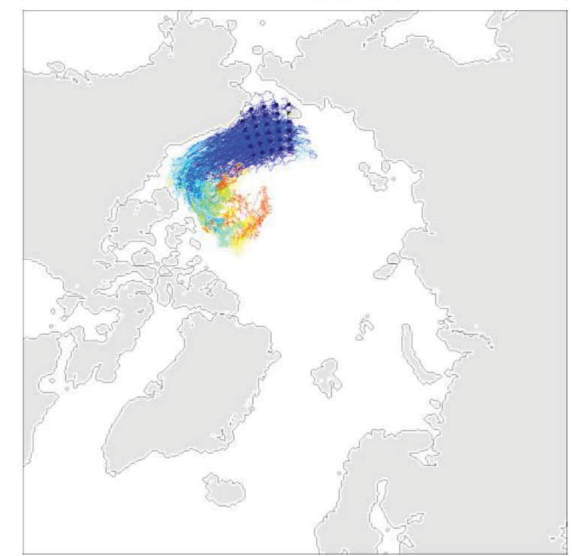

c)

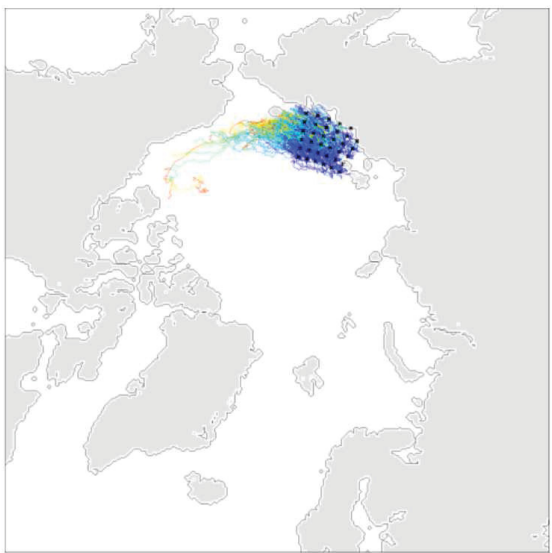

d)

e)
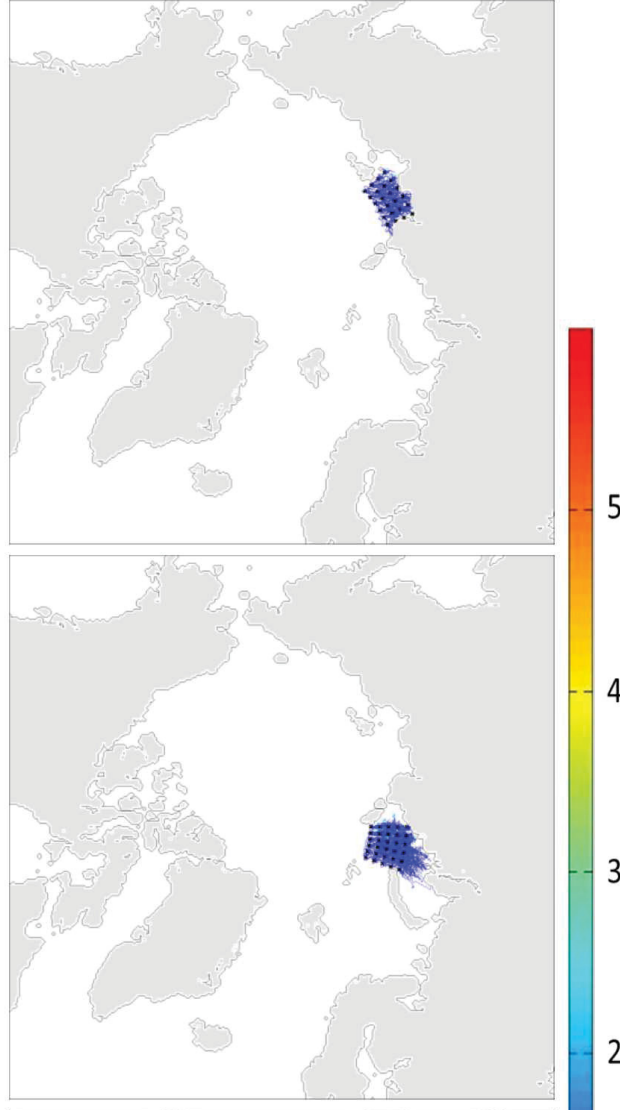

f)

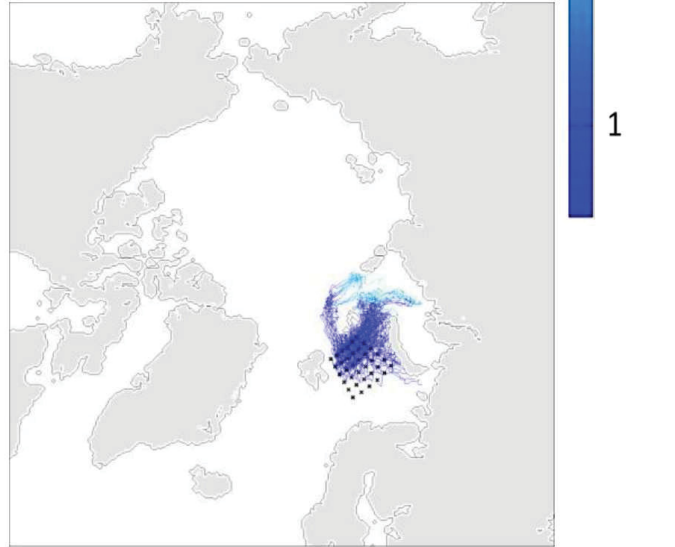

Figure 6-4: Observations: Backward trajectories of ice parcels between 1990 and 2000 for a maximum duration of 5 years in the Beaufort (a), Chukchi (b), East Siberian (c), Laptev (d), Kara (e) and Barents (f) seas. The colors indicate the duration of the tracking from the initial position (black crosses). 
a)

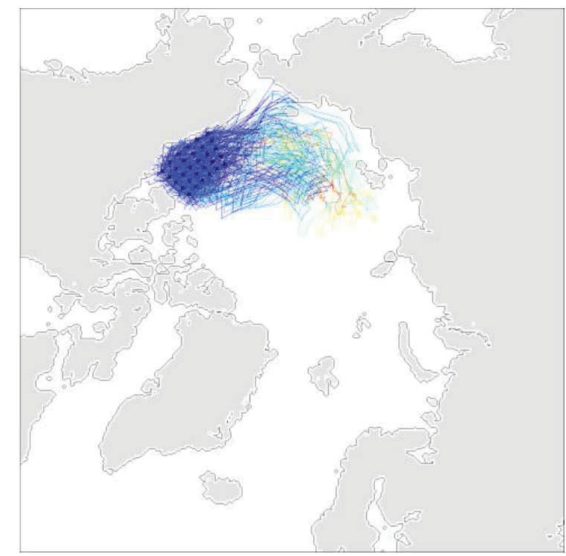

b)

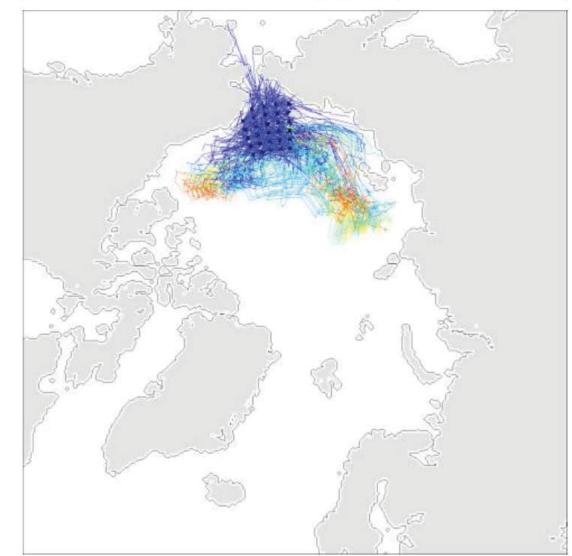

c)

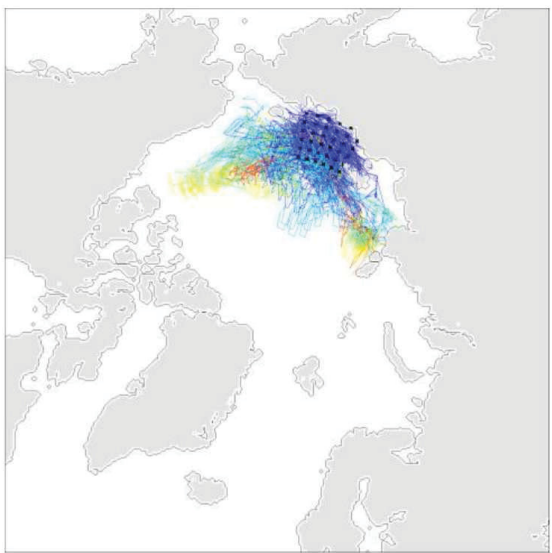

d)

e)

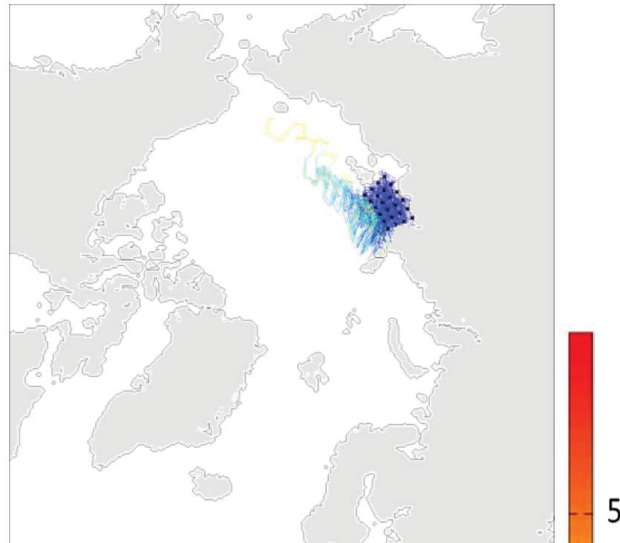

f)

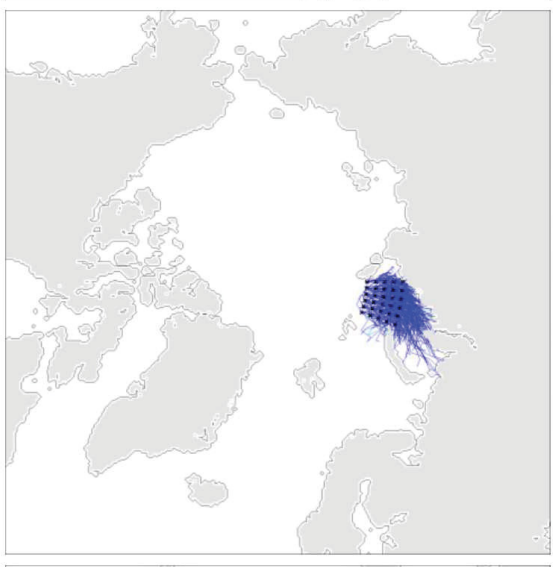

-4 ○

$\frac{\varrho}{\sim}$

욲

$3 \stackrel{+}{\stackrel{+}{a}}$

品:

2

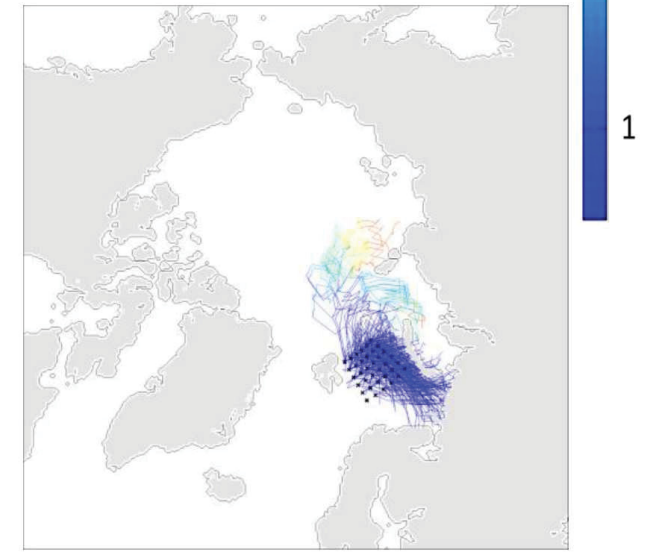

Figure 6-5: CCSM4: Backward trajectories of ice parcels between 1990 and 2000 for a maximum duration of 5 years in the Beaufort (a), Chukchi (b), East Siberian (c), Laptev (d), Kara (e) and Barents (f) seas. The colors indicate the duration of the tracking from the initial position (black crosses). 
a)

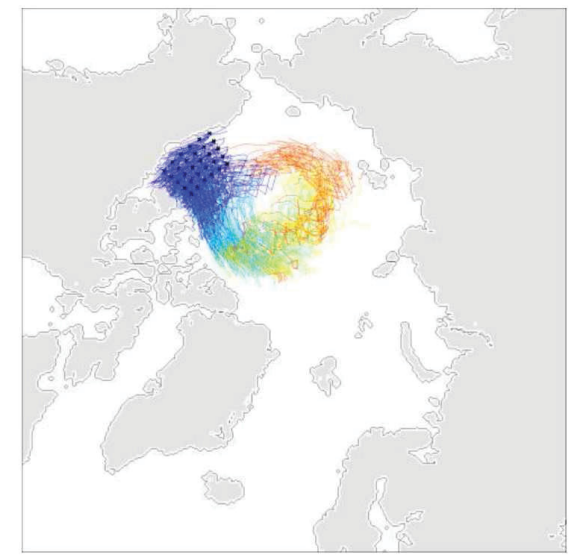

b)

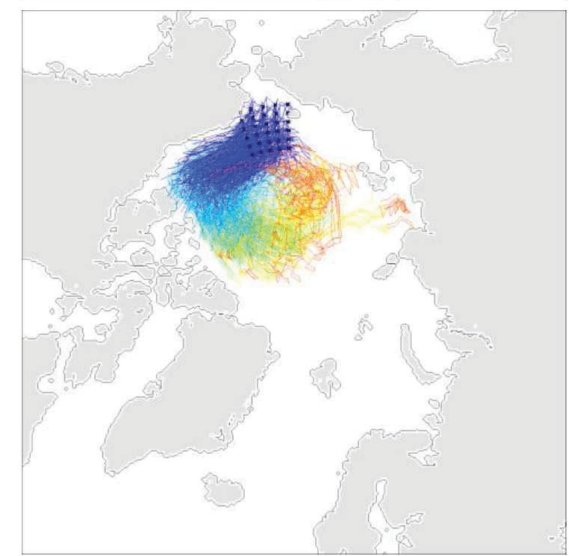

c)

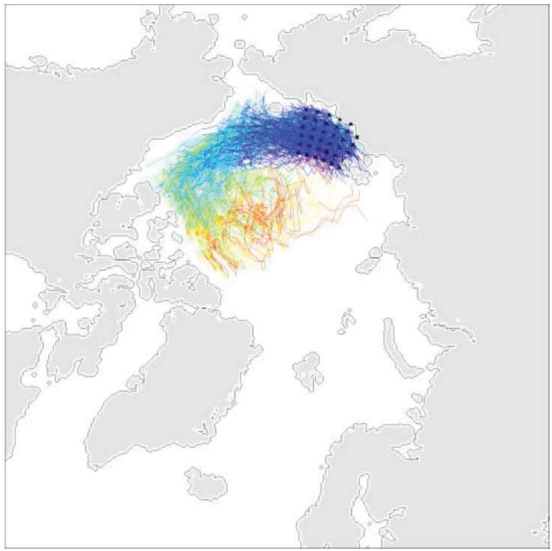

d)

e)
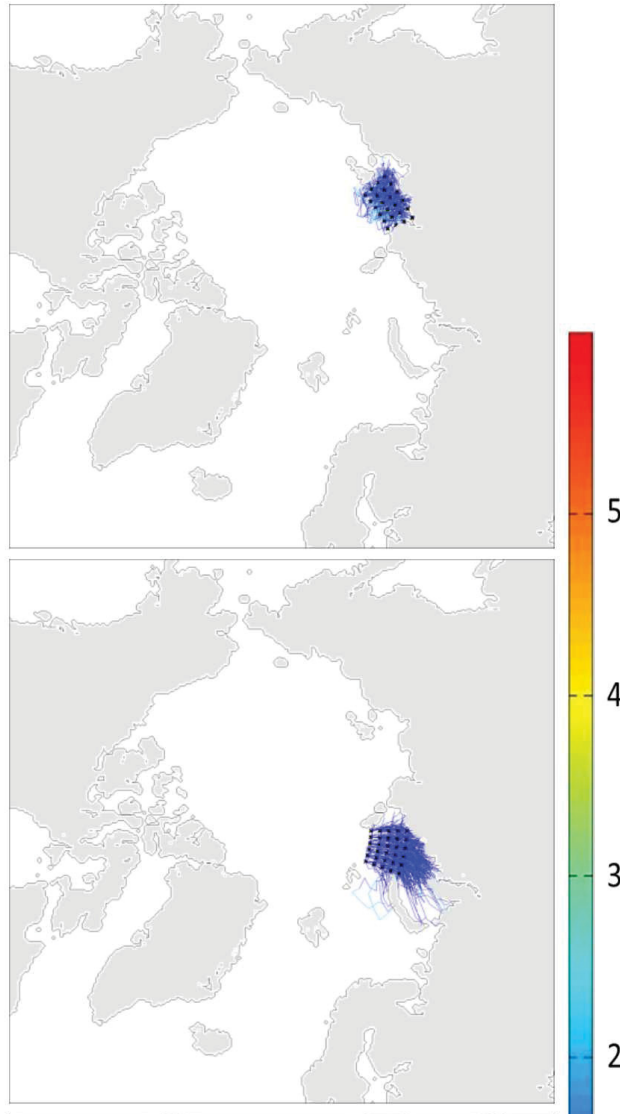

f)

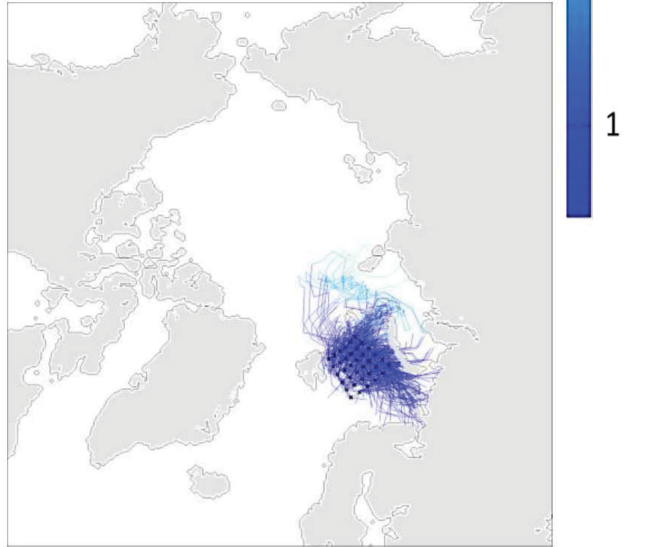

Figure 6-6: CESM-LE: Backward trajectories of ice parcels between 1990 and 2000 for a maximum duration of 5 years in the Beaufort (a), Chukchi (b), East Siberian (c), Laptev (d), Kara (e) and Barents (f) seas. The colors indicate the duration of the tracking from the initial position (black crosses). 
a)

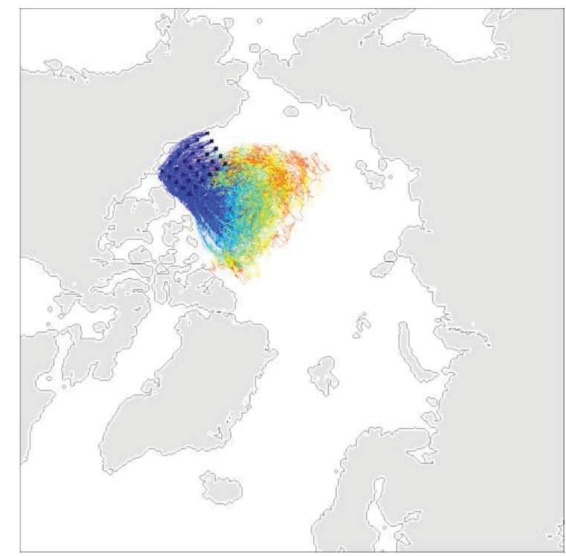

b)

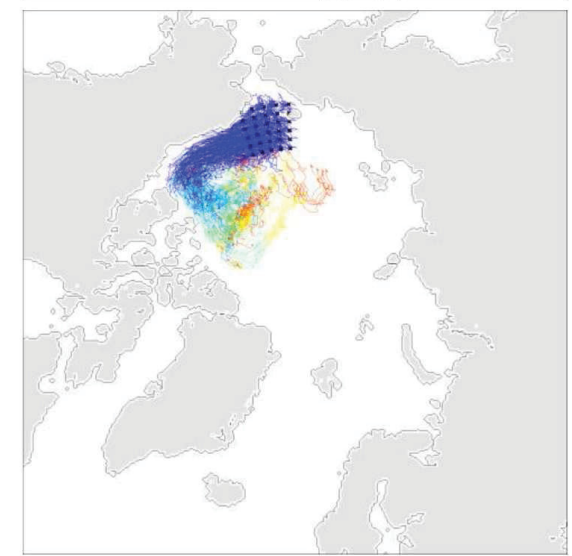

c)

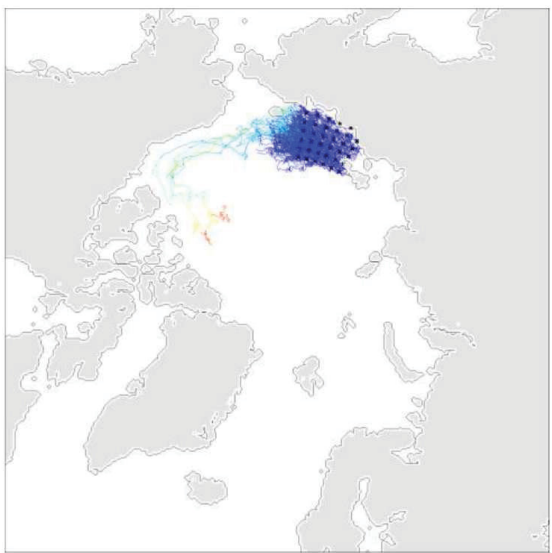

d)

e)
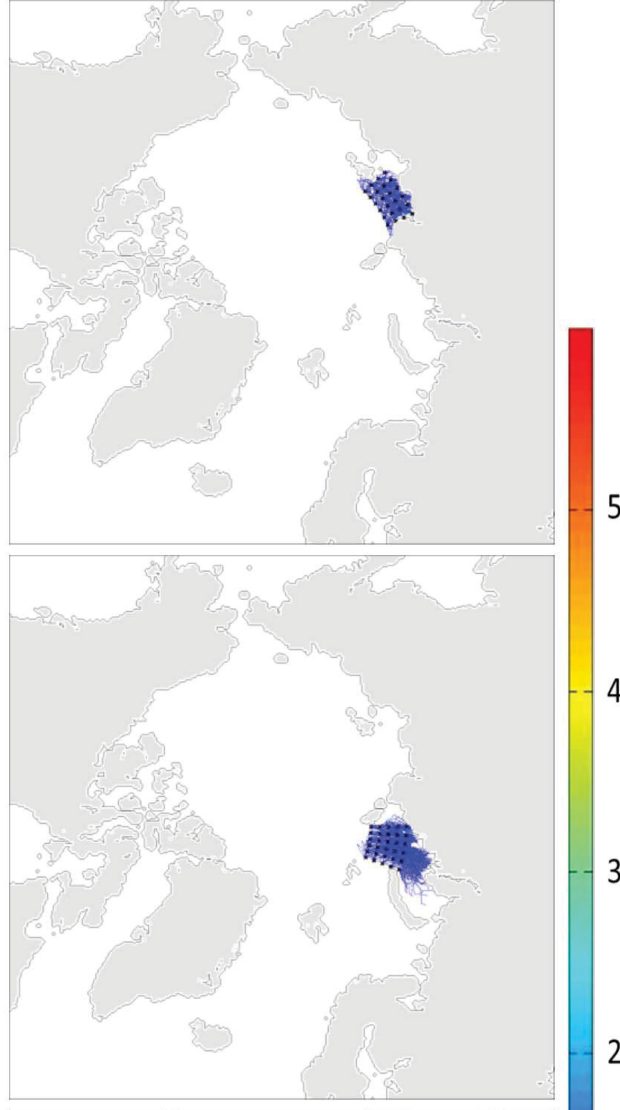

f)

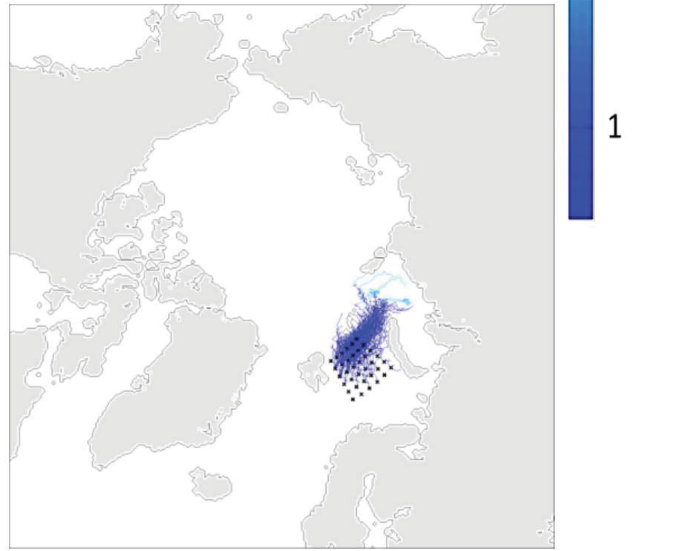

Figure 6-7: Observations: Backward trajectories of ice parcels between 2000 and 2010 for a maximum duration of 5 years in the Beaufort (a), Chukchi (b), East Siberian (c), Laptev (d), Kara (e) and Barents (f) seas. The colors indicate the duration of the tracking from the initial position (black crosses). 
a)

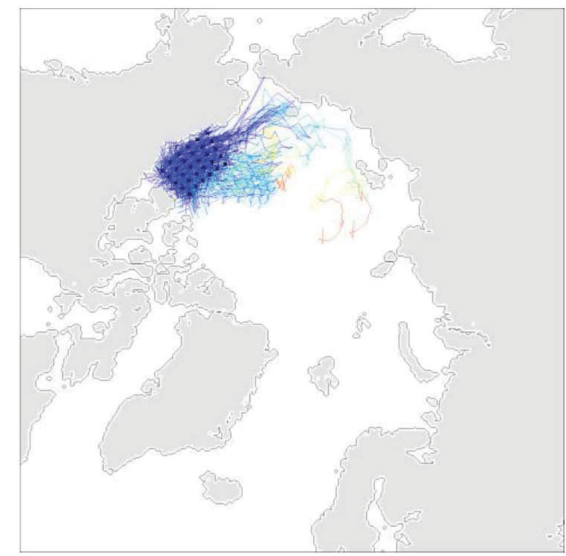

b)

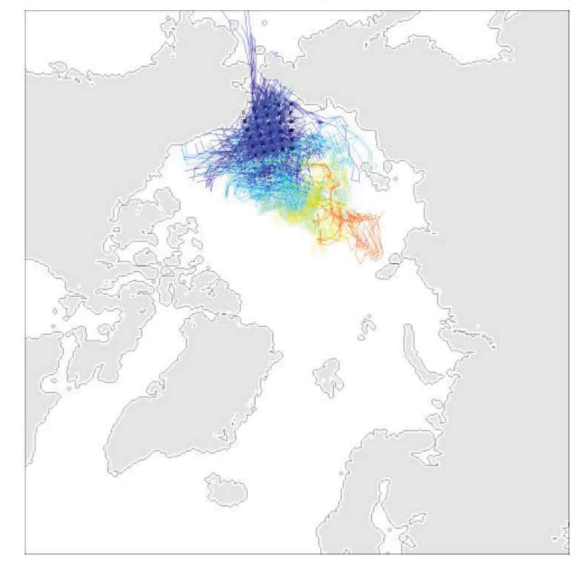

c)

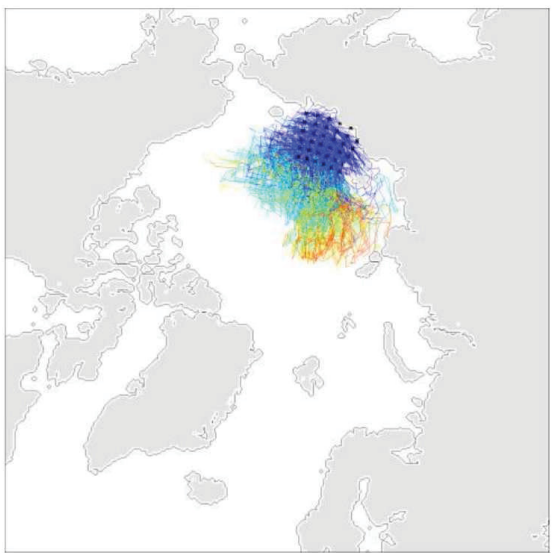

d)

e)

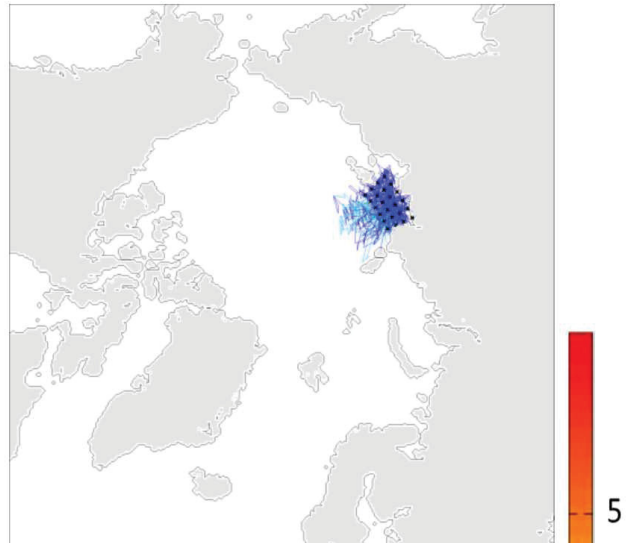

f)

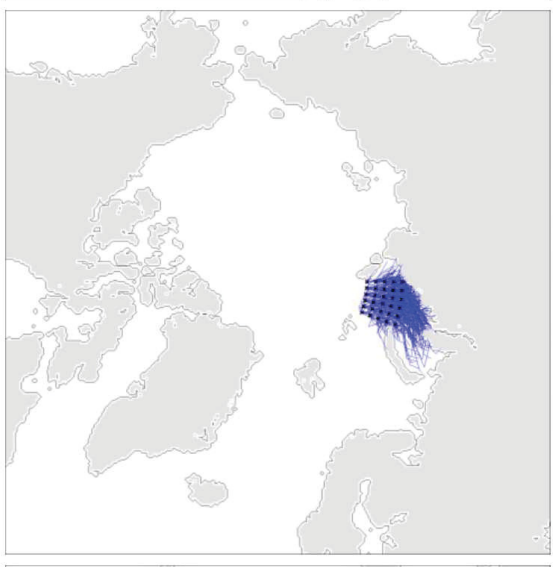

-4 ○

$\frac{\varrho}{\sim}$

욲

$3 \stackrel{+}{\stackrel{+}{a}}$

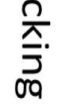

2

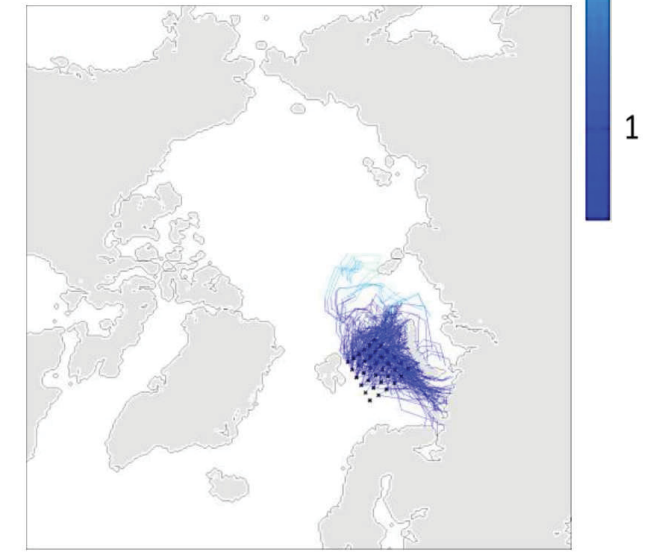

Figure 6-8: CCSM4: Backward trajectories of ice parcels between 2000 and 2010 for a maximum duration of 5 years in the Beaufort (a), Chukchi (b), East Siberian (c), Laptev (d), Kara (e) and Barents (f) seas. The colors indicate the duration of the tracking from the initial position (black crosses). 
a)

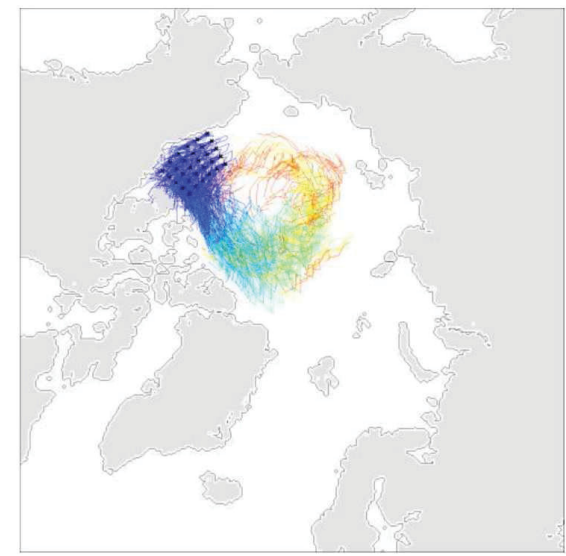

b)

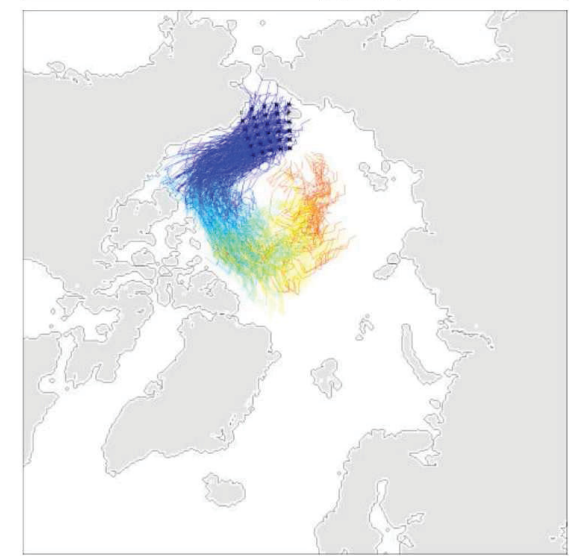

c)

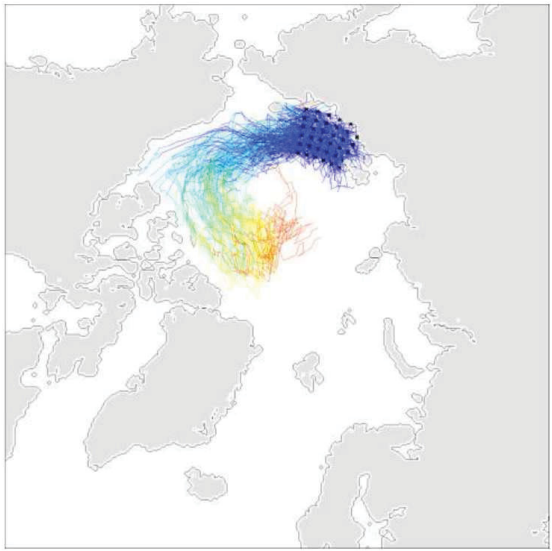

d)

e)
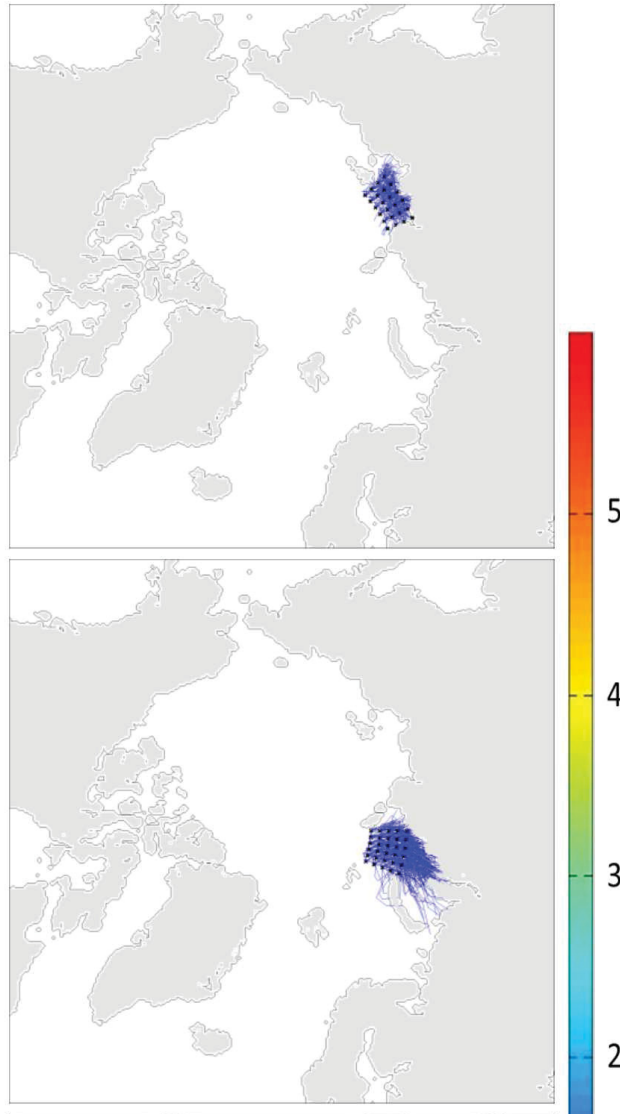

f)

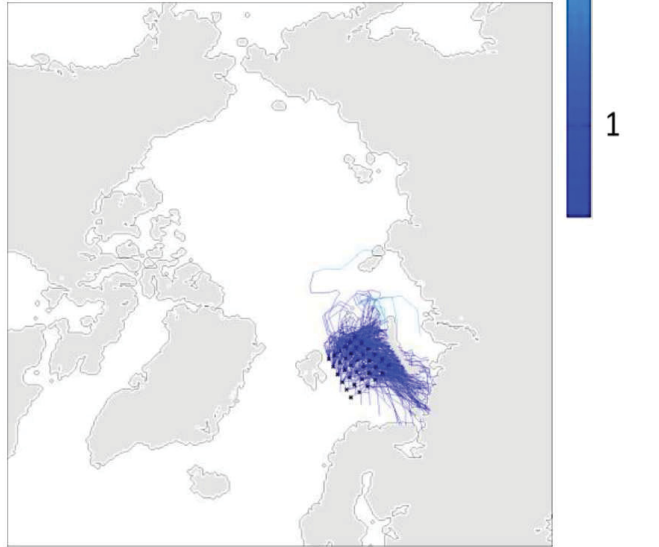

Figure 6-9: CESM-LE: Backward trajectories of ice parcels between 2000 and 2010 for a maximum duration of 5 years in the Beaufort (a), Chukchi (b), East Siberian (c), Laptev (d), Kara (e) and Barents (f) seas. The colors indicate the duration of the tracking from the initial position (black crosses). 
a)

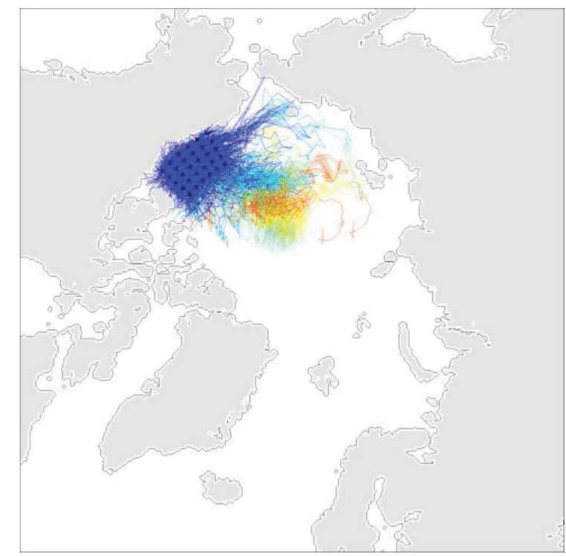

b)

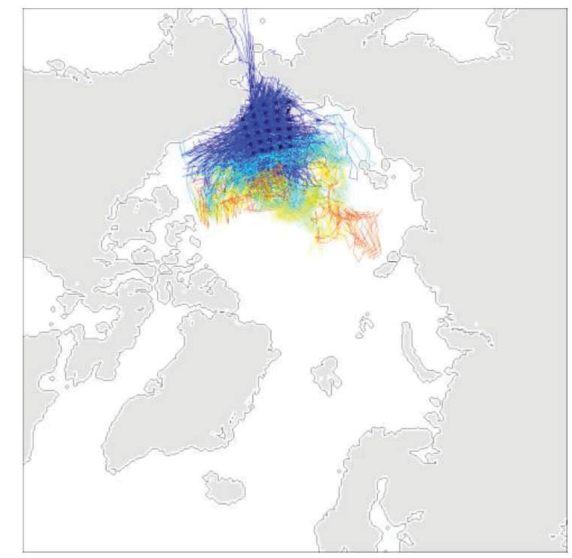

c)

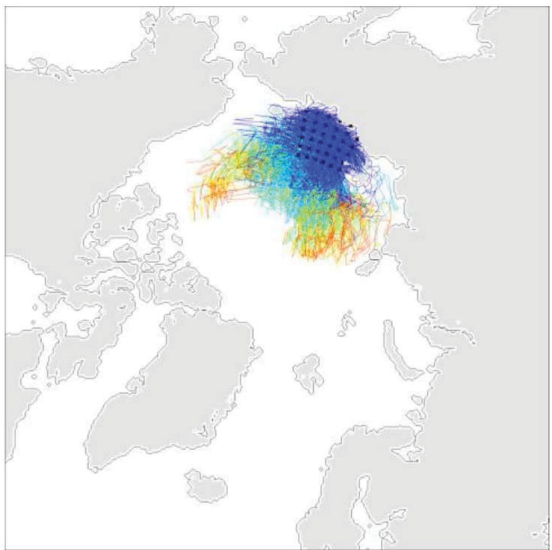

d)

e)

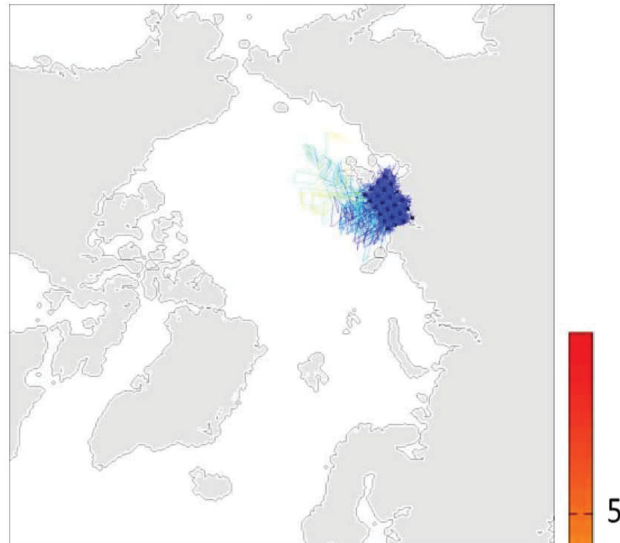

5

f)

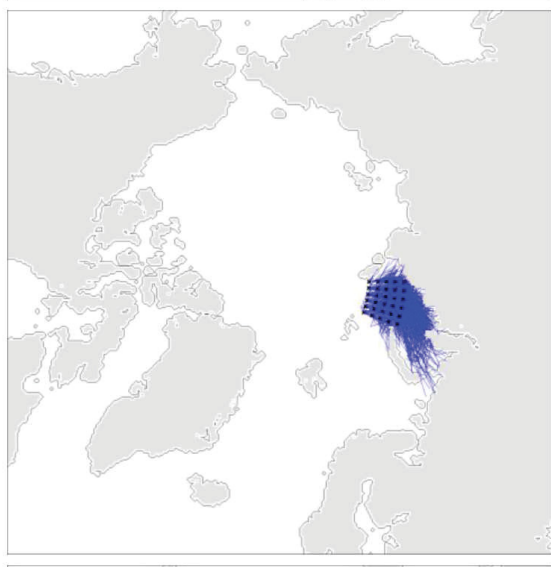

-4 市

$\frac{\infty}{\sim}$

욲

$3 \stackrel{+}{\stackrel{+}{a}}$

品:

2

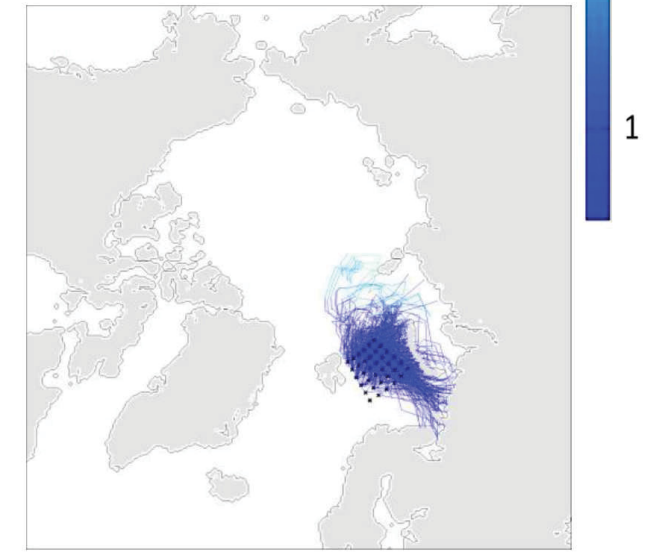

Figure 6-10: CCSM4: Backward trajectories of ice parcels between 2000 and 2020 for a maximum duration of 5 years in the Beaufort (a), Chukchi (b), East Siberian (c), Laptev (d), Kara (e) and Barents (f) seas. The colors indicate the duration of the tracking from the initial position (black crosses). 
a)

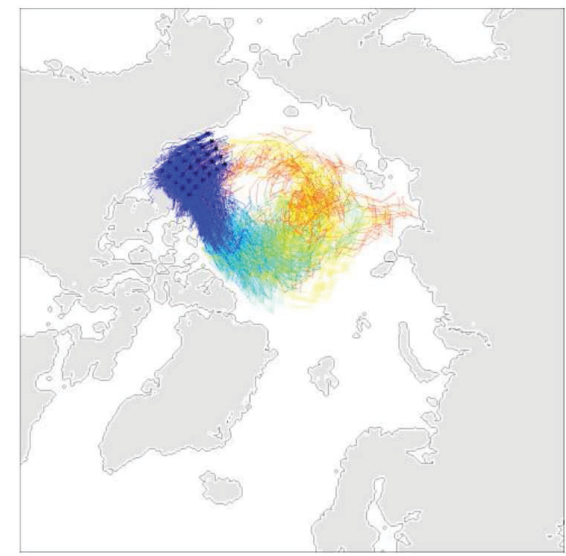

b)

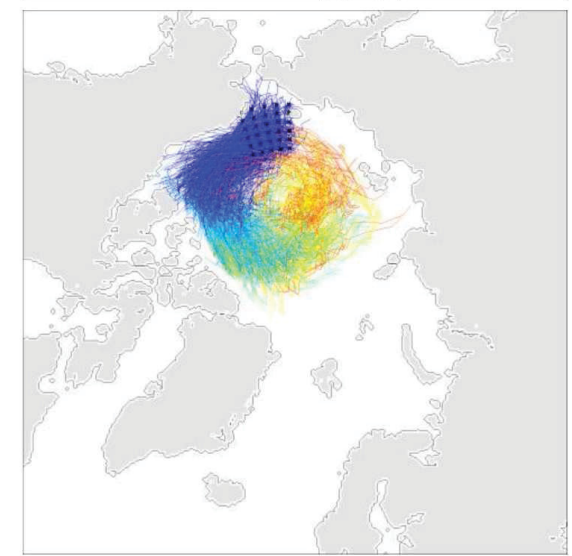

c)

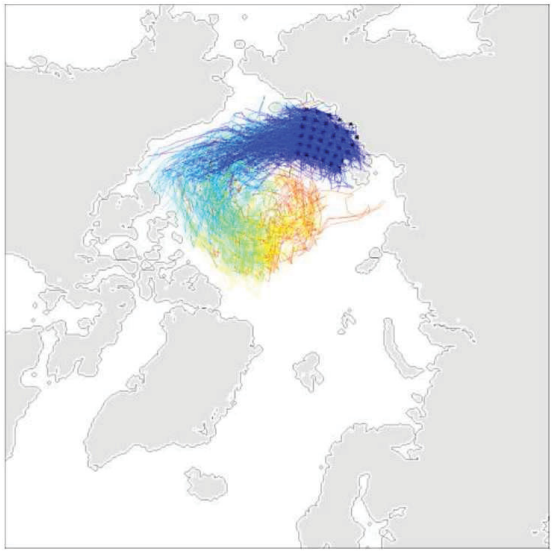

d)

e)

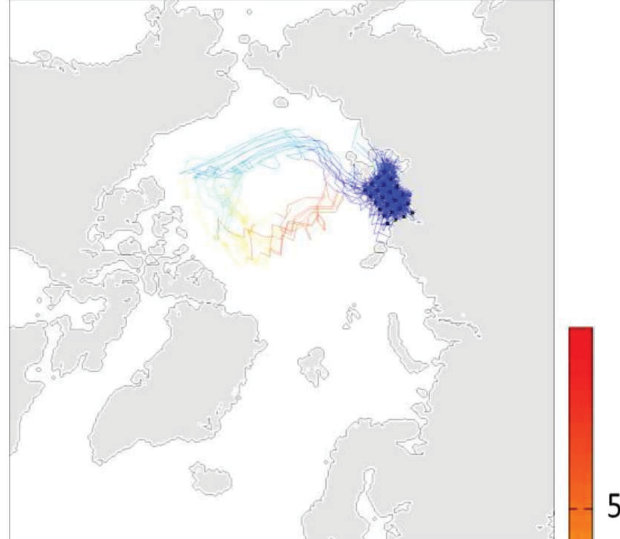

5

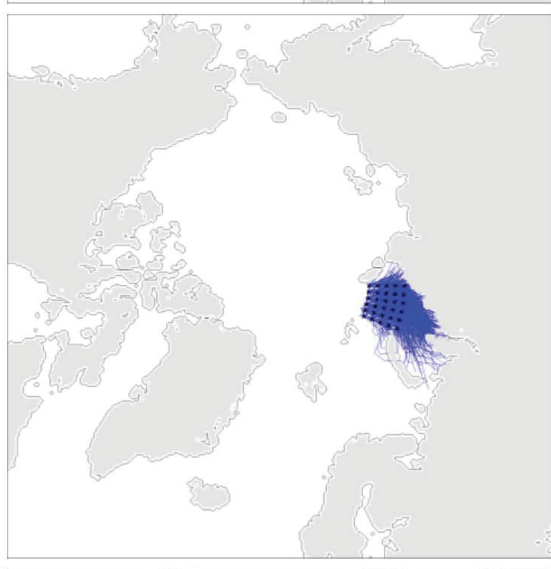

f)

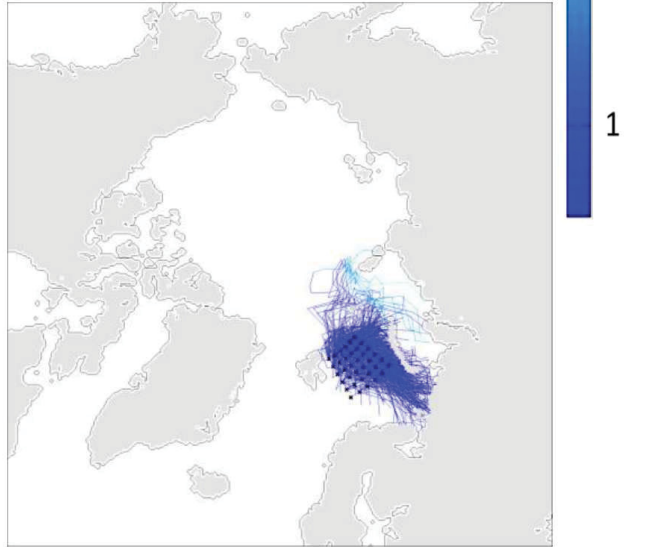

Figure 6-11: CESM-LE: Backward trajectories of ice parcels between 2000 and 2020 for a maximum duration of 5 years in the Beaufort (a), Chukchi (b), East Siberian (c), Laptev (d), Kara (e) and Barents (f) seas. The colors indicate the duration of the tracking from the initial position (black crosses). 
a)

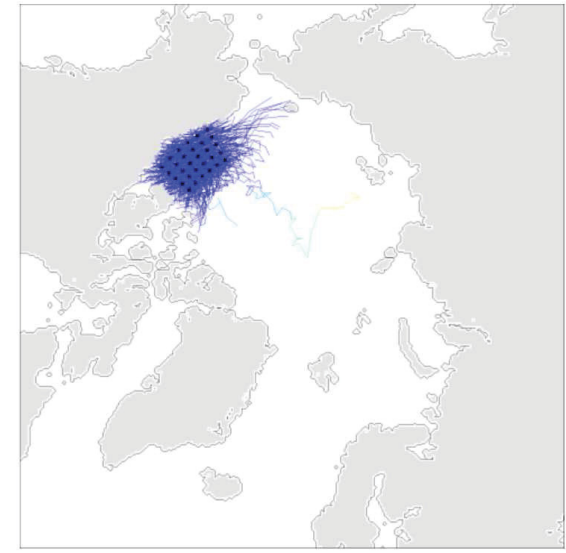

b)

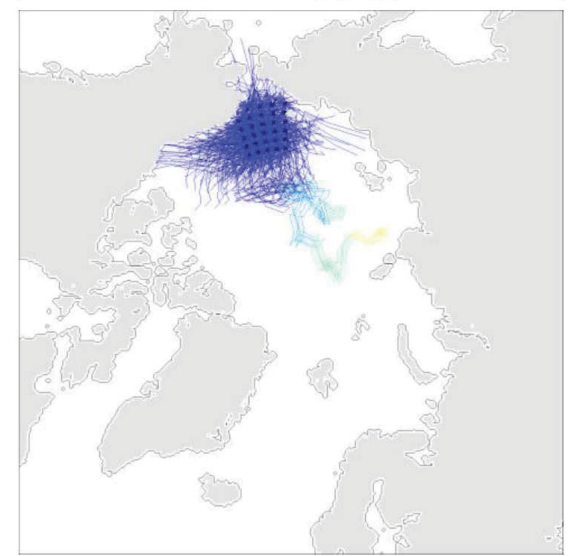

c)

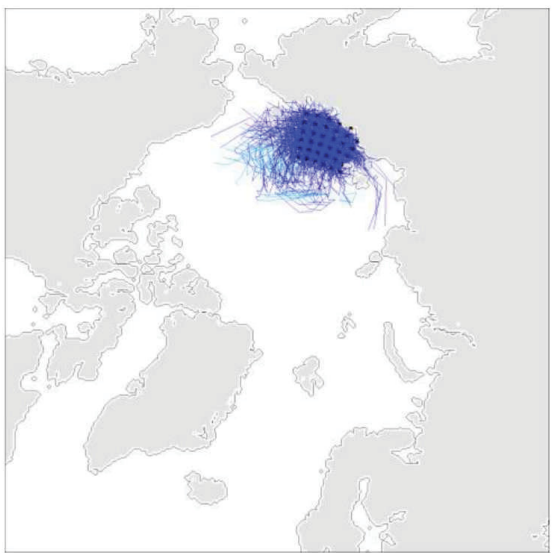

d)

e)
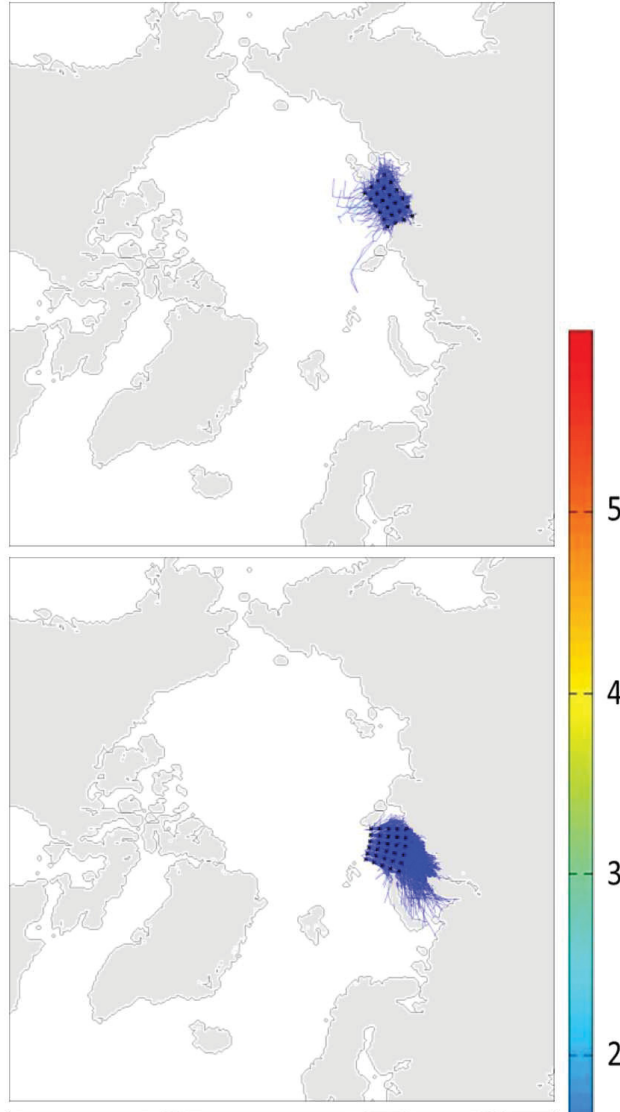

f)

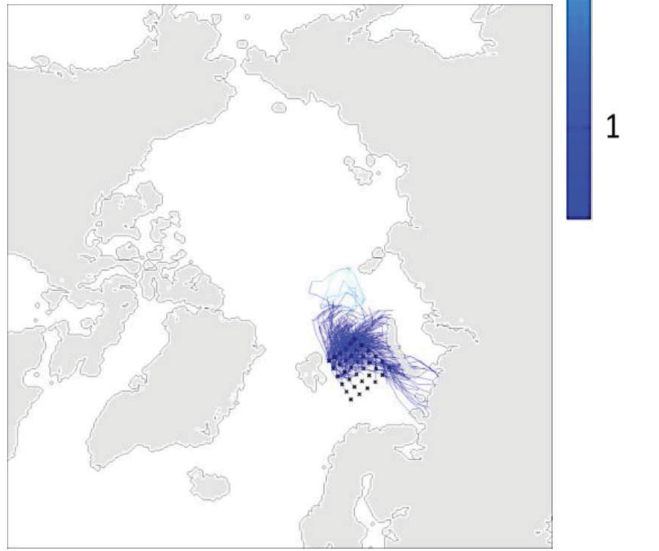

Figure 6-12: CCSM4: Backward trajectories of ice parcels between 2040 and 2060 for a maximum duration of 5 years in the Beaufort (a), Chukchi (b), East Siberian (c), Laptev (d), Kara (e) and Barents (f) seas. The colors indicate the duration of the tracking from the initial position (black crosses). 
a)

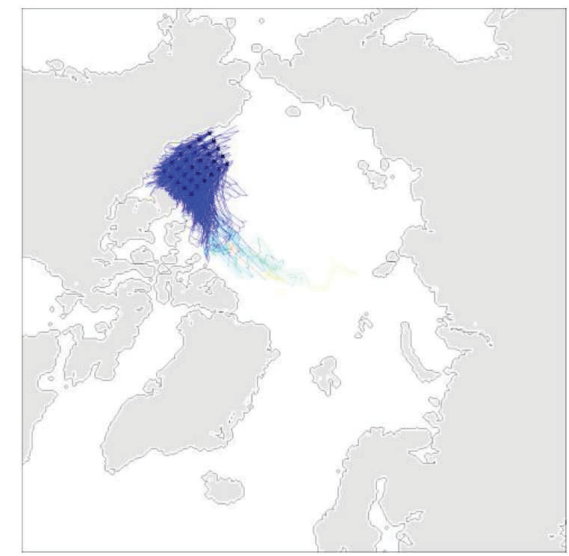

b)

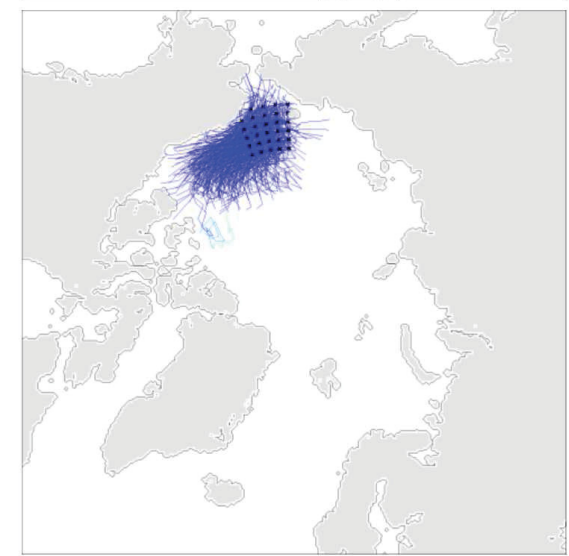

c)

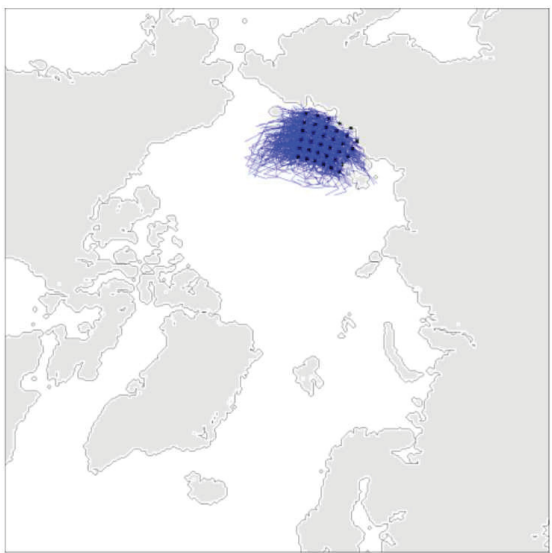

d)

e)
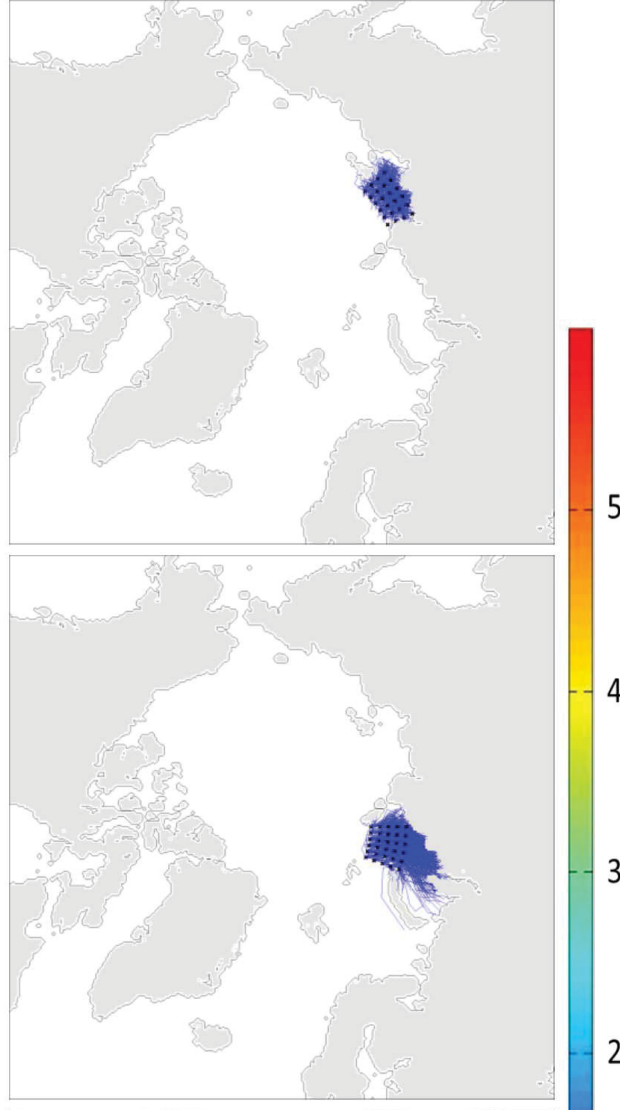

f)

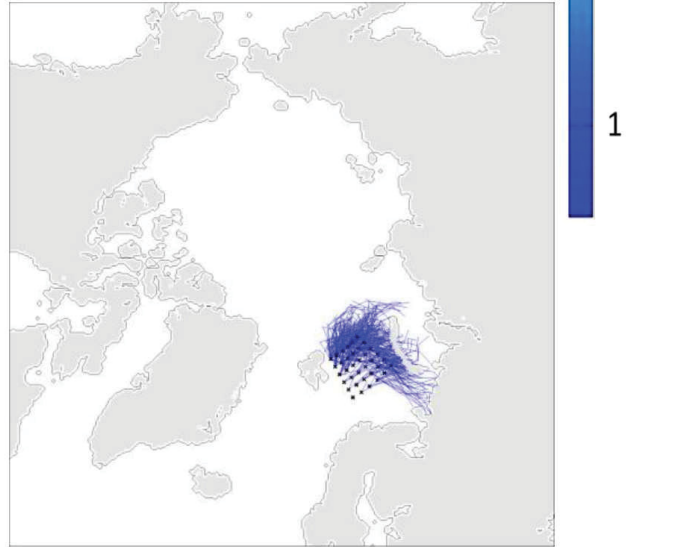

Figure 6-13: CESM-LE: Backward trajectories of ice parcels between 2040 and 2060 for a maximum duration of 5 years in the Beaufort (a), Chukchi (b), East Siberian (c), Laptev (d), Kara (e) and Barents (f) seas. The colors indicate the duration of the tracking from the initial position (black crosses). 
a)

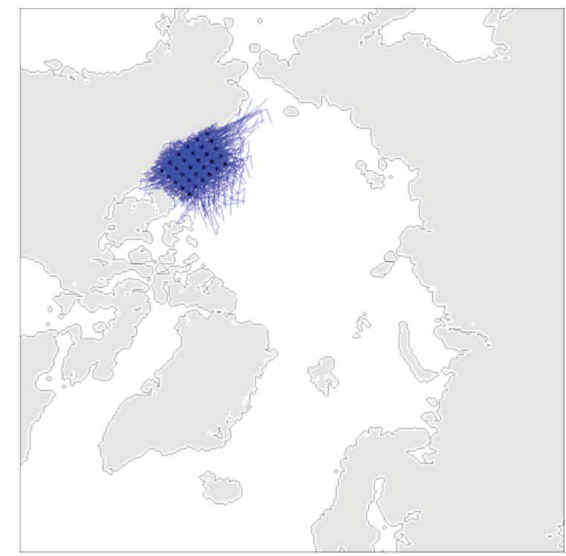

b)

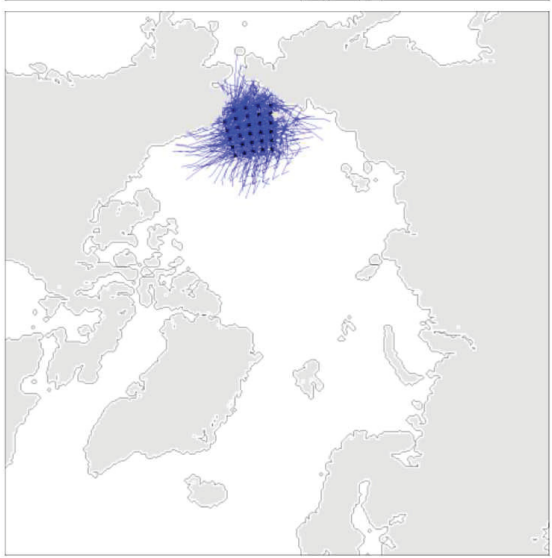

c)

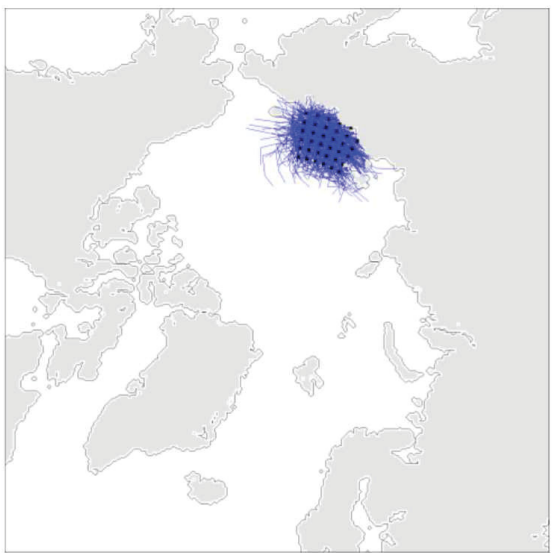

d)

e)

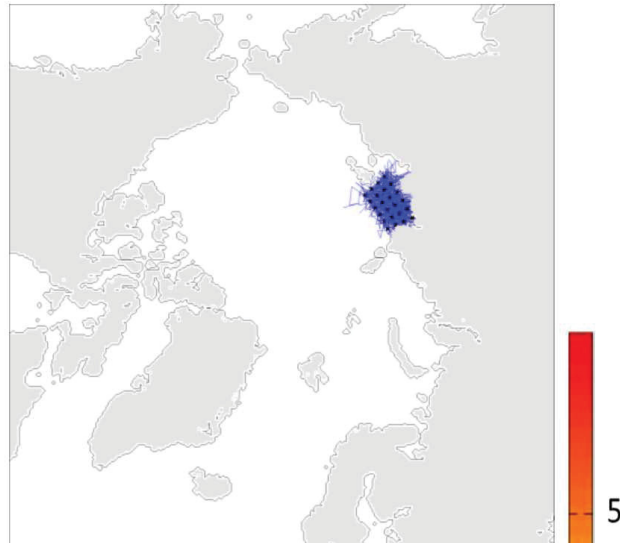

f)

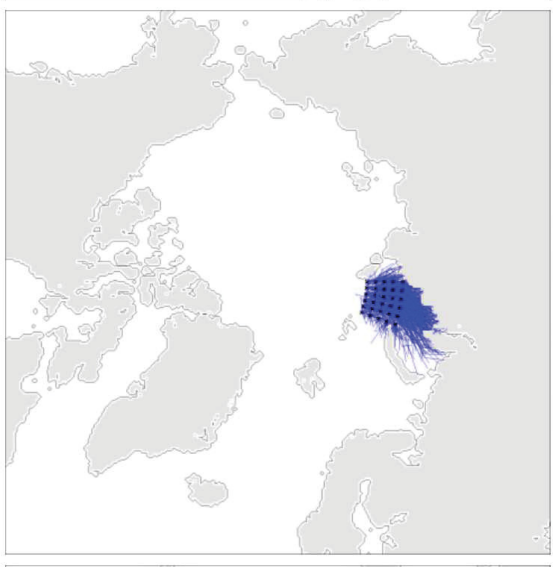

-4 ه

$\frac{\infty}{\sim}$

욲

$3 \stackrel{+}{\stackrel{+}{a}}$

品:

2

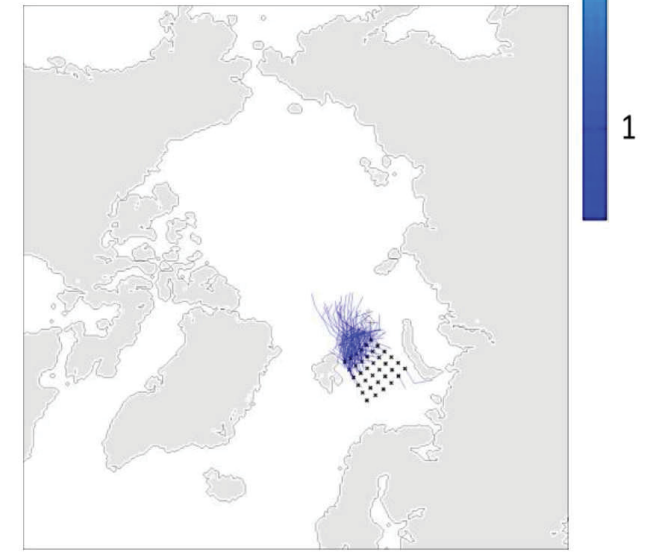

Figure 6-14: CCSM4: Backward trajectories of ice parcels between 2080 and 2100 for a maximum duration of 5 years in the Beaufort (a), Chukchi (b), East Siberian (c), Laptev (d), Kara (e) and Barents (f) seas. The colors indicate the duration of the tracking from the initial position (black crosses). 
a)

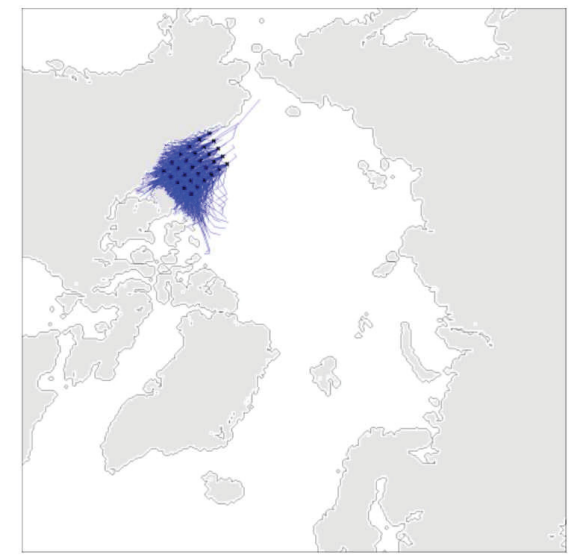

b)

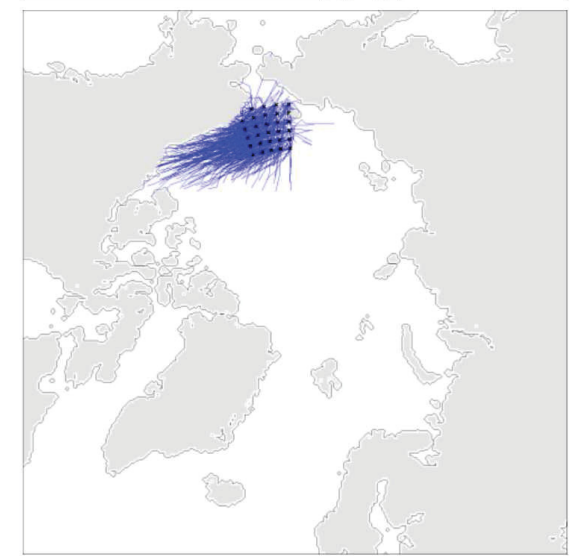

c)

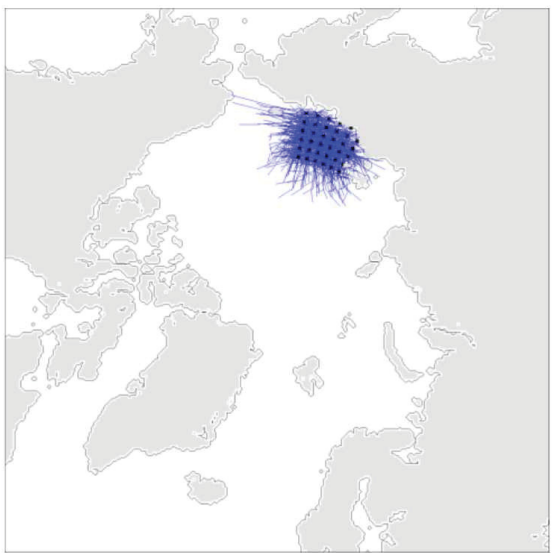

d)

e)

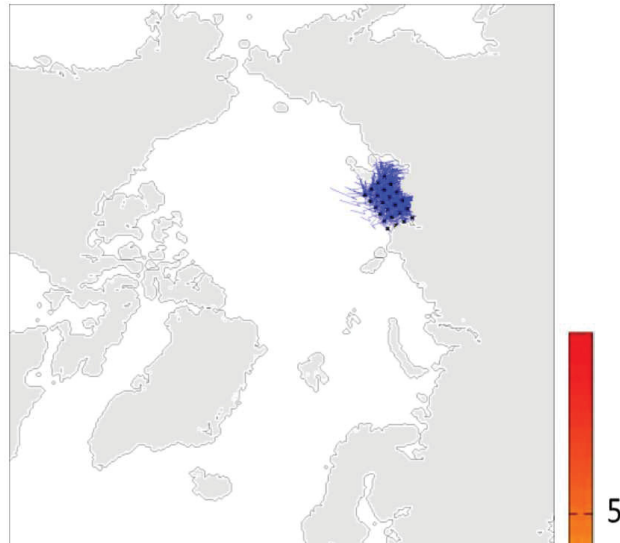

f)

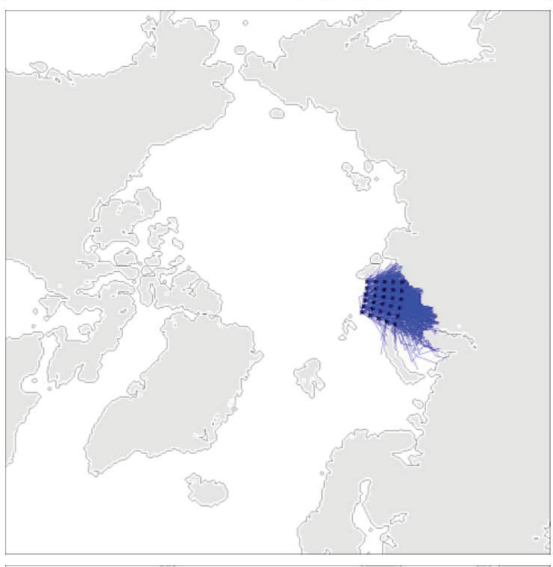

-4 ○

$\frac{\varrho}{\sim}$

욲

$3 \stackrel{+}{\stackrel{+}{a}}$

品:

2

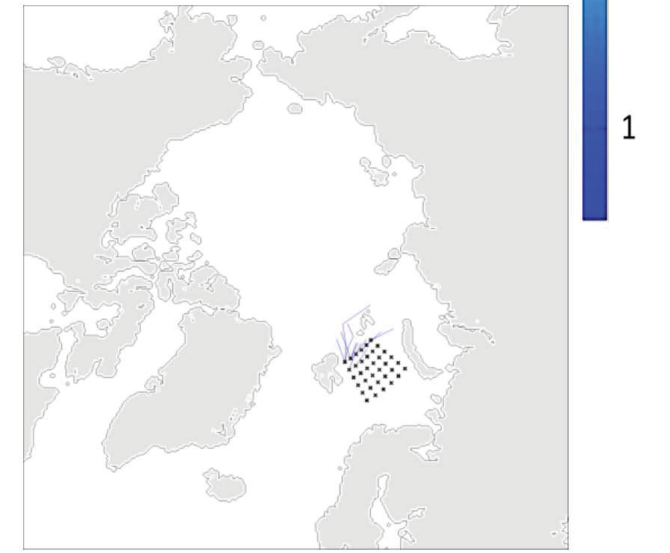

Figure 6-15: CCSM4: Backward trajectories of ice parcels between 2080 and 2100 for a maximum duration of 5 years in the Beaufort (a), Chukchi (b), East Siberian (c), Laptev (d), Kara (e) and Barents (f) seas. The colors indicate the duration of the tracking from the initial position (black crosses). 


\section{References}

Lennart Bengtsson, Vladimir A Semenov, and Ola M Johannessen. The early twentieth-century warming in the arctic-a possible mechanism. Journal of Climate, 17(20):4045-4057, 2004.

CM Bitz, John C Fyfe, and Gregory M Flato. Sea ice response to wind forcing from amip models. Journal of Climate, 15(5):522-536, 2002.

CM Bitz, MM Holland, EC Hunke, and RE Moritz. Maintenance of the sea-ice edge. Journal of climate, 18(15):2903-2921, 2005.

Hauke Blanken, Bruno Tremblay, Susan Gaskin, and Alexander Slavin. Arctic oil spills: a risk assessment of transport in sea ice and ocean surface waters from ten potential spill sites. Marine Pollution Bulletin, 2015. in revision.

Mary J Brodzik, Brendan Billingsley, Terry Haran, Bruce Raup, and Matthew H Savoie. Ease-grid 2.0: Incremental but significant improvements for earth-gridded data sets. ISPRS International Journal of GeoInformation, 1(1):32-45, 2012.

Michael Byers. Who owns the Arctic?: Understanding sovereignty disputes in the North. Douglas \& McIntyre, 2010.

Kurt M Campbell, Jay Gulledge, John R McNeill, John Podesta, Peter Ogden, Leon Fuerth, R James Woolsey, Alexander T Lennon, Julianne Smith, and Richard Weitz. The age of consequences: the foreign policy and national security implications of global climate change. Technical report, DTIC Document, 2007.

Josefino C Comiso, Claire L Parkinson, Robert Gersten, and Larry Stock. Accelerated decline in the arctic sea ice cover. Geophysical Research Letters, 
35(1), 2008.

Gijs De Boer, William Chapman, Jennifer E Kay, Brian Medeiros, Matthew D Shupe, Steve Vavrus, and John Walsh. A characterization of the present-day arctic atmosphere in ccsm4. Journal of Climate, 25(8):2676-2695, 2012.

DP Dee, SM Uppala, AJ Simmons, P Berrisford, P Poli, S Kobayashi, U Andrae, MA Balmaseda, G Balsamo, P Bauer, et al. The era-interim reanalysis: Configuration and performance of the data assimilation system. Quarterly Journal of the Royal Meteorological Society, 137(656):553-597, 2011.

RR Dickson, TJ Osborn, JW Hurrell, J Meincke, J Blindheim, B Adlandsvik, T Vinje, G Alekseev, and W Maslowski. The arctic ocean response to the north atlantic oscillation. Journal of Climate, 13(15):2671-2696, 2000.

WJ Emery, C Wo Fowler, and JA Maslanik. Satellite-derived maps of arctic and antarctic sea ice motion: 1988 to 1994. Geophysical Research Letters, 24(8):897-900, 1997.

C Fowler, WJ Emery, and J Maslanik. Satellite-derived evolution of arctic sea ice age: October 1978 to march 2003. Geoscience and Remote Sensing Letters, IEEE, 1(2):71-74, 2004.

C Fowler, J Maslanik, W Emery, and M Tschudi. Polar pathfinder daily $25 \mathrm{~km}$ ease-grid sea ice motion vectors. version 2. Digital media, Boulder, Colorado USA: NASA National Snow and Ice Data Center Distributed Active Archive Center, 2013.

Jennifer A Francis and Stephen J Vavrus. Evidence linking arctic amplification to extreme weather in mid-latitudes. Geophysical Research Letters, 39(6), 2012

Jennifer A Francis and Stephen J Vavrus. Evidence for a wavier jet stream in response to rapid arctic warming. Environmental Research Letters, 10(1): 014005, 2015 . 
JC Fyfe, GJ Boer, and GM Flato. The arctic and antarctic oscillations and their projected changes under global warming. Geophysical Research Letters, 26(11):1601-1604, 1999.

Donald L Gautier, Kenneth J Bird, Ronald R Charpentier, Arthur Grantz, David W Houseknecht, Timothy R Klett, Thomas E Moore, Janet K Pitman, Christopher J Schenk, John H Schuenemeyer, et al. Assessment of undiscovered oil and gas in the arctic. Science, 324(5931):1175-1179, 2009.

Peter R Gent, Gokhan Danabasoglu, Leo J Donner, Marika M Holland, Elizabeth C Hunke, Steve R Jayne, David M Lawrence, Richard B Neale, Philip J Rasch, Mariana Vertenstein, et al. The community climate system model version 4. Journal of Climate, 24(19):4973-4991, 2011.

Melissa Gervais, Eyad Atallah, John Gyakum, and Bruno Tremblay. Arctic air masses in a warming world. Journal of Climate, 2015. in revision.

NP Gillett and JC Fyfe. Annular mode changes in the cmip5 simulations. Geophysical Research Letters, 40(6):1189-1193, 2013.

Sirpa Hakkinen, Andrey Proshutinsky, and Igor Ashik. Sea ice drift in the arctic since the 1950s. Geophysical Research Letters, 35(19), 2008.

Marika M Holland and Julienne Stroeve. Changing seasonal sea ice predictor relationships in a changing arctic climate. Geophysical Research Letters, 38 (18), 2011.

Marika M Holland, Cecilia M Bitz, and Bruno Tremblay. Future abrupt reductions in the summer arctic sea ice. Geophysical Research Letters, 33(23), 2006 .

Marika M Holland, Mark C Serreze, and Julienne Stroeve. The sea ice mass budget of the arctic and its future change as simulated by coupled climate models. Climate Dynamics, 34(2-3):185-200, 2010. 
James W Hurrell, Marika M Holland, Peter R Gent, S Ghan, Jennifer E Kay, PJ Kushner, J-F Lamarque, William G Large, D Lawrence, Keith Lindsay, et al. The community earth system model: A framework for collaborative research. Bulletin of the American Meteorological Society, 94(9):1339-1360, 2013.

Jun Inoue, Masatake E Hori, and Koutarou Takaya. The role of barents sea ice in the wintertime cyclone track and emergence of a warm-arctic coldsiberian anomaly. Journal of Climate, 25(7):2561-2568, 2012.

Alexandra Jahn and Marika M Holland. Implications of arctic sea ice changes for north atlantic deep convection and the meridional overturning circulation in ccsm4-cmip5 simulations. Geophysical Research Letters, 40(6):1206-1211, 2013.

Alexandra Jahn, Kara Sterling, Marika M Holland, Jennifer E Kay, James A Maslanik, Cecilia M Bitz, David A Bailey, Julienne Stroeve, Elizabeth C Hunke, William H Lipscomb, et al. Late-twentieth-century simulation of arctic sea ice and ocean properties in the ccsm4. Journal of Climate, 25(5): 1431-1452, 2012.

Zuo Jin-Qing, Li Wei-Jing, and Ren Hong-Li. Representation of the arctic oscillation in the cmip5 models. Advances in Climate Change Research, 4 (4):242-249, 2013.

JE Kay, C Deser, A Phillips, A Mai, C Hannay, G Strand, JM Arblaster, SC Bates, G Danabasoglu, J Edwards, et al. The community earth system model (cesm) large ensemble project: A community resource for studying climate change in the presence of internal climate variability. Bulletin of the American Meteorological Society, 2014.

VC Khon, II Mokhov, Mojib Latif, VA Semenov, and Wonsun Park. Perspectives of northern sea route and northwest passage in the twenty-first 
century. Climatic Change, 100(3-4):757-768, 2010.

RW Lindsay, J Zhang, A Schweiger, M Steele, and H Stern. Arctic sea ice retreat in 2007 follows thinning trend. Journal of Climate, 22(1):165-176, 2009.

Jiping Liu, Mirong Song, Radley M Horton, and Yongyun Hu. Reducing spread in climate model projections of a september ice-free arctic. Proceedings of the National Academy of Sciences, 110(31):12571-12576, 2013.

JA Maslanik, C Fowler, J Stroeve, S Drobot, J Zwally, D Yi, and W Emery. A younger, thinner arctic ice cover: Increased potential for rapid, extensive sea-ice loss. Geophysical Research Letters, 34(24), 2007.

James A Maslanik, Mark C Serreze, and Roger G Barry. Recent decreases in arctic summer ice cover and linkages to atmospheric circulation anomalies. Geophysical Research Letters, 23(13):1677-1680, 1996.

JA Maslank, C Fowler, J Heinrichs, RG Barry, and WJ Emery. Remotelysensed and simulated variability of arctic sea-ice concentrations in response to atmospheric synoptic systems. International Journal of Remote Sensing, 16(17):3325-3342, 1995.

Gerald A Meehl, Warren M Washington, Julie M Arblaster, Aixue Hu, Haiyan Teng, Jennifer E Kay, Andrew Gettelman, David M Lawrence, Benjamin M Sanderson, and Warren G Strand. Climate change projections in cesm1 (cam5) compared to ccsm4. Journal of Climate, 26(17):6287-6308, 2013.

Walter N Meier and Mingrui Dai. High-resolution sea-ice motions from amsr-e imagery. Annals of Glaciology, 44(1):352-356, 2006.

Walter N Meier and James A Maslanik. Improved sea ice parcel trajectories in the arctic via data assimilation. Marine pollution bulletin, 42(6):505-511, 2001. 
Walter N Meier, James A Maslanik, and Charles W Fowler. Error analysis and assimilation of remotely sensed ice motion within an arctic sea ice model. Journal of Geophysical Research: Oceans (1978-2012), 105(C2):3339-3356, 2000.

WN Meier, F Fetterer, M Savoie, S Mallory, R Duerr, and JC Stroeve. Noaa/nsidc climate data record of passive microwave sea ice concentration, version 2. Digital media, Boulder, Colorado USA: National Snow and Ice Data Center, 2013.

RL Miller, GA Schmidt, and DT Shindell. Forced annular variations in the 20th century intergovernmental panel on climate change fourth assessment report models. Journal of Geophysical Research: Atmospheres (1984-2012), 111(D18), 2006.

National Snow and Ice Data Center. Ice Motion from Passive Microwave: SMMR, SSM/I, SSMIS, and AMSR-E, cited 2015. [Available online at http: //nsidc.org/data/docs/daac/nsidc0116_icemotion/smmr_ssmi.html].

James E Overland, Jennifer A Francis, Edward Hanna, and Muyin Wang. The recent shift in early summer arctic atmospheric circulation. Geophysical Research Letters, 39(19), 2012.

JE Overland and M Wang. The arctic climate paradox: The recent decrease of the arctic oscillation. Geophysical Research Letters, 32(6), 2005.

G Peng, WN Meier, DJ Scott, and MH Savoie. A long-term and reproducible passive microwave sea ice concentration data record for climate studies and monitoring. Earth System Science Data, 5(2):311-318, 2013.

Donald K Perovich, Bonnie Light, Hajo Eicken, Kathleen F Jones, Kay Runciman, and Son V Nghiem. Increasing solar heating of the arctic ocean and adjacent seas, 1979-2005: Attribution and role in the ice-albedo feedback. Geophysical Research Letters, 34(19), 2007. 
GP Peters, TB Nilssen, L Lindholt, MS Eide, S Glomsrød, LI Eide, and JS Fuglestvedt. Future emissions from shipping and petroleum activities in the arctic. Atmospheric Chemistry and Physics, 11(11):5305-5320, 2011.

Vladimir Petoukhov and Vladimir A Semenov. A link between reduced barents-kara sea ice and cold winter extremes over northern continents. Journal of Geophysical Research: Atmospheres (1984-2012), 115(D21), 2010

Stephanie Pfirman, William F Haxby, Roger Colony, and Ignatius Rigor. Variability in arctic sea ice drift. Geophysical Research Letters, 31(16), 2004.

Monika Rauthe and Heiko Paeth. Relative importance of northern hemisphere circulation modes in predicting regional climate change. Journal of climate, 17(21):4180-4189, 2004.

Ignatius G Rigor. IABP drifting buoy, pressure, temperature, position, and interpolated ice velocity. Digital media, Polar Science Center, Applied Physics Laboratory, Univ. of Washington, Seattle, in association with the National Snow and Ice Data Center, Boulder, Colorado, 2002.

Ignatius G Rigor and John M Wallace. Variations in the age of arctic sea-ice and summer sea-ice extent. Geophysical Research Letters, 31(9), 2004.

Ignatius G Rigor, John M Wallace, and Roger L Colony. Response of sea ice to the arctic oscillation. Journal of Climate, 15(18):2648-2663, 2002.

Mark C Serreze, Marika M Holland, and Julienne Stroeve. Perspectives on the arctic's shrinking sea-ice cover. science, 315(5818):1533-1536, 2007.

Laurence C Smith and Scott R Stephenson. New trans-arctic shipping routes navigable by midcentury. Proceedings of the National Academy of Sciences, 110(13):E1191-E1195, 2013.

Asgeir Sorteberg and Børge Kvingedal. Atmospheric forcing on the barents sea winter ice extent. Journal of Climate, 19(19):4772-4784, 2006. 
Asgeir Sorteberg, Nils Gunnar Kvamstø, and Øyvind Byrkjedal. Wintertime nordic seas cyclone variability and its impact on oceanic volume transports into the nordic seas. The Nordic Seas: An integrated Perspective, pages $137-156,2005$.

Michael Steele, Jinlun Zhang, and Wendy Ermold. Mechanisms of summertime upper arctic ocean warming and the effect on sea ice melt. Journal of Geophysical Research: Oceans (1978-2012), 115(C11), 2010.

J Stroeve, A Barrett, M Serreze, and A Schweiger. Using records from submarine, aircraft and satellite to evaluate climate model simulations of arctic sea ice thickness. The Cryosphere Discussions, 8(2):2179-2212, 2014.

Julienne Stroeve, Marika M Holland, Walt Meier, Ted Scambos, and Mark Serreze. Arctic sea ice decline: Faster than forecast. Geophysical research letters, 34(9), 2007.

Julienne C Stroeve, Vladimir Kattsov, Andrew Barrett, Mark Serreze, Tatiana Pavlova, Marika Holland, and Walter N Meier. Trends in arctic sea ice extent from cmip5, cmip3 and observations. Geophysical Research Letters, 39(16), 2012a.

Julienne C Stroeve, Mark C Serreze, Marika M Holland, Jennifer E Kay, James Malanik, and Andrew P Barrett. The arctics rapidly shrinking sea ice cover: a research synthesis. Climatic Change, 110(3-4):1005-1027, 2012 b.

Qiuhong Tang, Xuejun Zhang, Xiaohua Yang, and Jennifer A Francis. Cold winter extremes in northern continents linked to arctic sea ice loss. Environmental research letters, 8(1):014036, 2013.

L-B Tremblay, LA Mysak, and AS Dyke. Evidence from driftwood records for century-to-millennial scale variations of the high latitude atmospheric circulation during the holocene. Geophysical Research Letters, 24(16):20272030, 1997. 
Mark Tschudi, Charles Fowler, James Maslanik, and Julienne Stroeve. Tracking the movement and changing surface characteristics of arctic sea ice. Selected Topics in Applied Earth Observations and Remote Sensing, IEEE Journal of, 3(4):536-540, 2010.

Walter B Tucker, John W Weatherly, Duane T Eppler, L Dennis Farmer, and Diane L Bentley. Evidence for rapid thinning of sea ice in the western arctic ocean at the end of the 1980s. Geophysical Research Letters, 28(14): 2851-2854, 2001.

Stephen J Vavrus, Marika M Holland, Alexandra Jahn, David A Bailey, and Benjamin A Blazey. Twenty-first-century arctic climate change in ccsm4. Journal of Climate, 25(8):2696-2710, 2012.

Jesse C Vermaire, Michael FJ Pisaric, Joshua R Thienpont, Colin J Courtney Mustaphi, Steven V Kokelj, and John P Smol. Arctic climate warming and sea ice declines lead to increased storm surge activity. Geophysical Research Letters, 40(7):1386-1390, 2013.

Timo Vihma. Effects of arctic sea ice decline on weather and climate: A review. Surveys in Geophysics, 35(5):1175-1214, 2014.

John E Walsh, Adam S Phillips, Diane H Portis, and William L Chapman. Extreme cold outbreaks in the united states and europe, 1948-99. Journal of Climate, 14(12):2642-2658, 2001.

Jia Wang, Jinlun Zhang, Eiji Watanabe, Moto Ikeda, Kohei Mizobata, John E Walsh, Xuezhi Bai, and Bingyi Wu. Is the dipole anomaly a major driver to record lows in arctic summer sea ice extent? Geophysical Research Letters, 36(5), 2009.

James Williams, Bruno Tremblay, Robert Newton, and Richard Allard. Dynamic preconditioning of the September sea-ice extent minimum. Journal of Climate, 2015. in revision. 
Rebecca A Woodgate, Tom Weingartner, and Ron Lindsay. The 2007 bering strait oceanic heat flux and anomalous arctic sea-ice retreat. Geophysical Research Letters, 37(1), 2010.

Jiayan Yang. The seasonal variability of the arctic ocean ekman transport and its role in the mixed layer heat and salt fluxes. Journal of climate, 19(20): 5366-5387, 2006.

J Zhang, WD Hibler III, M Steele, and DA Rothrock. Arctic ice-ocean modeling with and without climate restoring. Journal of Physical Oceanography, 28(2):191-217, 1998.

Jinlun Zhang, Ron Lindsay, Mike Steele, and Axel Schweiger. What drove the dramatic retreat of arctic sea ice during summer 2007? Geophysical Research Letters, 35(11), 2008. 